\title{
Graphene and MXene-based transparent conductive electrodes and supercapacitors
}

\author{
Chuanfang (John) Zhang ${ }^{\mathrm{a}, \mathrm{b}, *}$, Valeria Nicolosi ${ }^{\mathrm{a}, \mathrm{b}}$ \\ ${ }^{a}$ CRANN and AMBER Research Centers, Trinity College Dublin, Dublin 2, Ireland ${ }^{b}$ \\ School of Chemistry, Trinity College Dublin, Dublin 2, Ireland
}

\section{A R T I C LEIN F O}

\section{Keywords:}

Transparent conductive electrodes

Graphene

MXene

Transparent supercapacitor

Figure of merit

\begin{abstract}
A B S T R A C T
The great popularity of portable, smart electronics has intensively stimulated the development of energy storage devices and other cutting-edge products, such as displays and touch panels. Interactive devices such as smart phone, tablets, and other touchable devices require mechanical robust transparent conductive electrodes (TCEs). Developing transparent supercapacitor as the power source is of significance to the next generation transparent electronics. Recently, graphene and MXene, the two representatives in the large two-dimensional family, have shown excellent electronic conductivity and attracted great research attention in the energy storage field. Importantly, high-performance TCEs are the prerequisite of building transparent supercapacitors. This review provides a comprehensive analysis of graphene and MXene-based flexible TCEs covering detailed thin film fabrication methods, evaluation metrics, performance limitations as well as approaches to beat these limitations. We especially focus on the fundamentals in the TCEs, such as figure of merit, percolations as well as conductivity behaviours. Graphene and MXene-based transparent supercapacitors are analysed, with a particular focus on transparent, freestanding graphene papers. Finally, the challenges and prospects of MXene for TCEs and transparent supercapacitors, in conjunction with a critical analysis of MXene shortcomings, are discussed.
\end{abstract}

\section{Introduction}

In the past decade, the proliferation of smart optoelectronic devices, such as touch panels, liquid crystal displays (LCDs), photovoltaics, smart windows, and organic light-emitting diodes (OLEDs), etc., has greatly coloured our life [1]. Transparent conductive electrodes (TCEs), with a combination of high transparency and electrical conductivity, are critical components in these optoelectronic devices, as shown in Fig. 1 [1-4]. The global market for TCEs was $\$ 4.8$ billion in 2013 , and soared to nearly $\$ 7.1$ billion in 2018 . Currently, the majority of TCEs is consumed by the LCD and touch panel industry $[5,6]$.

The dominant materials used today for TCEs are transparent conductive oxides (TCOs) [7]. Among which tin-doped indium oxide (ITO) is the most successful material in the commercial market and well-studied one in the research labs [8]. Attributed to its extremely good optoelectronic properties, such as low sheet resistance $\left(\mathrm{R}_{\mathrm{s}}, 10-100 \Omega / \mathrm{sq}\right)$ at high transmittance $(\mathrm{T}>85 \%)$, ITO-based TCEs have occupied a $\$ 5.1$ billion market in 2017 with an expected growth rate of $20 \%$. Despite that, its intrinsic drawbacks cannot be ignored: (1) The scarcity of indium leads to high cost of ITO production. (2) ITO-based TCEs are quite fragile, limiting their further applications in the flexible electronics. The susceptible to crack or fracture nature will deteriorate the ITObased TCEs performance, such as linearity and sensing accuracy when used as an interfacing device [9]. Although by transferring (or sputtering) ITO films from glass to a flexible polyethylene terephthalate (PET) substrate, and/or optimizing the indium and tin ratio will improve the mechanical properties of these TCEs, additional production cost is unavoidable. (3) Manufacturing ITO needs hightemperature treatment, which complexes the production and consumes significant energy. (4) The instability of ITO films in acid or base media limits their application, such as in organic solar cells [10]. Another widespread type of TCO, fluorine-doped tin oxide (FTO), also suffers from similar drawbacks as ITO.

These main drawbacks of ITO and FTO have greatly stimulated the quest of alternatives with better mechanical properties, comparable optoelectronic properties and most importantly, at lower costs [6,11-13]. Of particular interest are paid on conducting polymers, such as poly $(3,4-$ ethylenedioxythiophene):poly(styrenesulfonate)

(PEDOT:PSS), polypyrrole, and polythiophene, etc. [14]. After a simple chemical doping, these conducting polymer-based TCEs showcase

\footnotetext{
*Corresponding author at: CRANN and AMBER Research Centers, Trinity College Dublin, Dublin 2, Ireland. E-mail addresses: 


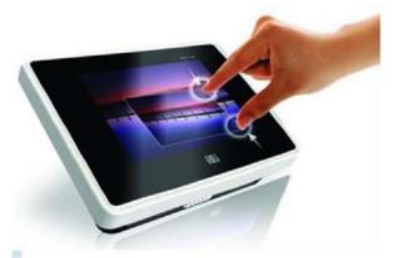

Touch panel

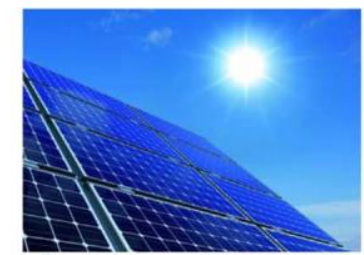

Solar cells

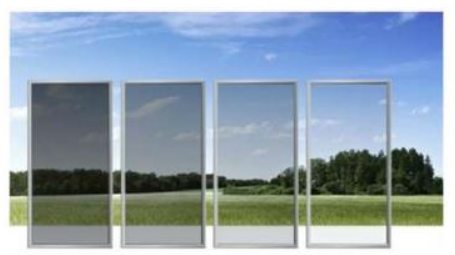

Electrochromic functional glass

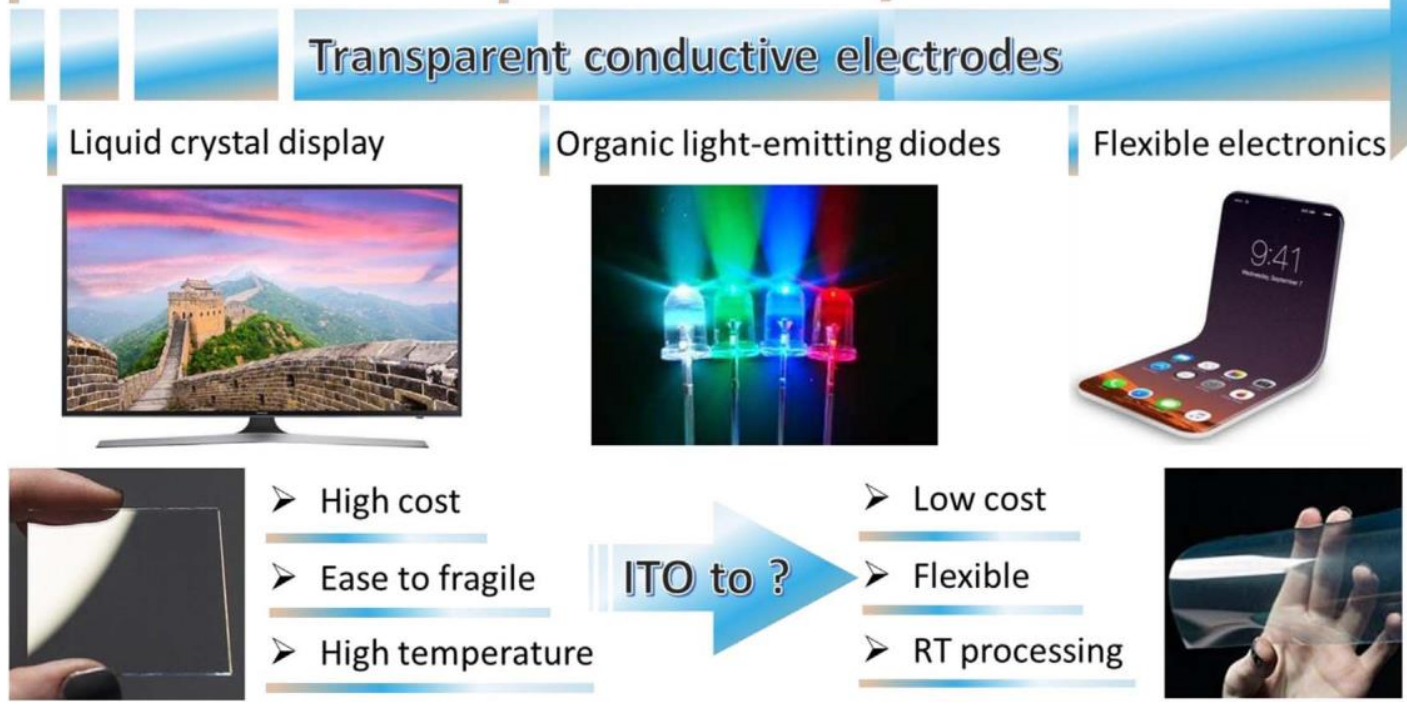

Fig. 1. Applications of transparent conductive electrodes. Also included are the current challenges of ITO and expected features in the ITO substitutes. Images are from the internet.

excellent dc conductivity [15]. However, the biggest concern for the polymerbased TCEs is the films' instability upon exposure to humidity, UV light or high-temperature conditions [6]. Metallic nanostructures, including silver nanowires [16], nanoparticles [17], metal grids and metallic mesh [12,18], are all excellent candidates for the TCEs with improved flexibility. However, the large diameter of these metal nanowires scatters light and leads to the haze effect, which is undesirable for the display industry [1]. In addition, the aging stability of metallic nanostructures is another big concern [12]. Carbon nanotubes (CNTs) possesses excellent dc conductivity, chemical stability, high aspect ratio as well as ease of solution processing, thus have been received substantial research interests in the TCEs field. However, in the TCEs fabrication, small CNT bundles as well as well-dispersed solution are usually required, which sharply increase the production cost [6].

On top of the abovementioned applications such as in touch panels and displays etc., incorporating TCEs into energy harvesting/storage devices, namely, Li-ion batteries [19,20] and supercapacitors [21,22], is a crucial technology for the next generation of portable, wearable, smart electronics [4,23-25]. Transparent flexible energy storage systems typically require the material of choice that can simultaneously act as current collectors to transport electrons and active material to store charge. In other words, the perspective material of interest should possess high conductivity, excellent optoelectronic properties and charge-storage capability.

As the most famous member in the two-dimensional (2D) family, graphene has been intensively researched in many areas such as catalysis [26], water purification [26], energy storage [27-32], sensing [24,33,34], etc. In particular, due to its extremely high electron mobility and excellent optoelectronic response $\left(R_{\mathrm{s}} \sim 60 \Omega / \mathrm{sq}\right.$ at $\mathrm{T} \sim 97.7 \%$ for single-layer graphene [1,2,34]), graphene has been regarded as an ideal alternative to replace ITO and FTO. Similar to CNTs-derived TCEs [6,35-40], graphene-based TCEs are flexible and chemically stable, with their optoelectronic properties largely determined by the thin film fabrication methods [25,35,41-43]. As the energy storage materials, graphene-based supercapacitor also demonstrate very high volumetric energy density and power density [44,45]. Importantly, graphene- based transparent supercapacitors are reported with longterm cycling, high rateresponse as well as high capacitance [46-49].

As the rising star in the 2D family, transition metal carbide and nitrides, known as MXenes, have emerged and rapidly drawn intensive research attention [50,51]. Being the most widely investigated MXene type, titanium carbide $\left(\mathrm{Ti}_{3} \mathrm{C}_{2} \mathrm{~T}_{\mathrm{x}}, \mathrm{T}_{\mathrm{x}}\right.$ stands for various surface functionalities such as $-\mathrm{OH}$, $\mathrm{O}$, and/or $-\mathrm{F}$, and $\mathrm{n}=1,2$, or 3 [52-55]) exhibits a metallic conductivity and excellent capacitive charge storage behaviour [56-58]. Compared to other TCOs, metallic mesh and carbon nanomaterials, $\mathrm{Ti}_{3} \mathrm{C}_{2} \mathrm{~T}_{\mathrm{x}}$ MXene nanosheets have a series of advantages including high flexibility, ease of dispersing in water and high volumetric capacitance, rendering its bright future in the production of both high-performance TCEs and transparent, flexible supercapacitors [59-68].

The past decade has witnessed the "gold rush" of 2D materials with graphene and MXene as two typical representatives. Various methods in the materials synthesis, thin films fabrication and applications, have been developed extensively on both graphene and MXenes [56,57,69-78]. The number of publications on TCEs and transparent supercapacitors based on graphene and MXene is also increasing [48,49,70,79-82]. For example, Xu and Liu discussed the fabrication strategies in producing graphene TCEs as well as their applications [2]. Hu et al. summarized the emerging TCEs based on CNTs, graphene and metallic nanostructures in the perspectives of both materials synthesis and their optoelectronic properties [1]. This indicates that there is certainly an increasing interest in the TCE field. Quite unexpectedly, neither reviews on graphene-based transparent supercapacitors, nor summary of MXene-based TCEs, are available. In the context of the fast growth of both materials in many areas, a comprehensive review summarizing the recent progresses of graphene and MXene-based TCEs and transparent supercapacitors is thus in urgent demand.

Here, we first describe the properties of graphene, followed by a brief summary on the fabrication methods of graphene TCEs. Then we discuss the performance limitations on graphene TCEs. Further, we provide strategies to improve the optoelectronic properties and approaches in beating the performance limitations. On the basis of graphene TCEs, we introduce MXenes 
and discuss their synthesis and properties in brief. Then, we review the progresses on MXene-based TCEs, focusing on the thin film fabrication methods as well as limitations. Metrics on the charge storage properties are proposed using $\mathrm{Ti}_{3} \mathrm{C}_{2} \mathrm{~T}_{\mathrm{x}}$ MXene TCE as a typical example. Using the figure of merits (both capacitive, $\mathrm{FoM}_{\mathrm{c}}$, and electrical, $\mathrm{FoM}_{\mathrm{e}}$ ), we are able to compare the optoelectronic properties of a vast of TCEs, and electrochemical responses of various transparent supercapacitors. Finally, the challenges and perspectives in these fields are also discussed. It is thus assured that the TCEs will continue to grow and play an important role in future transparent, flexible electronics.

\section{Graphene-based TCEs}

\subsection{Properties of graphene}

Since the discovery in 2004 [83], the one-atom-thick graphene has aroused extensive research interests continuously and thus intrigued a "gold rush" worldwide. Ideally, graphene is defined as the carbon monolayer packed into a 2D honeycomb with a $\mathrm{sp}^{2}$-hybridized configuration [84]. The high-quality graphene produced by the mechanical cleavage method showcases many unique properties, including extremely high electron mobility of $2.5 \times 10^{5} \mathrm{~cm}^{2}$ $\mathrm{V}^{-1} \mathrm{~s}^{-1}$ [85], very high thermal conductivity (> $3000 \mathrm{~W} \mathrm{~m}^{-1} \mathrm{~K}^{-1}$ ) [86] and mechanical strength of $130 \mathrm{GPa}$ [87], etc. A pure, single-layered graphene nanosheet is a semiconductor, demonstrating a bandgap of $0 \mathrm{eV}$ [83] and a very high Fermi velocity $\left(\mathrm{v}_{\mathrm{F}}=2.5 \times 10^{6} \mathrm{~m} \mathrm{~s}^{-1}\right)$, due to electrons delocalized on the sheets [88]. Detailed properties of monolayer graphene and comparison to its allotropes can be found in Table 1. Notably, graphene monolayer is transparent with the optical absorption of $2.3 \%$ [89]. Therefore, for the few-layered graphene, the transmittance varies as $\mathrm{T} \sim 100-2.3 \mathrm{~N}(\%)$, where $\mathrm{N}$ is the number of layers [90]. Despite that, for the graphene-like materials [91] obtained through other techniques (Fig. 2), such as liquid-phase exfoliation [92,93], oxidation/reduction of graphene oxide [94], chemical vapour deposition (CVD) [95-98], etc. [99,100], the supreme characteristics have not been observed yet [89]. Consequently, compromised optoelectronic properties are typically experienced in these lower-quality graphene-based TCEs. This highlights the crucial importance of both graphene synthesis and thin film fabrication strategies.

In general, producing pristine graphene with minimum defects on the mono- (or few) layers, followed by compacting the nanosheets into a continuous network, are two critical steps in fabricating highperformance graphene-based TCEs. This requires elaborate route design from the material synthesis to TCE fabrication. While mechanical (or micromechanical) cleavage of natural graphite can give large size, high-quality graphene flakes, however, the low yield of graphene coupled with the film-transfer procedure significantly hinder this

Table 1

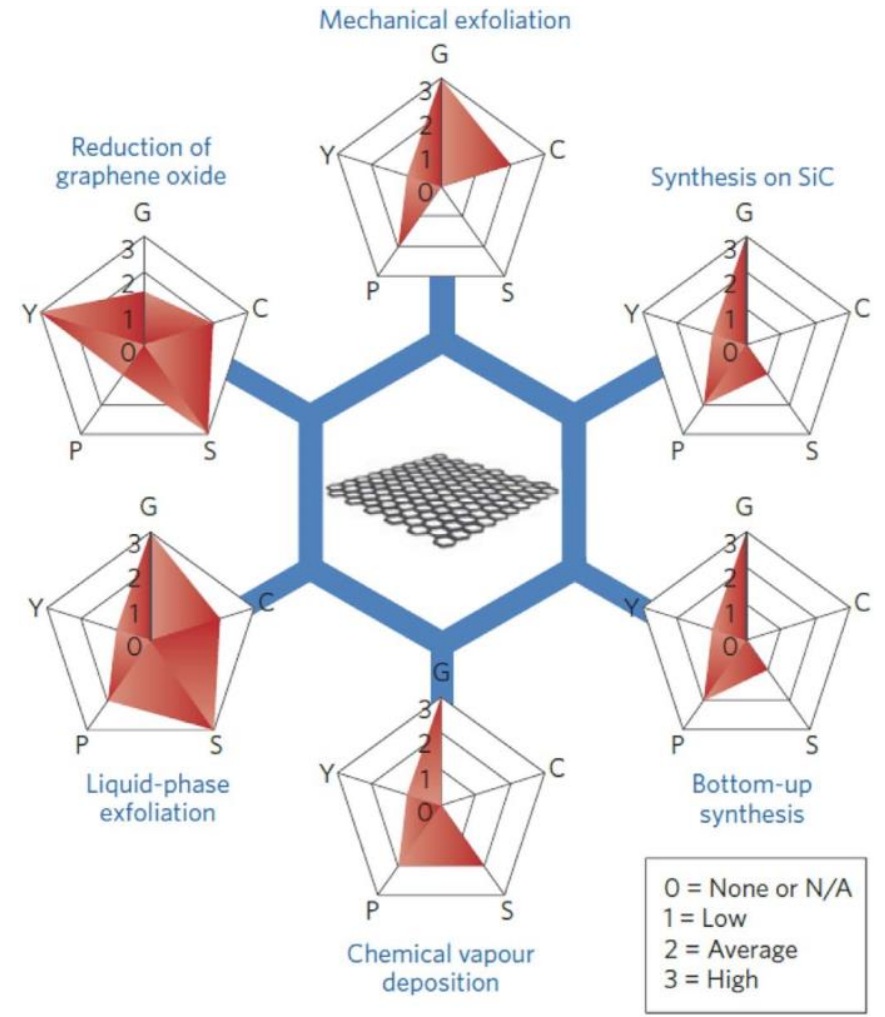

Fig. 2. Typical routes to graphene synthesis. Each route is evaluated in five aspects, including graphene quality $(\mathrm{G})$, cost effective $(\mathrm{C}$, a lower value suggests a higher production cost), scalability (S), purity (P) and yield (Y) of the overall production process. Reprinted with permission from Ref. [101]. Copyright 2014 Springer Nature.

method from mass production $[89,102]$. On the other hand, by choosing suitable solvents, natural graphite can be directly exfoliated into defects-free graphene dispersions (non-aqueous [93] or aqueous [103]) upon sonication [92,104] or shear-mixing [93]. Nevertheless, controlling the layer number of the exfoliated graphene while improving the portion of monolayers have proven to be difficult/timeconsuming [105]. Fig. 2 compares various synthesis routes in terms of quality $(\mathrm{G})$, cost $(\mathrm{C})$, scalability $(\mathrm{S})$, purity $(\mathrm{P})$ and yield $(\mathrm{Y})$ of the overall production process [101]. Of particular interest must be paid is the chemical oxidation-reduction approach, which gives a high yield of reduced graphene oxide with plenty of defects, both intrinsically (edges and deformations) and extrinsically (O- and H-containing groups) [101]. While excellent reviews on the roadmap of graphene covering electronic structure, modelling, synthesis, devices, etc. are available $[1,2,84]$, we will focus on the fabrication of graphene-based TCEs from various methods as well as the comparison of their optoelectronic properties.

A comparison of graphene properties to other carbonaceous materials. Reprinted with permission from Ref. [101]. Copyright 2014 Springer Nature.

\begin{tabular}{|c|c|c|c|c|}
\hline Properties & Graphene & Carbon nanotube & Fullerene & graphite \\
\hline Dimensions & 2 & 1 & 0 & 3 \\
\hline Hybridization & $\mathrm{sp}^{2}$ & Mostly $\mathrm{sp}^{2}$ & Mostly $\mathrm{sp}^{2}$ & $\mathrm{sp}^{2}$ \\
\hline Hardness & Highest (for single layer) & High & High & High \\
\hline Tenacity & Flexible, elastic & Flexible, elastic & Elastic & Flexible, non-elastic \\
\hline Experimental SSA $\left(\mathrm{m}^{2} \mathrm{~g}^{-1}\right)$ & $\sim 1500$ & $\sim 1300$ & $80-90$ & $\sim 10-20$ \\
\hline Electrical conductivity $\left(\mathrm{S} \mathrm{cm}^{-1}\right)$ & $\sim 2000$ & Structure-dependent & $10-10$ & Anisotropic: $2-3 \times 10^{4 \mathrm{a}}, 6^{\mathrm{b}}$ \\
\hline Thermal conductivity $\left(\mathrm{W} \mathrm{m}{ }^{-1} \mathrm{~K}^{-1}\right.$ ) & $4840-5300$ & 3500 & 0.4 & Anisotropic: $1500-2000^{\mathrm{a}}, 5-10^{\mathrm{b}}$ \\
\hline
\end{tabular}

a direction $b$

c direction. 

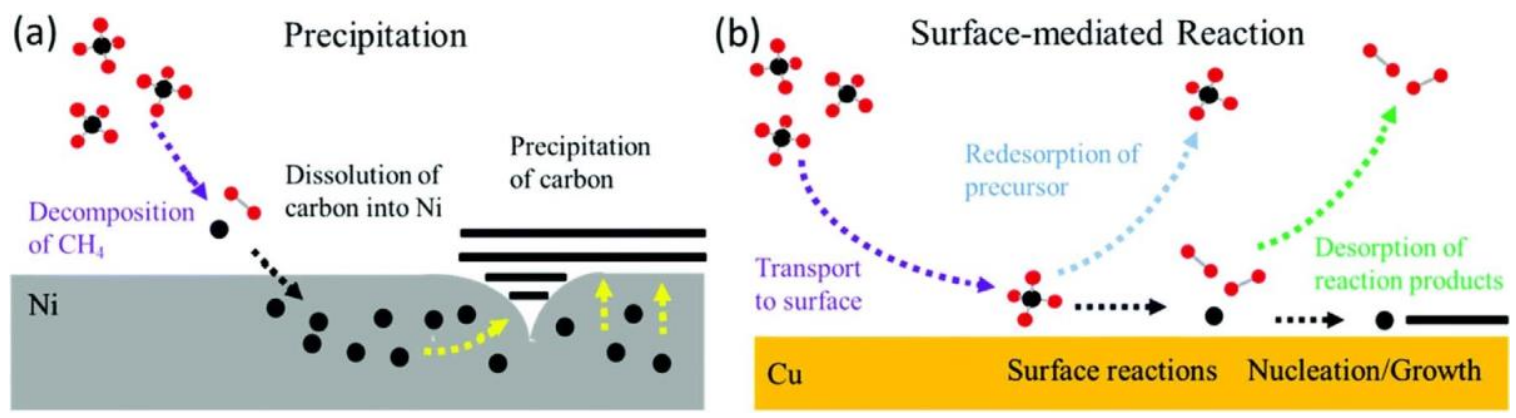

Fig. 3. Growth mechanisms of graphene films using CVD methods on (a) Ni and (b) Cu substrates, respectively. Reprinted with permission from Ref. [106]. Copyright 2015 Royal Society of Chemistry.

\subsection{Fabrication methods}

\subsubsection{CVD graphene-based TCEs}

Growing graphene through the CVD route represents the most promising synthesis approach. In general, the transition metal substrate (typically, $\mathrm{Ni}$ and $\mathrm{Cu}$ ) works as the catalyst which accelerates the decomposition of hydrocarbon carbon under high temperature $\left(900-1000^{\circ} \mathrm{C}\right)$. In the case of $\mathrm{Ni}$, these resultant carbon atoms are dissolved on the $\mathrm{Ni}$ surface due to a higher carbon solubility in the latter, forming the Ni-C solid solution. Upon cooling down under Ar flow, the carbon atoms release from the solution and rearrange into mono- or fewlayer graphene films (Fig. 3a) [106]. It's well accepted that single-crystalline Ni with larger grain size gives a higher monolayer/bilayer graphene ratio. On the other hand, due to a lower carbon solubility in $\mathrm{Cu}$, once the $\mathrm{Cu}$ surface is covered by the first layer of graphene, no more catalytic sites are available for the further hydrocarbon decomposition. Consequently, a predominantly monolayer graphene is observed when $\mathrm{Cu}$ is used as the catalytic substrate. This process can be interpreted as self-controlled surface adsorption mode/diffusion and precipitation (Fig. 3b) [106-108]. The number of graphene layers can be precisely controlled by adjusting the duration of the precursor, according to the report by Park et al. [108]. It's also worth noting that hydrogen plays an important role in the graphene growth kinetics and quality; the higher diffusion coefficient $\left(2 \times 10^{4} \mathrm{~cm}^{2} \mathrm{~s}^{-1}\right)$ of hydrogen leads to the dissociative hydrogen competing with $\mathrm{CH}_{4}$ dehydrogenation on the $\mathrm{Cu}$ surface, blocking the $\mathrm{Cu}$ sites and forming point defects consisting of hybridized $\mathrm{sp}^{3} \mathrm{C}-\mathrm{H}$ bonds [109]. However, the dissociative hydrogen species tend to recombine (or resurface) on $\mathrm{Ni}$ surface and thus yield more free $\mathrm{Ni}$ sites for the $\mathrm{CH}_{\mathrm{x}}(\mathrm{x}=1-4)$ dehydrogenation. As a result, optimizing the ratio of $\mathrm{CH}_{4}$ to $\mathrm{H}_{2}$ is crucial in achieving highquality, more uniform graphene films [109].

Once the CVD process is completed, a transfer process, including etching of the $\mathrm{Ni}$ (or $\mathrm{Cu}$ ) and transferring to the target substrate (such as PET, glass and $\mathrm{SiO}_{2} / \mathrm{Si}$ ), is required in order to obtain graphenebased TCEs. Typically, the asobtained graphene on the catalytic substrate is firstly covered by a protective polymer matrix (such as polydimethylsiloxane, PDMS). Then the whole "sandwich" is immersed in corrosive etchant (such as $\mathrm{Fe}\left(\mathrm{NO}_{3}\right)_{3}, \mathrm{FeCl}_{3}$ or $\left(\mathrm{NH}_{4}\right)_{2} \mathrm{~S}_{2} \mathrm{O}_{8}$, etc.) to remove the metal catalyst. Afterwards, the as-obtained graphene/ polymer film is cleaned and transferred to the target substrate (with a high surface energy). By removing the polymer layer, the CVD-grown graphene films are obtained. These processes are pioneered by Hong et al., who produced the first stretchable, transparent, large-scale patterned graphene films (Fig. 4) [43]. These films showed $\mathrm{R}_{\mathrm{s}}=280 \Omega \mathrm{sq}^{-1}$ with $\mathrm{T}=\sim 80 \%$, indicating the quality of the CVD-grown graphene flakes are as high as mechanically cleaved graphene $[83,89]$. Hu et al. used $\mathrm{Cu}$ as the catalytic substrate and obtained high-quality, large grain size (up to ten micrometers) graphene flakes, which showcased a high carrier mobility $\left(5080.5 \mathrm{~cm}^{2} \mathrm{~V}^{-1} \mathrm{~s}^{-1}\right)$ and excellent optoelectronic properties, such as $\mathrm{R}_{\mathrm{s}}=600 \Omega \mathrm{sq}^{-1}$ at $\mathrm{T}=96.5 \%$ and $\mathrm{R}_{\mathrm{s}}=400 \Omega$ $\mathrm{sq}^{-1}$ at $\mathrm{T}=86.7 \%[107]$.
To ensure the continuous production of CVD-grown graphene films, Bae, Hong and the co-authors reported a roll-to-roll strategy, as shown in Fig. 5a-b. The monolayer 30-in. graphene TCEs (Fig. 5c) show a $\mathrm{R}_{\mathrm{s}}$ as low as $125 \Omega \mathrm{sq}^{-1}$ with optical transmittance up to $97.4 \%$. By increasing the number of layers to 4 via a layer-by-layer stacking method, $\mathrm{R}_{\mathrm{s}}$ further decreased to $\sim 30 \Omega \mathrm{sq}^{-1}$ at $\mathrm{T}$ $=90 \%$. Such excellent optoelectronic properties are superior to ITO, suggesting a great potential in replacing this fragile, expensive TCE [25]. The reason behind the extraordinary optoelectronic performance is due to the chemical pdoping of graphene films by nitric acid, as confirmed by the large peak shift $(\Delta v$ $=18 \mathrm{~cm}^{-1}$ ) in the Raman spectra after $\mathrm{HNO}_{3}$ treatment [25]. To further push the limit, Kobayashi et al. used selective Joule heating of the $\mathrm{Cu}$ foil and combined with roll-to-roll strategy to produce graphene TCEs with length up to $100 \mathrm{~m}$ (Fig. 5d-e) [110]. The as-obtained graphene flakes are of high-quality and uniform, best evidence in the SEM image (Fig. 5f), Raman spectrum (tiny D peak, Fig. $5 \mathrm{~g}$ ) as well as resistance change in different regions (Fig. $5 \mathrm{~h}$ ). The 100-m-long graphene TCE demonstrates a charge carrier mobility of $\sim 600 \mathrm{~cm}^{2}$ $\mathrm{V}^{-1} \mathrm{~s}^{-1}$ and $\mathrm{R}_{\mathrm{s}}$ as low as $150 \Omega \mathrm{sq}^{-1}$ after doping with $\mathrm{RuCl}_{3}$ [110], which is sufficiently low for touch panel applications.

Apart from the advantages brought by CVD method in manufacturing graphene-based TCEs, the drawbacks of this route should also be noticed. The biggest concern is that the etching of transition metal catalytic substrate is not environmentally friendly; the etchant is usually very corrosive. In addition, the metal substrate is unrecyclable, one needs to remove a heavy amount of metal to obtain a quite small amount of graphene (i.e., $300 \mathrm{~kg} \mathrm{Cu}$ for $1 \mathrm{~g}$ graphene) [111]. Said otherwise, the yield of graphene is yet to be improved. Another serious concern is that, some metallic residues may be introduced to the graphene TCEs during the transfer step. Ambrosi and Pumera transferred the commercially available graphene/Ni samples, which was undergone the wetetching in the $\mathrm{FeCl}_{3}$ or $\mathrm{Fe}\left(\mathrm{NO}_{3}\right)_{3}$ solution (Fig. 6a). After repeated rinsing with DI-water, significant contamination of $\mathrm{Fe}$ and $\mathrm{Ni}$ impurities were observed in the transferred graphene films, as seen in Fig. 6b-c. While Fe metal impurities could be introduced by the etchant solution, $\mathrm{Ni}$ residues are due to the incomplete etching process. Notably, these impurities may greatly alter the optoelectronic and electrochemical responses of the transferred graphene TCEs when used as an electrode material (Fig. 6d-e) [112]. Therefore, careful characterizations are necessary to confirm the quality of the transferred graphene TCEs. As an alternative, developing etchant-free routes to give graphene TCEs should also be taken into consideration to avoid metal contamination and minimize the environment impact as much as possible. In addition to the metal impurities, there are also some polymer residues that are left on the graphene surface upon the polymer removal [113]. This is especially true when the polymer needs to be dissolved, such as PMMA (in acetone) [111]. These residues might negatively impact the transmittance and conductive networks and thus need to be completely removed [113]. By vacuum annealing in a reductive environment, such as $\mathrm{H}_{2}-\mathrm{N}_{2}$ or $\mathrm{H}_{2}-\mathrm{Ar}$ at $200-400{ }^{\circ} \mathrm{C}$, the polymer residues can be evaporated. However, the plastic substrate 


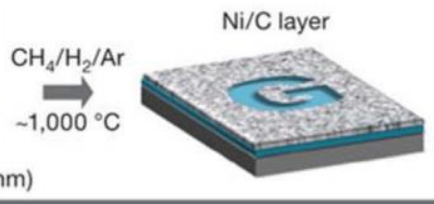

$\mathrm{s}$

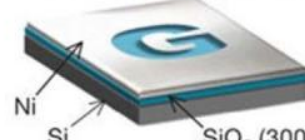

b PDMS/graphene/ $/ \mathrm{Ni}_{\mathrm{SiO}} / \mathrm{Si}$

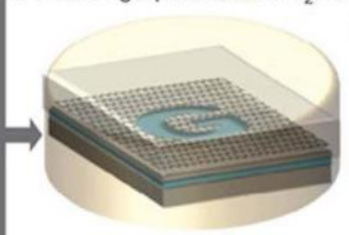

C Graphene/Ni/SiO $/ \mathrm{Si}$

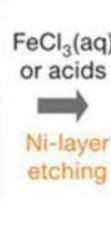

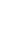

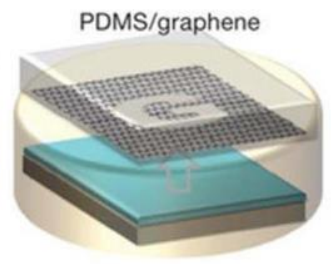

Floating graphene/ $\mathrm{Ni}$

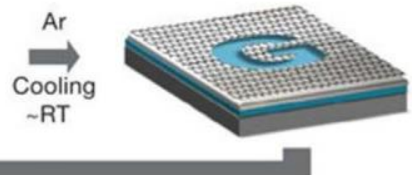

Graphene on a substrate

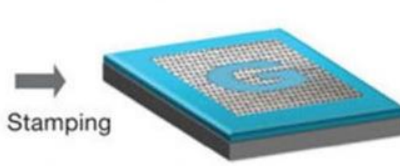

Downside contact (scooping up)
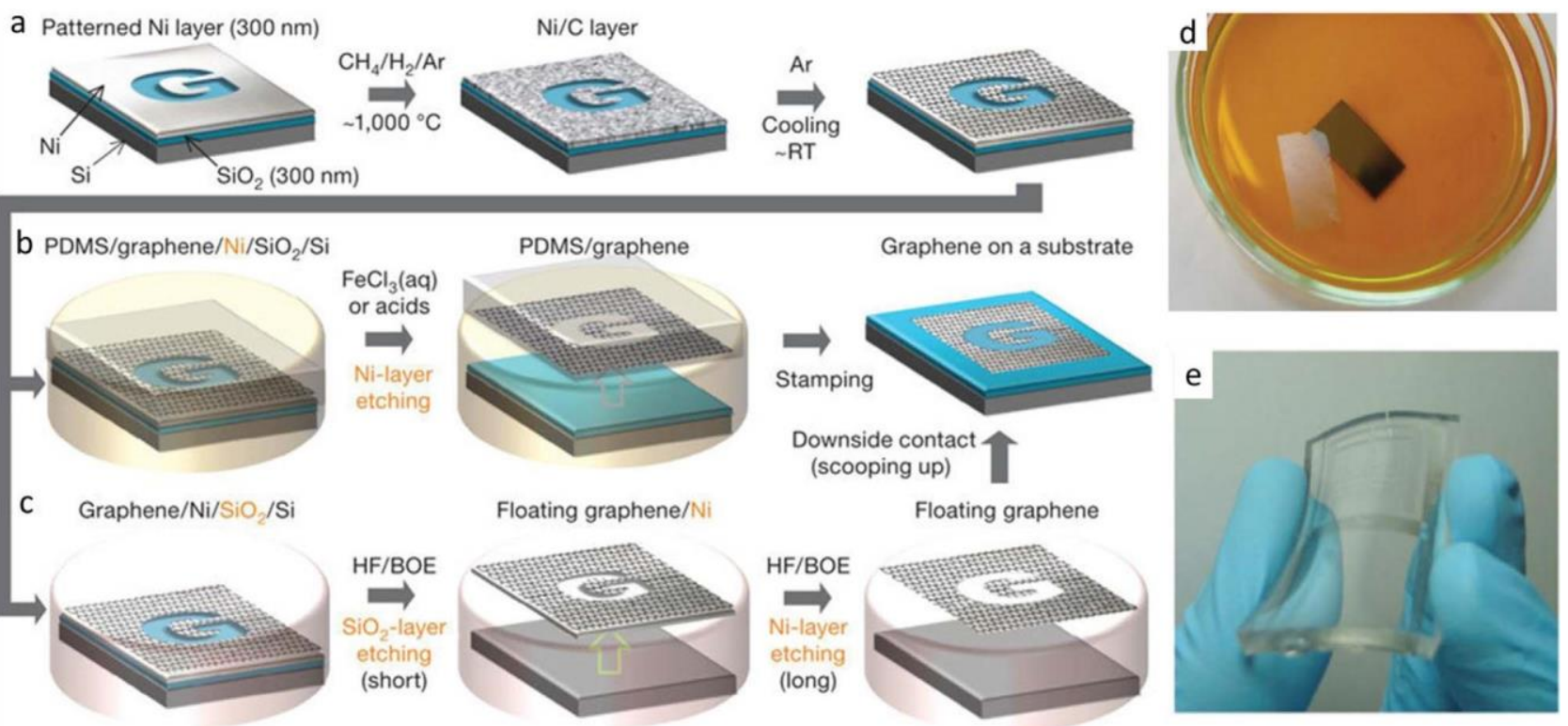

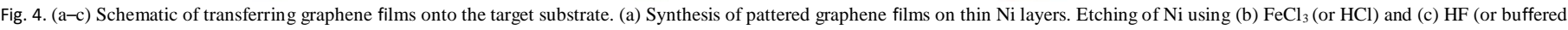

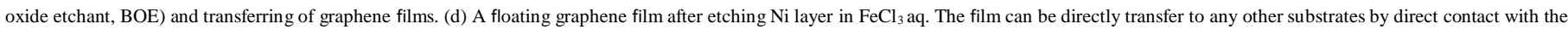
substrate. (e) The graphene films on the PDMS substrate is transparent and flexible. Reprinted with permission from Ref. [43]. Copyright 2009 Springer Nature.
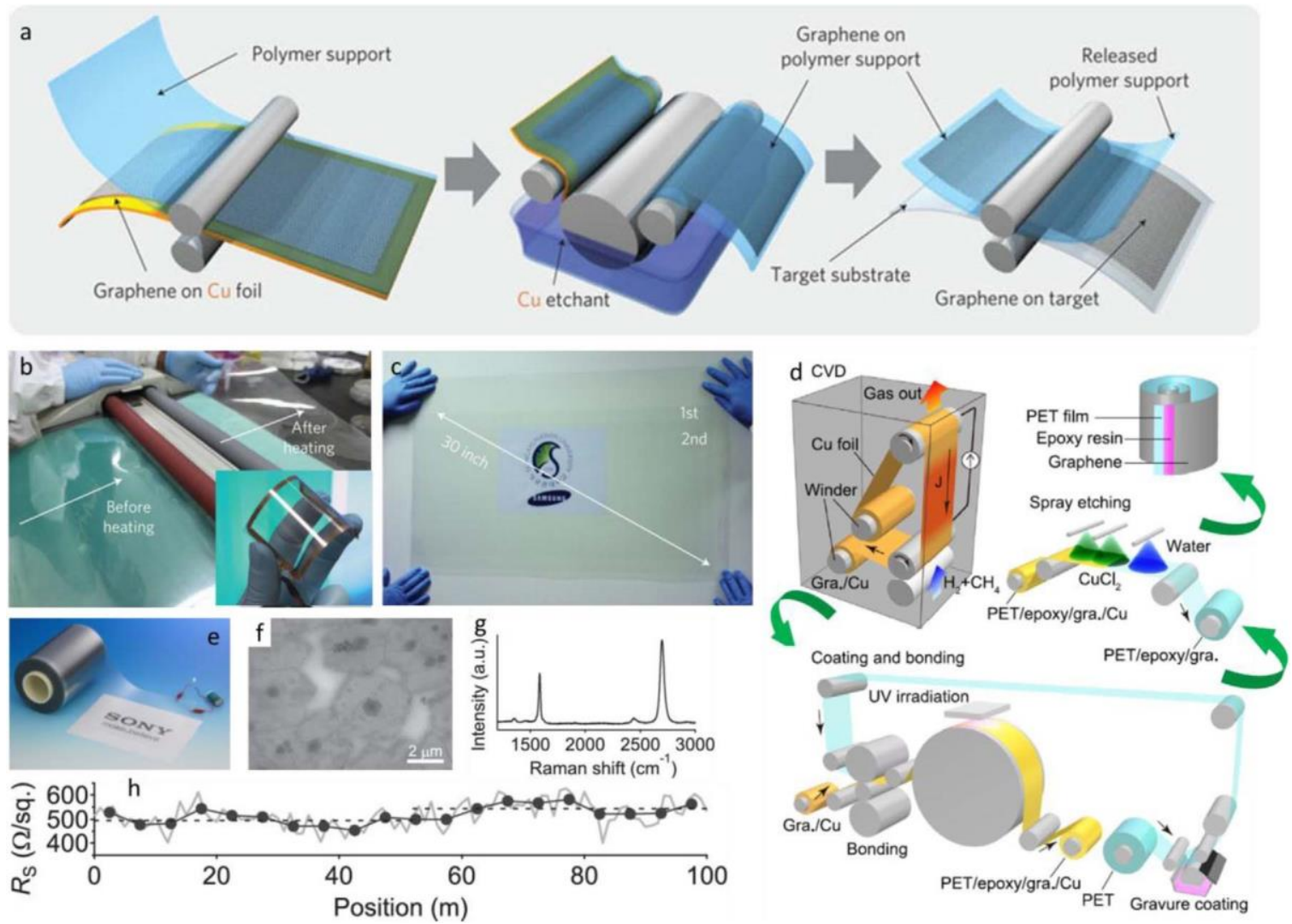

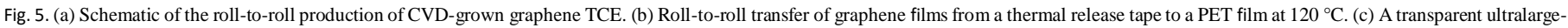

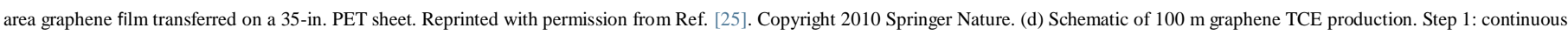

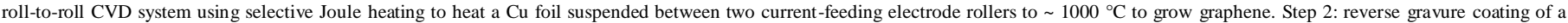

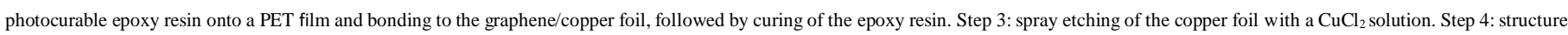

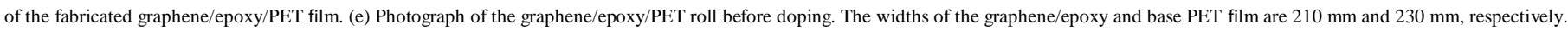

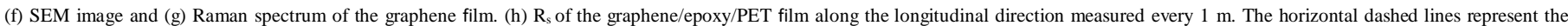
averaged data in 0-52 m and 52-100 m regions. Reprinted with permission from Ref. [110]. Copyright 2013 American Institute of Physics (AIP). 
a

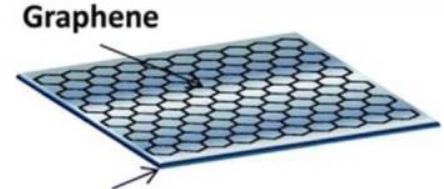

Ni-foil

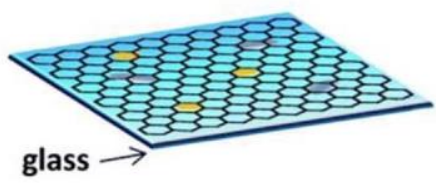

$\mathrm{Ni}$

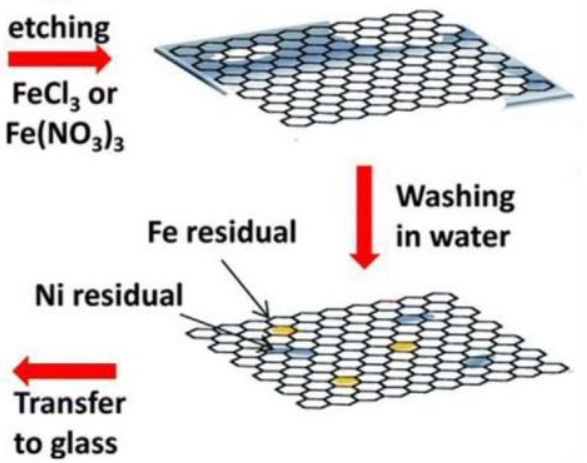

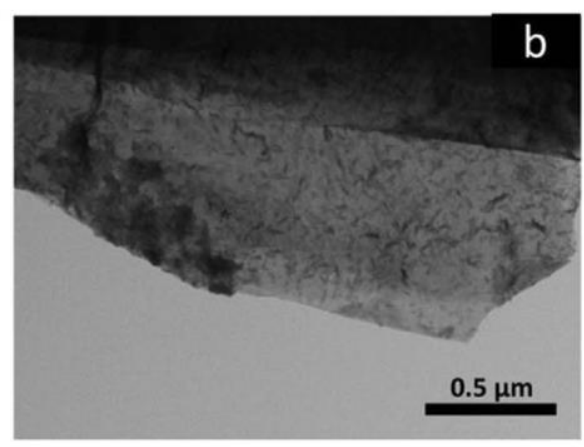
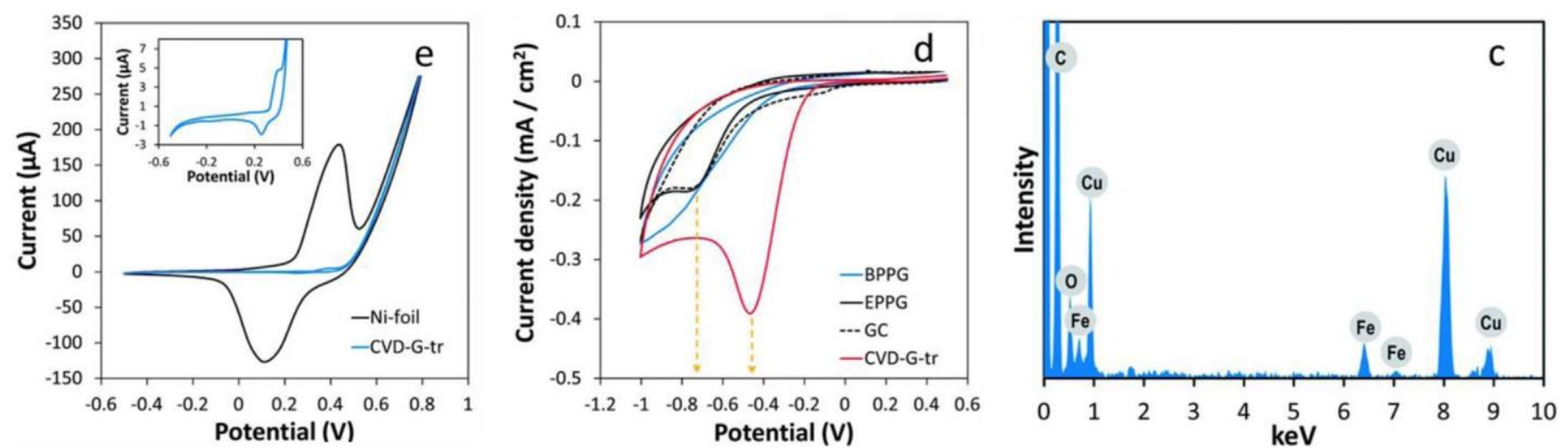

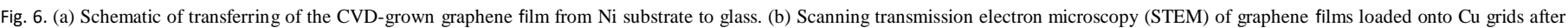

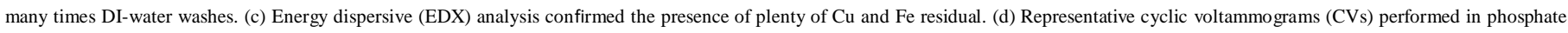

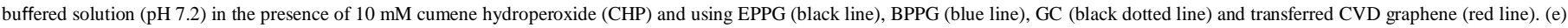
CVs (after 100 potential scans) performed in $0.1 \mathrm{M} \mathrm{NaOH}$ solution using clean Ni foil (black line) and transferred CVD graphene (blue line).

Reprinted with permission from Ref. [112]. Copyright 2014 Royal Society of Chemistry.

cannot bear such a high temperature [2]. Other routes, such as inserting an additional buffer layer (2-(diphenylphosphory)spirofluorene, SPPO1)-which has a high solubility in the solvent- between graphene and PMMA, or simply choosing conductive polymer (such as PEDOT:PSS) as the supporting layer and target substrate, residuefree graphene TCEs can be achieved [113]. Despite all these exciting progresses, developing transfer-free methods and growing graphene films directly on the target substrate (such as dielectric ones) [114], would greatly simplify the steps, give high-quality graphene TCEs without polymer or metal residues, and thus should be encouraged in the future.

\subsubsection{Reduced graphene oxide-based TCEs}

Aside from CVD-derived graphene, depositing graphite oxide (GO) nanosheets followed by reduction is another promising route to fabricate graphene-based TCEs. The quality of the GO flakes and thin film fabrication methods largely determine the optoelectronic properties of the resultant graphene TCEs. This highlights the importance of GO synthesis as well as the solution processing of GO.

The most common route to GO is by aggressively oxidizing the natural graphite using a mixture of sodium nitrate, potassium permanganate and concentrated sulfuric acid [77,91,115-119]. This process is widely known as the modified Hummers method, proposed by Hummers and Offerman [120]. Once being oxidized, the interlayer spacing of the GO increases to $\sim 1.2 \mathrm{~nm}$, 3 time wider than that of natural graphite $(0.34 \mathrm{~nm})[91,99,115,120]$. The expanded interlayer spacing allows the liquid-phase exfoliation of graphite oxide into mono- or few-layer GO nanosheets under the assistance of ultrasonic agitation or thermal expansion $[2,32,100]$. The as-obtained GO sheets are decorated with plenty of negatively-charged groups, such as hydroxyl and epoxy groups on the basal planes while carboxyl groups on the edges, respectively $[2,120]$. These groups endow the GO sheets with a very good hydrophilicity. Thus, GO can be electrostatically stable in the form of colloidal aqueous solution without the need of surfactant [121,122]. This brings significant advantages in solution processing of GO dispersion, such as spraycoating [123], spin-casting [116], dipcoating [116], electrophoretic deposition [124], Langmuir-Blodgett assembly (including layer-by-layer, LBL) [125], vacuum filtration [126], etc., based on which transparent GO films are obtained [115]. Among these methods, spin-coating gives compact, uniform GO films on a flat substrate [116]. To achieve this, typically a concentrate GO solution is required and placed on the substrate, followed by rotation. The film thickness can be controlled by varying the speed, duration and concentration of the solution [127,128]. On the other hand, spraying the GO solution, regardless of the concentration, can control the thickness of the resultant GO films more efficiently by varying the number of paths [123]. While dip-coating requires multiple steps, thus, time-consuming, to achieve GO films, electrophoretic deposition allows a fast fabrication rate [124]. However, the substrate is limited to the conductive ones, and exclude plastic, such as PET as a result. For the vacuum filtration, $\mathrm{GO}$ nanosheets are forced to compactly stack on the cellulose ester membrane and thus the network is formed. Additional step is that the membrane has to be removed [99], leaving the concern that there are some cellulose residues, similar as the polymer removal in the CVD-grown graphene transfer process [114]. For the LangmuirBlodgett and LBL assembly, GO film thickness can be effectively and easily manipulated [125]. It's worth mentioning that crosslinking agents, with positively charge species, need to be added to counteract the strong electrostatic repulsion between the GO sheets [2]. This 
method allows the production of continuous and uniform GO films on arbitrary substrates, including flexible ones on a large scale.

Once the GO films are prepared, restore the $\mathrm{sp}^{2} \mathrm{C}-\mathrm{C}$ bonds are necessary in order to achieve conductive films. The reduced GO, usually known as rGO, is

obtained by thermal or chemical reduction. Generally, thermal reduction is more effective in removing the surface groups (such as - $\mathrm{OH},-\mathrm{O}$, and $-\mathrm{COOH}$ ) than the chemical reduction route [2]. By heating up the GO films at 400-1100

${ }^{\circ} \mathrm{C}$, all these oxygencontaining groups are removed in the form of $\mathrm{CO}_{2}$ and

$\mathrm{CO}$, resulting in much improved electronic conductivity in rGO $[32,116]$.

However, in this temperature range, plastic substrate can't be used to support the rGO film. On the other hand, the chemical reduction route employs a reductive agent, such as hydrazine [31], hydrogen iodide (HI) [115] and $\mathrm{NaBH}_{4}[129]$ to remove the surface functionalities on the GO nanosheets.

Despite a mass production can be achieved, the chemical reduction process is quite dangerous and generates lots of environmental unfriendly wastes $[130,131]$. Great caution must be taken when chemically converting GO to rGO. Besides, this aggressive route also introduces plenty of defects on the basal planes, which compromises the optoelectronic properties of the rGObased TCEs [120]. As an alternative, using the in-situ formed hydrogen was reported as an efficient reducing agent to obtain $\mathrm{rGO}$ in an eco-friendly manner [127].

Chhowalla et al. performed the pioneering work on fabricating the rGO TCEs through vacuum-filtration, followed by a combination of hydrazine vapour exposure and low-temperature annealing treatments, as shown in Fig. $7 \mathrm{a}-\mathrm{c}$ [126]. The films showcased a lowest $\mathrm{R}_{\mathrm{s}}$ of $105{\mathrm{k} \Omega \mathrm{sq}^{-1}}^{-1}$ at $\mathrm{T}$ of $\sim 58 \%$. Later, Dai et al. produced graphene films through LB method (Fig. $7 \mathrm{~d}-\mathrm{f}$ ), which showcased $\mathrm{R}_{\mathrm{s}}$ of $8 \mathrm{k} \Omega ~ s q^{-1}$ at $\mathrm{T}$ of $\sim 83 \%$. The graphene films were obtained by exfoliation-reintercalation-expansion strategy [125]. By spin-casting the GO solution followed by hydrazine vapour reduction at $400{ }^{\circ} \mathrm{C}$ or graphitization at $1100{ }^{\circ} \mathrm{C}$, Chen et al. were able to produce rGO-based TCEs with $\mathrm{R}_{\mathrm{s}}$ of 100 $1000 \Omega \mathrm{sq}^{-1}$ at $\mathrm{T}$ of $\sim 80 \%$ [116]. The rGO films that Cheng et al. fabricated based on large-area GO nanosheets also exhibited quite similar results, including $\mathrm{R}_{\mathrm{s}}$ of $840 \Omega \mathrm{sq}^{-1}$ at $\mathrm{T}$ of $\sim 78 \%$ [115]. To further decrease $\mathrm{R}_{\mathrm{s}}$ a

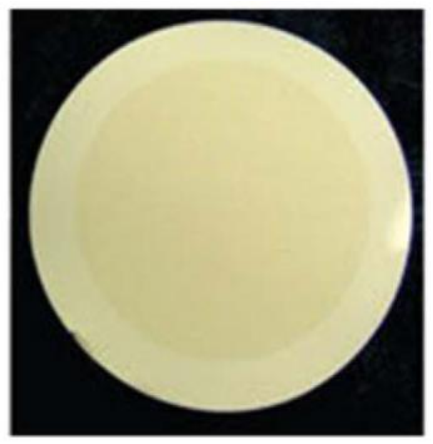

d

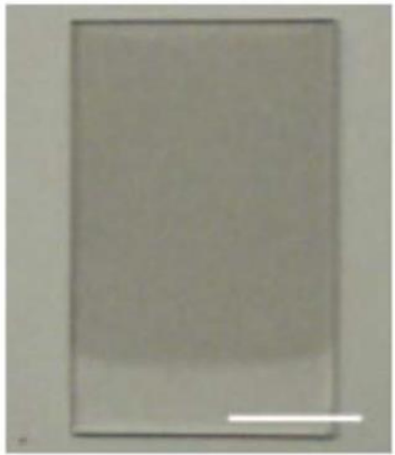

b

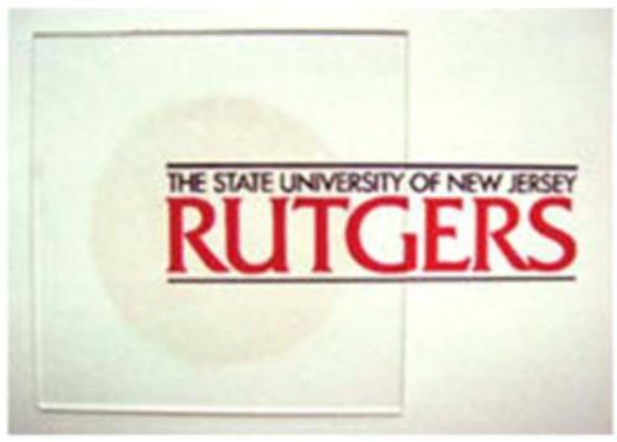

c

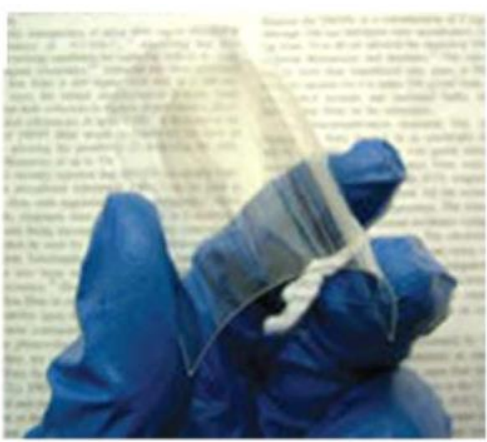

while maintain $\mathrm{T}$ of the films, rGO can be hybridized with other nanostructures, such as CNTs [132,133], metallic grids [134], PEDOT:PSS [113], Cu nanowires [128] and Ag nanowires [120,135], etc. [2,133]. These approaches will be discussed in detail in Section 2.4.2. Typical details of rGO-based TCEs, including GO synthesis, modification as well as the optoelectronic properties of the films, are summarized in Table 2.

\subsubsection{Graphene solution-based TCEs}

Despite great progresses have been achieved on the mass production of GO and solution processing techniques, the usage of environmentally unfriendly chemicals as well as the introduction of destructive network severely limit the application of rGO TCE based on GO solution [1,2]. For the sake of potentially large-scale production, one needs to develop high-quality graphene flakes suspended in dispersion, which is compatible with the aforementioned solution processing
Fabrication and optoelectronic properties of various graphene-based TCEs.

\begin{tabular}{|c|c|c|c|c|c|}
\hline Method & Reduction & Modification & $\begin{array}{l}\mathrm{T}(@ \\
550 \mathrm{~nm})\end{array}$ & $\mathrm{R}_{\mathrm{s}}(\Omega / \mathrm{sq})$ & Refs. \\
\hline Filtration & HI acid & $\mathrm{HNO}_{3}$ bath doping & $59 \%$ & 565 & {$[136]$} \\
\hline L-B assembly & I & l & $83 \%$ & $8 \mathrm{k}$ & [125] \\
\hline L-B assembly & HI acid & $\mathrm{HNO}_{3}$ bath doping & $91 \%$ & 1100 & [137] \\
\hline Spin-coating & Thermal & l & $80 \%$ & 870 & [138] \\
\hline Spin-coating & $\begin{array}{l}\mathrm{H}_{2} \text { from } \mathrm{Al} \\
\text { etching }\end{array}$ & $\begin{array}{l}\text { Ag nanowires } \\
\text { hybridization }\end{array}$ & $89 \%$ & $74 \pm 7$ & [127] \\
\hline $\begin{array}{l}\text { Dip-coating } \\
\quad+\text { LBL }\end{array}$ & Thermal & CTAB N N-doped $^{a}$ & $60 \%$ & 298 & [139] \\
\hline Rod coating & Metallic Sn & I & $75 \%$ & $6.7 \mathrm{k}$ & [140] \\
\hline
\end{tabular}

${ }^{a}$ Cetyltrimethylammonium bromide (CTAB).

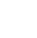




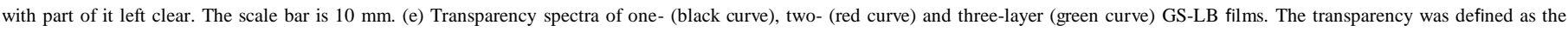
transmittance at a wavelength of $1000 \mathrm{~nm}$. (f) Resistance (red) and transmittance (blue) of one-, two- and three-layer LB films. Permission from Ref. [125]. Copyright 2008 Springer Nature.

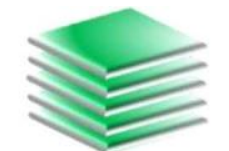

a
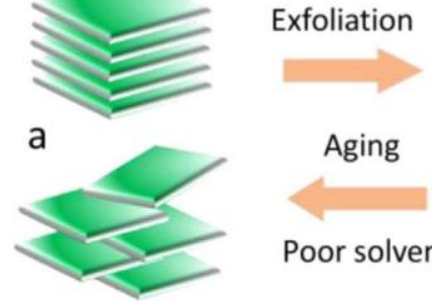

Aging

Poor solvent

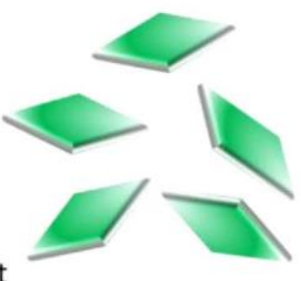

\section{Aging}

Good solvent

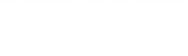

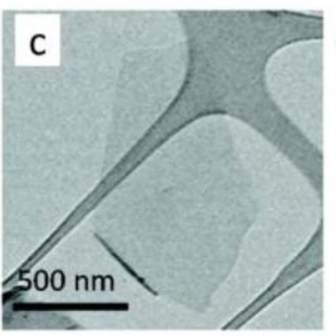
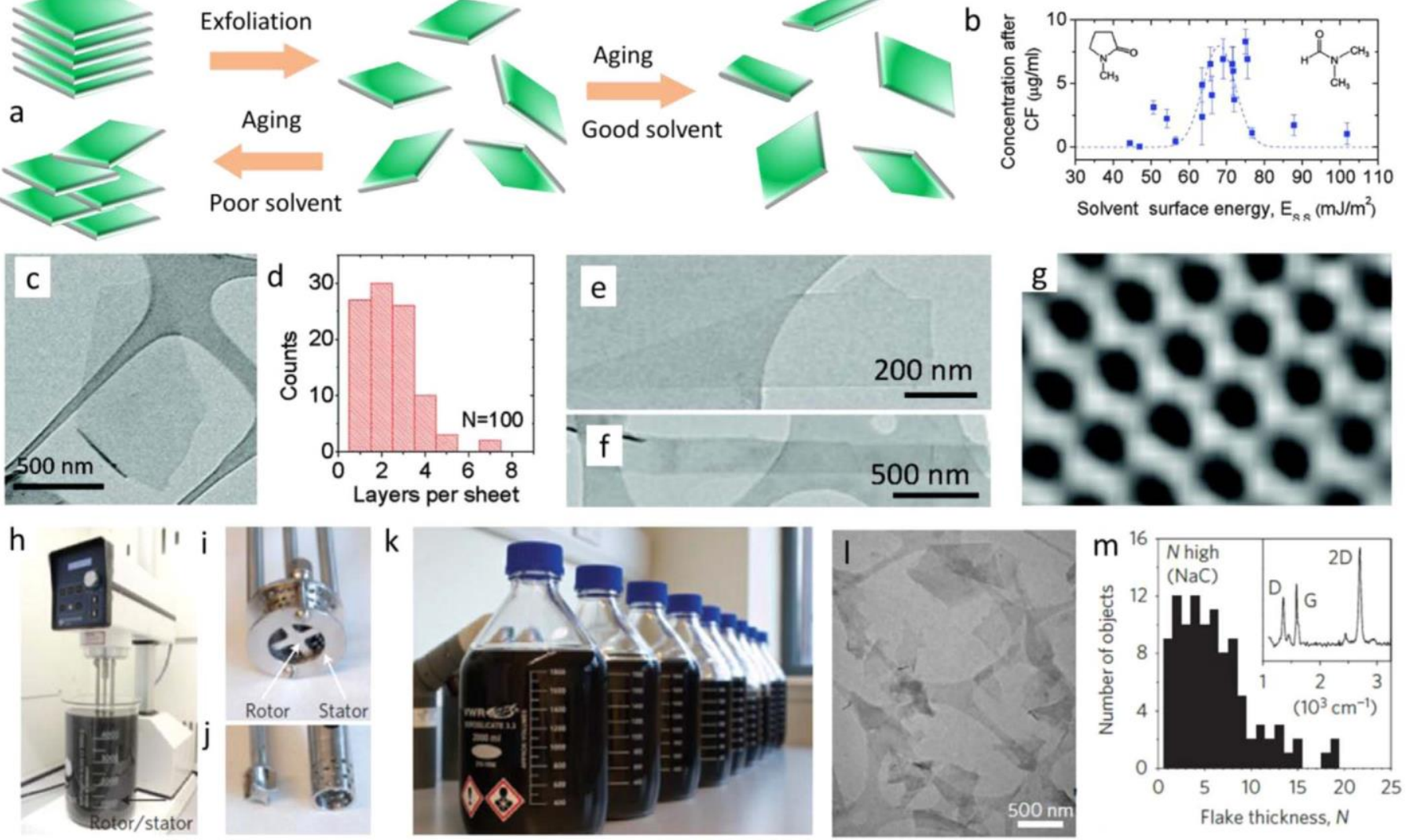

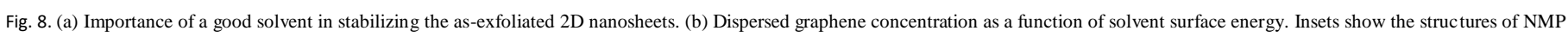

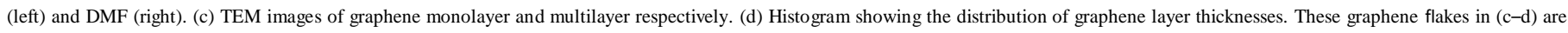

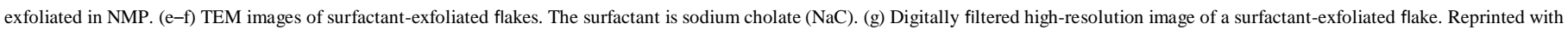

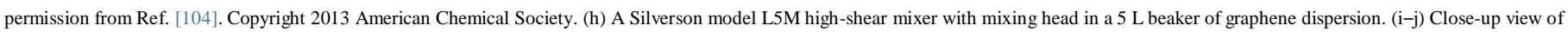

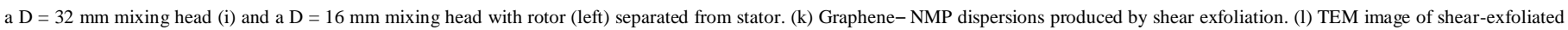

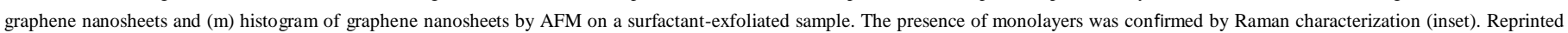
with permission from Ref. [93]. Copyright 2014 Springer Nature.

strategies, such as spin-coating, dip coating, spray-coating, and vacuum filtration-transfer etc.

This means that graphite needs to be exfoliated into few-layer (or monolayer) graphene in solvent. Such a top-down strategy is widely known as liquid-phase exfoliation, LPE [92,104,141]. According to Coleman et al., the concentration of graphene is thus maximized when the surface tension of the solvent matches with the surface energy of graphite [92,104,105,142,143]. Fig. 8 a shows the importance of the solvent. In good solvents, the nanosheets are exfoliated and stabilized against re-aggregation. However, a bad solvent not only yields a low concentration of graphene nanosheets, but also leads to the quick sedimentation after a period of time during aging. As evidenced in Fig. $8 \mathrm{~b}$, graphite tends to give a maximum graphene nanosheets concentration in the region of solvent surface energy $\sim 65-75 \mathrm{~mJ} \mathrm{~cm} 2$, falling into the range of graphite surface energy $[44,92,104,105,143]$. Typically, NMP is the ideal solvent for liquid-phase exfoliation of graphene, as nice flakes with a predominantly 1-4 layers are obtained (Fig. 8c-d). However, for the potential large-scale production, aqueous graphene solution is preferred, as it allows an efficient, green production of graphene-based thin films, coatings, and devices, etc. [84]. To achieve this, one needs to lower down the surface tension of water either using surfactant or polymer, and drags the value into the optimum region, that is, the region with surface tension roughly equals to the surface energy of graphite. Sodium cholate $(\mathrm{NaC})$ has been proved as an efficient surfactant in producing high-quality graphene dispersions, as seen in Fig. 8e-g [103,144]. By controlling the critical factors, such as the $\mathrm{NaC} /$ graphite ratio, initial concentration, sonication time, power and frequency, as well as centrifugation

parameters (speed, time, etc.), an aqueous dispersion enriched with high-quality graphene flakes can be obtained [103,104,144]. Removal of the surfactant is necessary, and can be realized by repeated washing with DI-water, or vacuum annealing of the graphene-based products [42]. Beside the $\mathrm{NaC}$, graphite can be also exfoliated under the assistance of household detergent [145] or polymers (such as poly(ethylene oxide)), or poly(ethylene glycol), PEG [146]. The former needs to combine with turbulence such as kitchen blender [145]. Indeed, when shear mixing graphite particles in suitable solvent/surfactant, a large-scale quantity of high-quality graphene dispersions can be achieved, according to Coleman et al. [93].

With high-quality graphene dispersions, one can readily prepare graphene thin films by either spray-coating or vacuum filtration, followed by transferring to the target substrate and dissolving the ester membrane with acetone [126]. For instance, Coleman et al. demonstrated flexible graphene-TCEs from exfoliated graphene dispersions stabilized by surfactant. The as-obtained films, which were annealed at $200-1000{ }^{\circ} \mathrm{C}$ under $\mathrm{H}_{2} / \mathrm{Ar}$ flow for $2 \mathrm{~h}$, showcased conductivities of up to $\sim 10^{4} \mathrm{~S} \mathrm{~m}^{-1}$ coupled with $\mathrm{T} \sim 90 \%$ [42]. Such a dc conductivity is also comparable to the best TCE produced from chemicallymodified graphene [147]. Graphene can also be exfoliated with the aid of Nafion, forming a stable water/ethanol solution [148]. After a low annealing temperature $\left(250{ }^{\circ} \mathrm{C}\right.$ for $\left.2 \mathrm{~h}\right)$ under vacuum, the resulting graphene films demonstrate a $\mathrm{R}_{\mathrm{s}}$ of $2.86 \mathrm{k} \Omega \mathrm{sq}^{-1}$ and a $\mathrm{T}$ of $84 \%$ at $550 \mathrm{~nm}$ [148]. Jo et al. exfoliated large size $(>1 \mu \mathrm{m})$ graphene nanosheets assisted by PEG. After treating with nitric acid and thionyl chloride $\left(\mathrm{SOCl}_{2}\right)$, the graphene TCEs show a $\mathrm{R}_{\mathrm{s}}$ of $300 \Omega \mathrm{sq}^{-1}$ and a $\mathrm{T}$ of $74 \%$ [146]. While these sheet resistances from 
exfoliated graphene dispersions are reasonable good, however, it's still relatively high to find application for certain areas such as displays and solar cells, where $\sim 10 \Omega \mathrm{sq}^{-1}$ is typically required [1]. Generally, comparing to CVDgrown graphene TCEs, liquid-phase exfoliated graphene TCEs showcase higher $R_{\mathrm{s}}$ at similar $\mathrm{T}$. This can be attributed to the much smaller size of graphene sheets after exfoliation. Smaller size means more boundaries and lower charge carrier mobility among the network, leading to inevitably poorer optoelectronic properties than the network with larger nanosheets. Continued improvements on the crucial aspects, such as increasing the nanosheet size, reducing defects, enhancing the electrical contacts on the junctions, as well as increasing the charge carrier number through doping are routes to boost the overall performance as TCEs. It could be anticipated that, in the next couple of years, some commercial products will be available, provided that substantial enhancement on the optoelectronic performance will be achieved.

\subsection{Evaluation metrics of graphene TCEs}

\subsubsection{Trade-off between $T$ and $R_{s}$}

Ideal TCE should possess both high $\mathrm{T}$ across the UV-vis-NIR spectrum and low $\mathrm{R}_{\mathrm{s}}$. In practical, the absorbance at $550 \mathrm{~nm}$ is defined as $\mathrm{T}$ in the UV-vis spectrum of the film, while $\mathrm{R}_{\mathrm{s}}$ can be obtained by a four-point (or two-point) probe method. Increasing the film thickness will reduce the $R_{s}$ at the cost of $T$. In other words, there is a trade-off between these two parameters. $\mathrm{T}$ is linked to the optical conductivity of the film, while $\mathrm{R}_{\mathrm{s}}$ is related to the intrinsic electronic conductivity of graphene. Importantly, $\mathrm{R}_{\mathrm{s}}$ is thickness-dependant; different thickness leads to different $R_{\mathrm{s}}$ and $\mathrm{T}$, making the direct comparison difficult. Therefore, it's necessary to put up with a performance metrics that can evaluate the optoelectronic properties of the graphene TCEs easily.

Among some variations, the one that Coleman et al. proposed, ratio of $\mathrm{dc}$ electrical conductivity $\left(\sigma_{\mathrm{dc}}\right)$ to optical conductivity $\left(\sigma_{\mathrm{op}}\right)$, so-called electrical figure of merit $\left(\mathrm{FoM}_{\mathrm{e}}=\sigma_{\mathrm{dc}} / \sigma_{\mathrm{op}}\right)$, is widely accepted $[15,16,23,35,37,38,41,42,132,149,150]$. The FoM $_{e}$ can be obtained through the following Eq. (1):

$$
T=\left(1+\frac{188.5^{\sigma}{ }_{o p-2}}{R_{s}}{ }_{\sigma d c}\right)
$$

To make the above equation valid, several requirements need to be met (1) the wavelength of the incident light is larger than the film thickness and (2) the fraction of reflected light is much less than the absorbance [6]. For most of the TCEs, these two conditions are usually met, thus Eq. (1) is frequently employed to estimate the optoelectronic properties of the TCEs. Simply, one needs to measure $T$ and $R_{s}$ for a given film and calculates the $F_{0 M}$ of the film at this thickness (or T) according to Eq. (1). A higher $\mathrm{FoM}_{\mathrm{e}}$ indicates better optoelectronic properties, and thus the corresponding film can be used in the applications that require higher $\mathrm{FoM}_{\mathrm{e}}$ values. For example, the touch panel requires $\mathrm{T}>85 \%$ and $\mathrm{R}_{\mathrm{s}}<500 \Omega \mathrm{sq}^{-1}$ while liquid crystal display (LCD) screen $\mathrm{T}>85 \%$ and $\mathrm{R}_{\mathrm{s}}<100 \Omega \mathrm{sq}^{-1}$. According to Eq. (1), the minimum FoM $_{\mathrm{e}}$ is calculated to be 4.5 in touch panel and 22.3 in LCD, respectively. Table 3 lists the specific requirements of TCEs in different applications.

Since the optoelectronic properties of graphene-TCEs are related to the thickness, thus knowing the film thickness is of importance. For the Table 3

The specific requirements of TCEs in various practical applications. Reprinted with permission

\begin{tabular}{|c|c|c|c|}
\hline Application & $\mathrm{T}(\%)$ & $\mathrm{R}_{\mathrm{s}}\left(\Omega \mathrm{sq}^{-1}\right)$ & $\sigma_{\mathrm{dc}} / \sigma_{\mathrm{op}}(\mathrm{FoMe})$ \\
\hline Touch panel & 85 & 500 & 4.5 \\
\hline LCD screen & 85 & 100 & 22.3 \\
\hline OLED display & 90 & 50 & 69.7 \\
\hline Photovoltaic electrode & 90 & 10 & 348 \\
\hline
\end{tabular}
from Ref. [6]. Copyright 2016 American Chemical Society. homogeneous opaque graphene films ( $<<70 \%$, Fig. 9a), the thickness can be measured accurately through atomic force microscopy (AFM) or contact profilometry. However, for the highly transparent films with $\mathrm{T}>90 \%$ (Fig. 9b), the thickness is beyond the resolution of contact profilometry. Instead, it can be predicted through Eq. (2), if the optical conductivity, $\sigma_{\mathrm{op}}$, is known:

$T=\left[1+188.5 \sigma t_{o p}\right]_{-2}$

By measuring T (@550 nm) of the films (Fig. 9c), the thickness can be thus obtained by calculation.

\subsubsection{Percolation problems}

Fig. $9 \mathrm{~d}$ plots $\mathrm{T}$ vs $\mathrm{R}_{\mathrm{s}}$ of graphene TCEs [42]. Also included is the dashed line by plotting Eq. (1). Clearly, in the films with $\mathrm{T}<70 \%$, the $\left(\mathrm{T}, \mathrm{R}_{\mathrm{s}}\right)$ points are roughly on the dashed line. However, in the region with $\mathrm{T}>80 \%$, obvious deviation is found; thinning down the film thickness leads to dramatically increased $R_{s}$. This issue is known as percolation effect, which is reflected by the deviation of bulk-like behaviour in the $T$ vs $R_{\mathrm{s}}$ and $R_{\mathrm{s}}$ vs t plot in the highly transparent region (dashed line in Fig. $9 \mathrm{~d}-\mathrm{f}$ ).

In principle, in the graphene TCEs, charge carriers flow along an individual nanosheet and then jump to another on the sheets boundaries. Therefore, the sheet resistance is a sum of junction resistance and intrinsic resistance from the nanosheets themselves. As charge carriers delocalize over the entire sheet and travel thousands of interatomic distances without scattering, individual graphene sheets showcase a very high Fermi velocity $v_{F}=10^{6} \mathrm{~m} / \mathrm{s}$, resulting in impressively high inplane conductivities [151]. Said otherwise, the junction resistance and therefore, the interflake tunnelling barriers largely determines the optoelectronic performance in the graphene-based TCEs. According to the 2D percolation theory, the percolation threshold $\left(\mathrm{N}_{\mathrm{c}}\right)$ can be described through the following Eq. (2):

$N_{c}=4.236^{2} \pi L_{s}^{2} \approx 1 / L$

where $\mathrm{L}_{\mathrm{s}}$ and $\mathrm{L}$ are the individual length and the aspect ratio of the graphene, respectively [152]. For typical exfoliated graphene flakes (layer number 1-10, Fig. $8 \mathrm{~m}$ ), the aspect ratio (L) is much lower than that of CNTs, resulting in a much higher percolation threshold. This means that the surface coverage to form a path and conduct the charge carriers is higher. However, in the highly transparent graphene TCEs $(\mathrm{T}>80 \%)$, the film thickness typically falls below $\mathrm{N}_{\mathrm{c}}$, leading to a nonuniform surface coverage and resulting in dramatically increased sheet resistances. Consequently, percolation problems are encountered.

\subsubsection{Theoretical limitation on graphene-TCEs}

De and Coleman compared the optoelectronic properties of graphene-based TCEs by collecting $\mathrm{T}$ and $\mathrm{R}_{\mathrm{s}}$ from various published papers (Fig. 10a), and calculated $\mathrm{FoM}_{\mathrm{e}}$ using Eq. (1) [41]. Fig. 10b summarizes the $\mathrm{FoM}_{\mathrm{e}}$ data. For the solution-exfoliated graphene, except the rGO films produced via spin-coating followed by hightemperature graphitization in vacuum [116], $\mathrm{FoM}_{\mathrm{e}} \sim 0.7$ may be close to the limiting value, although this value depends on the lateral flake

size. For the CVD-grown graphene films, a highest $\mathrm{FoM}_{\mathrm{e}}(=11)$ is observed. This can be explained that the interflake junctions, similar as junctions in the CNT networks, is much less in the quasi-continuous CVD grown films than the solution processed films [41].

The reasons for the relatively low $\mathrm{FoM}_{\mathrm{e}}$ values, in spite of the high DC conductivities in the graphitic films, are intriguing. For the films that Cai et al. and $\mathrm{Li}$ et al. prepared, $\sigma_{\mathrm{dc}}$ reached $2 \times 10^{6} \mathrm{~S} \mathrm{~m}^{-1}[153,154]$. However, the $\sigma_{\mathrm{op}}$ in these graphitic films also reached $1.8 \times 10^{5} \mathrm{~S} \mathrm{~m}^{-1}$. Therefore, it is this high optical conductivity that is responsible for the low $\mathrm{FoM}_{\mathrm{e}}$. 

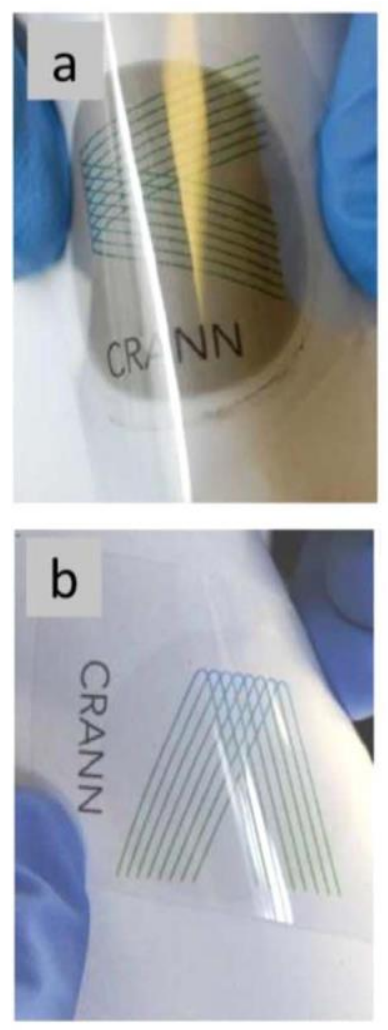
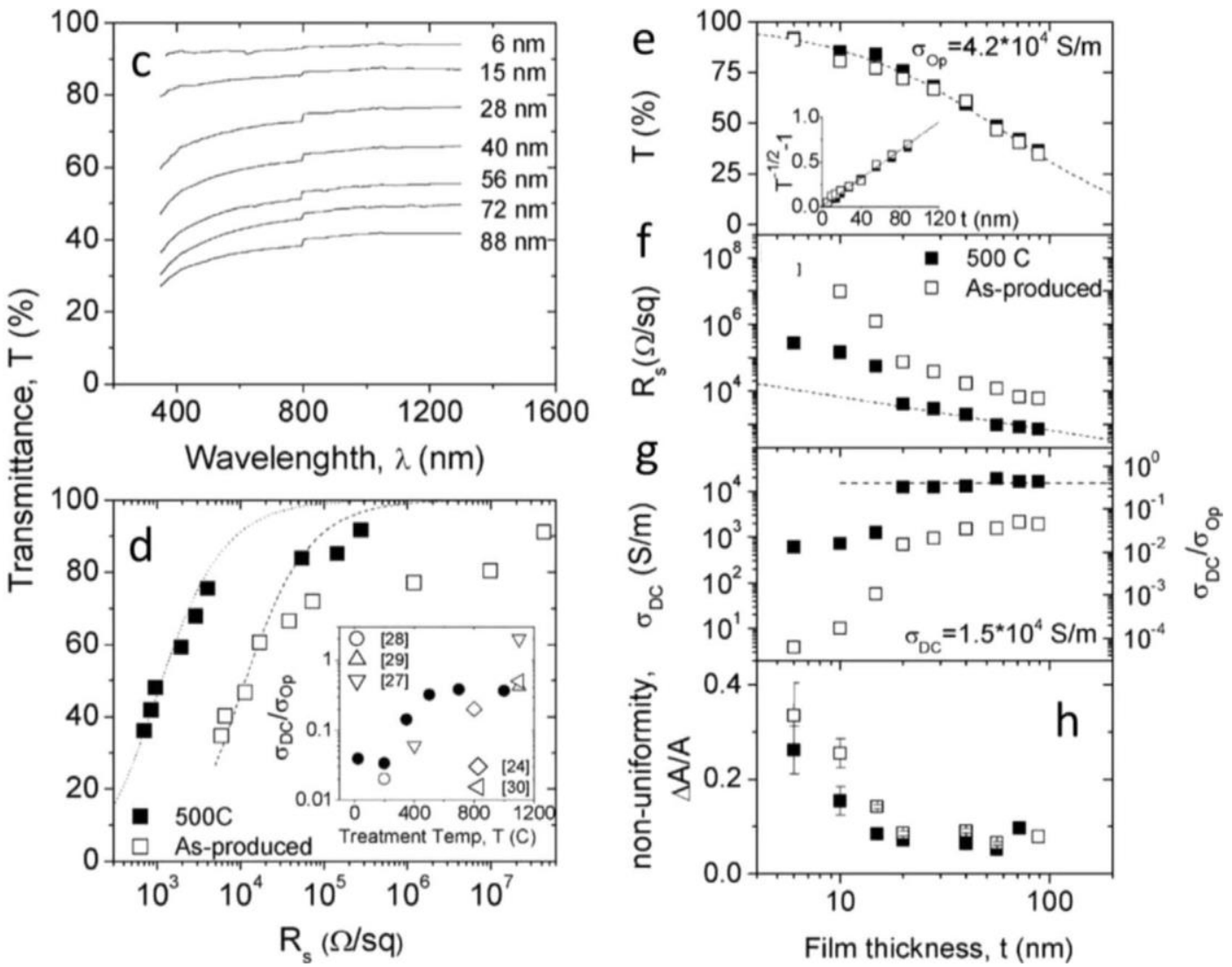

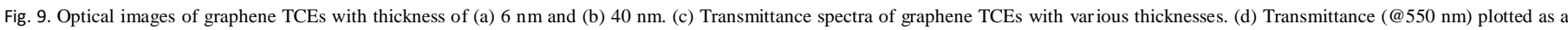

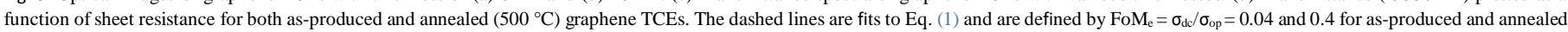

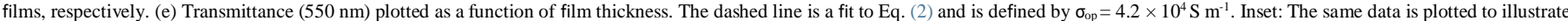

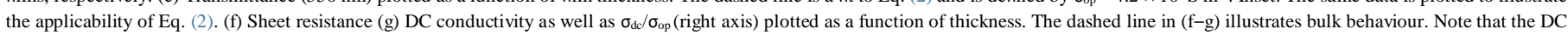

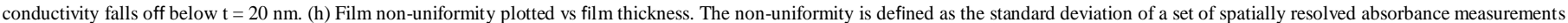
divided by the mean absorbance. Reprinted with permission from Ref. [42]. Copyright 2010 Wiley-VCH.
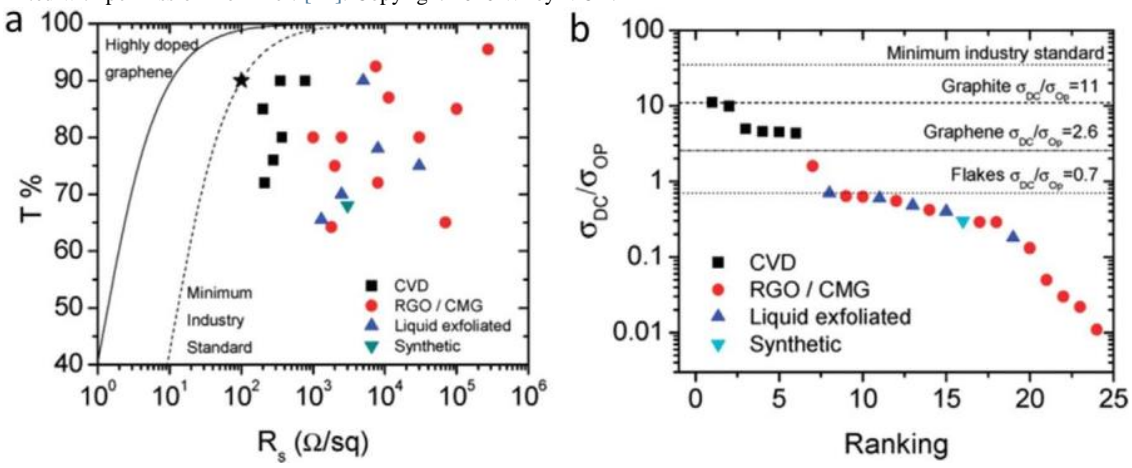

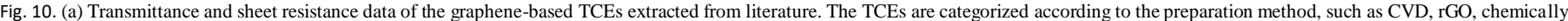

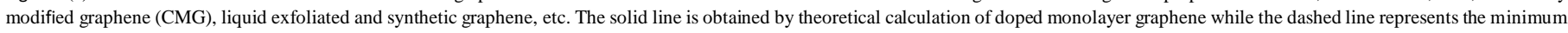
industry standard $\left(\mathrm{FoM}_{\mathrm{e}}=35\right)$. (b) $\mathrm{FoM}_{\mathrm{e}}$ comparison among various graphene TCEs. Reprinted with permission from Ref. [41]. Copyright 2010 American Chemical Society.

2.4. Beating the limitation

$\mathrm{FoM}=\mathrm{e} \sigma d c o p / \sigma=\sigma d c D$ op $D, 2 / \sigma, 2=4 \hbar \mu / n e$

To meet the industrial requirements, the limitations of graphene TCEs have to be beat. This can be realized either through doping, or via hybridizing with other materials to form composite nanostructures.

\subsubsection{Chemical doping}

De and Coleman proposed that when Fermi energy shift away from the Dirac point by applying a gate voltage or by doping, the 2D conductivity of graphene changes and is relying on the level of doping: $\sigma_{\mathrm{dc}, 2 \mathrm{D}}=n e \mu$, where $\mathrm{n}$ is the carrier density (electrons or holes, $\mathrm{cm}^{-2}$ ), $\mu$ is the carrier mobility [41]. Combining the optical conductivity, $\sigma_{\mathrm{op}, 2 \mathrm{D}}=\mathrm{e}^{2} / 4 \hbar[116], \mathrm{FoM}_{\mathrm{e}}$ can be written as:
Eq. (4) indicates that, to compete with ITO $\left(\mathrm{R}_{\mathrm{s}}<10 \Omega \mathrm{sq}^{-1}, \mathrm{~T}>85 \%\right.$, FoM $>220), n \mu>8.2 \times 10^{16} \mathrm{~V}^{-1} \mathrm{~s}^{-1}$ is required [41]. It was reported that by doping polyvinyl alcohol (PVA), the $\mathrm{n}$-doped graphene possessed a carrier density of $3 \times 10^{12} \mathrm{~cm}^{-2}$ [155]. Combining with the highly conductive graphene (with a carrier mobility of $4 \times 10^{4} \mathrm{~cm}^{2} \mathrm{~V}^{-1} \mathrm{~s}^{-1}$ ) that Ruoff et al. developed [154], $\mathrm{n} \mu=$ $1.2 \times 10^{17} \mathrm{~V}^{-1} \mathrm{~s}^{-1}$ is possible [41]. If these parameters can be achieved in one device, then $\mathrm{FoM}_{\mathrm{e}}=$

$\sigma_{\mathrm{dd}} / \sigma_{\mathrm{op}}$ reaches 330. Taking these values together into Eq. (1), the $\mathrm{R}_{\mathrm{s}}$ reaches $10.5 \Omega \mathrm{sq}^{-1}$ for a $\mathrm{T}=90 \%$ graphene TCE, which is quite close to the ITO limit.

As mentioned previously, after treating the CVD-grown graphene film in nitric acid (Fig. 5a-c), the p-doped four-layer graphene films demonstrate a 
high $\mathrm{T}=90 \%$ and a $\mathrm{R}_{\mathrm{s}}=30 \Omega \mathrm{sq}^{-1}$, indicating a $\mathrm{FoM}_{\mathrm{e}}$ as high as 116 according to Eq. (1) [25]. Similarly, the $\mathrm{AuCl}_{3}$-doped graphene reported by Im et al. also demonstrate a much decreased $\mathrm{R}_{\mathrm{s}}\left(\sim 70 \Omega \mathrm{sq}^{-1}\right)$ compared to the pristine graphene TCE $\left(\sim 890 \Omega \mathrm{sq}^{-1}\right)$ [156]. In a recent study, the five-layer CVD-grown graphene doped by thionyl chloride $\left(\mathrm{SOCl}_{2}\right)$ exhibits an almost three-fold decrease in the $\mathrm{R}_{\mathrm{s}}\left(25 \Omega \mathrm{sq}^{-1}\right)$ with $\mathrm{T}=87 \%\left(\mathrm{FoM}_{\mathrm{e}}=104\right)$ [157], suggesting the chemical doping method is universal. This is attributed to an increased hole concentration due to the covalent attachment of electron acceptor chlorine atoms at graphene defect sites with hydroxyl and carboxyl functionalities [157159]. Therefore, chemical doping ( $p$ type of $n$ type) of CVD-grown graphene is an effective approach to boost the optoelectronic properties of graphene TCEs, which hold a great promise in replacing ITO in the near future.

\subsubsection{Hybridizing with nanomaterials}

By fabricating graphene-based composite nanostructures, the optoelectronic properties of graphene TCEs can also be substantially improved and outperformed the theoretical result. For example, addition of small amount (3\%) graphene to CNTs network, followed by chemical doping (nitric acid treatment) was proved to be quite effective in enhancing the optoelectronic performance, as $\mathrm{R}_{\mathrm{s}}$ decreases to $100 \Omega \mathrm{sq}^{-1}$ at $\mathrm{T}=80 \%$, corresponding to $\mathrm{FoM}_{\mathrm{e}}$ $=18$ [132]. Lee et al. reported PEDOT:PSS-doped graphene TCEs. While the pristine graphene exhibits a $R_{\mathrm{s}}$ of $214 \pm 22 \Omega \mathrm{sq}^{-1}$, the composite showcases $80 \Omega \mathrm{sq}^{-1}$ at $\mathrm{T}=84 \%$, indicating a $\mathrm{FoM}_{\mathrm{e}}$ of 26 [113]. Blom et al. sprayed the graphene nanosheets on top of silver nanowires films (Fig. 11a) [160]. It's found that the electrochemically-exfoliated graphene nanosheets are quite efficient in reducing the sheet resistance of $\mathrm{Ag}$ nanowires, improving the surface roughness as well as enhancing the $\mathrm{Ag}$ nanowires ambient stability, as seen in Fig. $11 \mathrm{~b}$. Consequently, the hybrid Ag/graphene TCEs displays a sheet resistance of $13.7 \Omega \mathrm{sq}^{-1}$ at $\mathrm{T}=80 \%$, an indicative of $\mathrm{FoM}_{\mathrm{e}}=117$ (Fig. 11c) [160]. On the other hand, by compositing rGO platelet with $\mathrm{Cu}$ nanowires, synergistic effects can happen; the $\mathrm{Cu}$ nanowires can decrease or eliminate the platelet-platelet junction resistance, while the overlapped and continuous rGO films can bridge initially segregated $\mathrm{Cu}$ nanowires and eliminate the empty spaces (Fig. 11d) [128]. As a result, the hybrid films display $\mathrm{R}_{\mathrm{s}}$ of $34 \pm 2.6 \Omega \mathrm{sq}^{-1}$ at $\mathrm{T}=80 \%$ (Fig. 11e) [128]. Importantly, Tour et al. used a photolithography method to achieve metal grids $(\mathrm{Au}, \mathrm{Cu}, \mathrm{Al})$ on the substrate, then transferred a graphene layer prepared from CVD method on top of the metal grid, as shown in Fig. $11 \mathrm{f}-\mathrm{g}$. The hybrid transparent $\mathrm{Cu} / \mathrm{graphene}$ films demonstrate $3 \pm 1 \Omega \mathrm{sq}^{-1}$ at $\mathrm{T}=79 \%$ and $22 \pm 8 \Omega \mathrm{sq}^{-1}$ at $\mathrm{T}=91 \%\left(\mathrm{FoM}_{\mathrm{e}}=177\right)$, while the Au/graphene TCE showcased $20 \pm 4 \Omega \mathrm{sq}^{-1}$ at $\mathrm{T}=91 \%\left(\mathrm{FoM}_{\mathrm{e}}=195\right)$. To date, this is the highest value in terms of $\mathrm{FoM}_{\mathrm{e}}$ for graphenebased TCEs (as shown in Fig. 11h), indicating its great potential use in many applications [134]. There is no doubt to believe that by further optimizing the composition in the hybrid films, choosing other metal candidates as well as developing novel, facile thin-film fabrication techniques, graphene-based TCEs can surpass the optoelectronic properties of current dominate ITO electrodes, and find applications in many areas.

\section{MXene-based TCEs}

\subsection{Introduction on MXenes}

Since the discovery of $\mathrm{Ti}_{3} \mathrm{C}_{2}$ in 2011, the family of transition metal carbides, carbonitrides and nitrides, collectively referred to as MXenes, has quickly expanded in many areas [50-52,56,161-168]. By selectively etching of Aelement layers from MAX precursor in aqueous fluoride-containing acidic solutions, such as hydrofluoric acid, HF, or in-situ formed HF from lithium fluoride and hydrochloric acid, $\mathrm{LiF}+\mathrm{HCl}[51,52,55,71,169]$, or ammonium hydrogen bifluoride $\left(\mathrm{NH}_{4} \mathrm{HF}_{2}\right)$ [72,80,170], multi-layered (m-)MXene is thus obtained. The abundant surface functional groups impart hydrophilicity to MXenes [53]. When m-MXene is delaminated into monolayered or fewlayered nanosheets (d-MXene), a stable aqueous solution can be thus obtained, due to the electrostatic force on the negatively charged MXene nanosheets [57,72]. This allows a facile and environmentally friendly processing of the MXene solution into any items, such as composites, coatings and devices. Despite the presence of terminal surface groups, MXenes, especially the most intensively studied titanium carbide MXene $\left(\mathrm{Ti}_{3} \mathrm{C}_{2} \mathrm{~T}_{\mathrm{x}}\right)$, showcase a metallic conductivity as high as $9880 \mathrm{~S} \mathrm{~cm}^{-1}[171]$. The excellent electronic conductivity coupled with fast faradaic reactions result in impressive charge storage property, so called pseudocapacitance, in the MXenes [54,172-175]. In addition, monolayer MXene nanosheet is optical transparent, similar to the analogue graphene [80]. Collectively, MXenes are quite promising for the highperformance transparent conductive films and transparent supercapacitors. Several excellent reviews detailed the synthesis, exfoliation, structure and properties of MXenes [57,64,76,162,176]. Moreover, the applications of MXenes, especially in energy storage devices such as supercapacitors, metalion batteries/capacitors, have been extensively reported $[56,58,66,67,69,75,76,177-182]$. Considering that the number of publications on the MXenes grows enormously, we are not attempting to repeat the MXenes synthesis, properties and energy storage applications exhaustively, rather, we show some examples using MXenes as transparent conductive films.

\section{2. $\mathrm{Ti}_{3} \mathrm{C}_{2} \mathrm{~T}_{\mathrm{x}}$ MXene-based TCEs}

As mentioned previously, the percolation effect greatly limits the fabrication of highly transparent thin films with low sheet resistance. Developing advanced thin-film fabrication techniques as well as synthesizing materials with a high DC conductivity can effectively solve this problem. In this perspective, MXenes are ideal for the TCEs due to their metallic conductivity and hydrophilicity.

Halim et al. performed the pioneer work on the fabrication of $\mathrm{Ti}_{3} \mathrm{C}_{2} \mathrm{~T}_{\mathrm{x}}$ transparent films [80]. They sputter-deposited epitaxial $\mathrm{Ti}_{3} \mathrm{AlC}_{2}$ films on the substrate, followed by selective etching of the $\mathrm{Al}$ element [80]. The as-obtained epitaxial thin films were about $19 \mathrm{~nm}$ thick, corresponding to a $\mathrm{T}=90 \%$ in the visible-to-infrared range. Nevertheless, this route requires high-temperature for the deposition $\left(780^{\circ} \mathrm{C}\right)$ and $\mathrm{Al}$ etching after the sputtering, which greatly limits the scalable production. In other words, the film fabrication method must be facile, environmentally green and cost effectively.

When $\mathrm{m}-\mathrm{Ti}_{3} \mathrm{C}_{2} \mathrm{~T}_{\mathrm{x}}$ is intercalated with organic or water molecules, the interlayer spacing is expanded, leading to weakened Van del Waals interactions among the nanosheets $[50,165]$. Upon a bath sonication (under the inert gas) or direct hand-shaking, the $\mathrm{m}-\mathrm{Ti}_{3} \mathrm{C}_{2} \mathrm{~T}_{\mathrm{x}}$ delaminate into nanosheets aqueous solution with a predominant monolayer distribution $[58,72,173,183]$. Similar to $\mathrm{GO}$, the $\mathrm{d}-\mathrm{Ti}_{3} \mathrm{C}_{2} \mathrm{~T}_{\mathrm{x}}$ solution can be easily processed into $\mathrm{Ti}_{3} \mathrm{C}_{2} \mathrm{~T}_{\mathrm{x}}$-based TCEs with controlled thickness, thus, transparency, through spray-coating, spincoating or LBL techniques, etc. In addition, the ultrathin $\mathrm{Ti}_{3} \mathrm{C}_{2} \mathrm{~T}_{\mathrm{x}}$ nanosheets interconnect and weave into a continuous conductive network, which endows a good mechanical flexibility on the TCEs with less interflake tunnelling barriers or junctions.

For example, Gogotsi et al. sprayed the $\mathrm{Ti}_{3} \mathrm{C}_{2} \mathrm{~T}_{\mathrm{x}}$ aqueous solution onto a hot substrate and produced transparent homogenous films with thickness ranging from 5 to $70 \mathrm{~nm}$, as shown in Fig. 12(a-c) [184]. These films possess a transmittance of $40-91 \%$ (Fig. 12d). At a $\mathrm{T}=40 \%$ (thickness, $\mathrm{t} \sim 70 \mathrm{~nm}$ ), the $\mathrm{R}_{\mathrm{s}}$ is $500 \Omega \mathrm{sq}^{-1}$ (Fig. 12e). Decreasing the thickness to $5 \mathrm{~nm}$ leads to a dramatically improved transmittance $(\mathrm{T}=91 \%)$, however, at the cost of sheet resistance $\left(\mathrm{R}_{\mathrm{s}}\right.$ boosts to $\left.8 \mathrm{k} \Omega \mathrm{sq}^{-1}\right)$. 

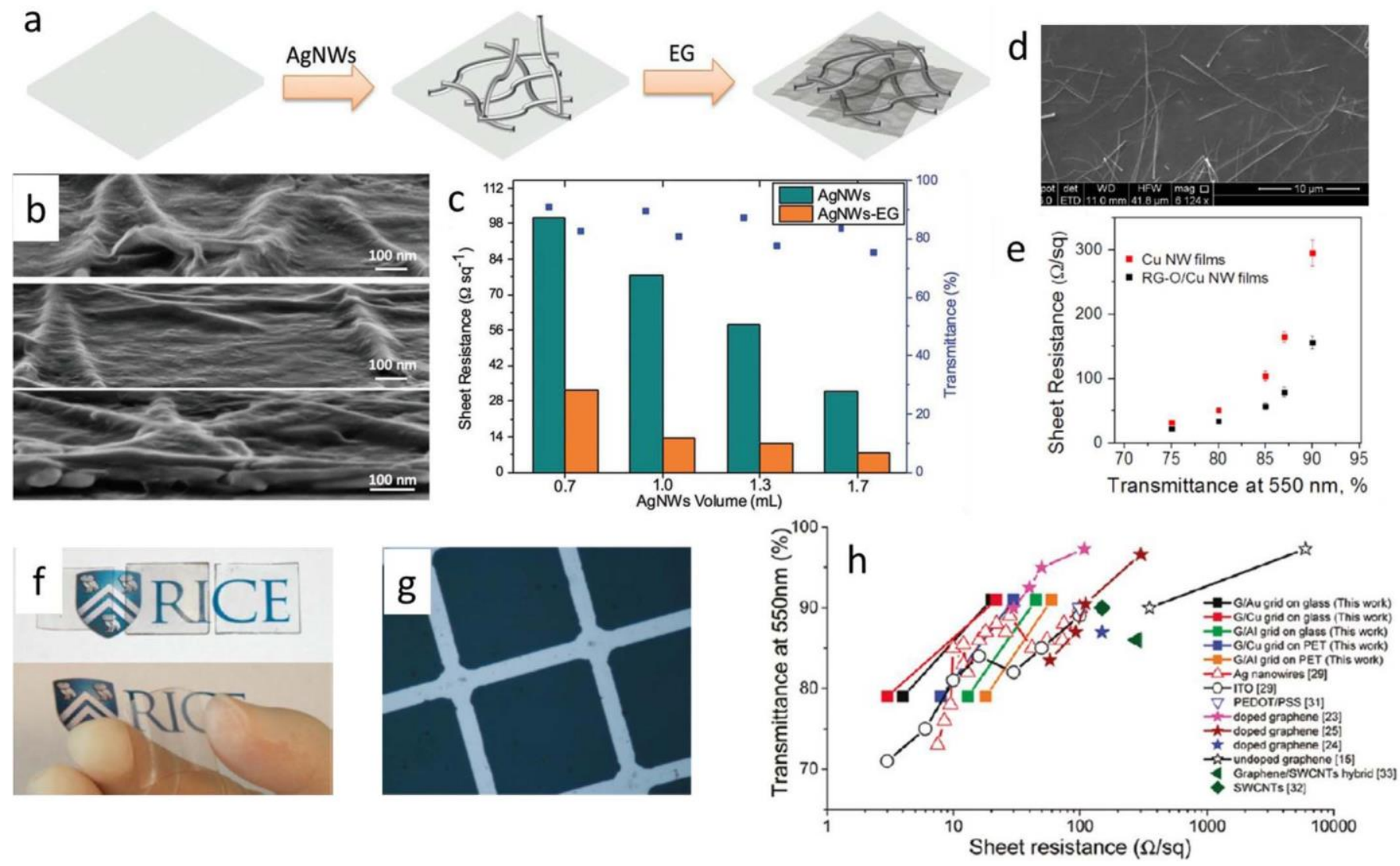

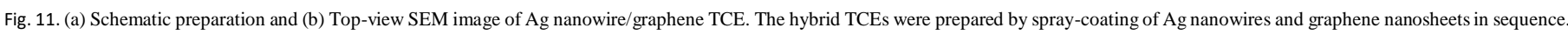

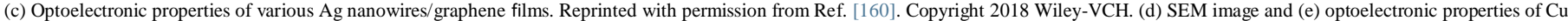

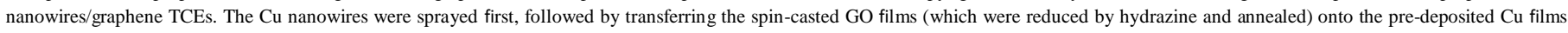

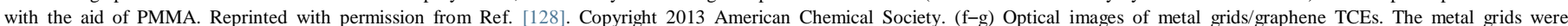

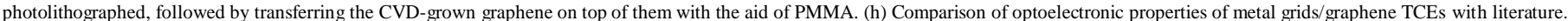
Reprinted with permission from Ref. [134]. Copyright 2011 American Chemical Society.

According to Eq. (1), the $\mathrm{FoM}_{\mathrm{e}}$ in these spray-coated $\mathrm{Ti}_{3} \mathrm{C}_{2} \mathrm{~T}_{\mathrm{x}}$ TCEs is around 0.5-0.7 [184]. Such a low FoM $\mathrm{e}_{\mathrm{e}}$ may due to the loose morphology in the MXene TCEs [184]. During the spray coating, the droplets are purged by the gas and sprayed onto the hot substrate, where the solvent (ethanol [184] or water [185]) get quickly evaporated. The as-generated vapour bubbles the nanosheets and creates plenty of voids/pores that negatively hinder the smooth transport of charge carriers among the randomly stacked network. Consequently, the DC conductivity in the sprayed $\mathrm{Ti}_{3} \mathrm{C}_{2} \mathrm{~T}_{\mathrm{x}} \mathrm{TCEs}$ is much lower. Another possible reason is that the intrinsic optical conductivity $\left(\sigma_{o p}\right)$ of $\mathrm{Ti}_{3} \mathrm{C}_{2} \mathrm{~T}_{\mathrm{x}}$ is very high. Nevertheless, the FoM ${ }_{\mathrm{e}}$ in these spray-coated $\mathrm{Ti}_{3} \mathrm{C}_{2} \mathrm{~T}_{\mathrm{x}}$ TCEs is still comparable to the exfoliated graphene TCEs (See Section 2.2.3) [41,42]. In another trial of spray coating of $\mathrm{Ti}_{3} \mathrm{C}_{2} \mathrm{~T}_{\mathrm{x}}$, the resistivity reaches $3.4 \times 10^{4} \Omega / \mathrm{cm}$ at a $\mathrm{T}=86.7 \%$, leading to a somewhat low FoM $_{\mathrm{e}}[185]$.

Taylor et al. solution-processed $\mathrm{Ti}_{3} \mathrm{C}_{2} \mathrm{~T}_{\mathrm{x}}$ dispersion into TCEs by a spincasting method (Fig. 13a) [81]. By controlling the spin velocity, the resultant $\mathrm{Ti}_{3} \mathrm{C}_{2} \mathrm{~T}_{\mathrm{x}}$ film thickness can be efficiently tuned. The metallic conductivity nature was confirmed in the $\mathrm{Ti}_{3} \mathrm{C}_{2} \mathrm{~T}_{\mathrm{x}}$ MXene by field effect transistor measurements, with an electronic conductivity estimated as high as $3092 \mathrm{~S} \mathrm{~cm}^{-1}$. Thus, the $\mathrm{Ti}_{3} \mathrm{C}_{2} \mathrm{~T}_{\mathrm{x}}$ films showcased good optoelectronic performances, such as a $\mathrm{R}_{\mathrm{s}}$ of 437 $\Omega \mathrm{sq}^{-1}$ at the $\mathrm{T}$ of $77 \%$ [81]. This corresponds to a $\mathrm{FoM}_{\mathrm{e}}$ of 3.1, a value that is much higher than the spray-coated $\mathrm{Ti}_{3} \mathrm{C}_{2} \mathrm{~T}_{\mathrm{x}}$ TCEs [184]. By vacuum-annealing the wet MXene films at $175{ }^{\circ} \mathrm{C}$, the trapped water molecules and other intercalated or adsorbed species can be removed, as a result, the $\mathrm{R}_{\mathrm{s}}$ dramatically reduced from 630 to $191 \Omega \mathrm{sq}^{-1}$ [186]. On the other hand, in the report by Barsoum et al., the $\mathrm{Ti}_{3} \mathrm{C}_{2} \mathrm{~T}_{\mathrm{x}}$ TCEs displayed an electronic conductivity up to $6500 \mathrm{~S} \mathrm{~cm}^{-1}$ while simultaneously transmitting $>97 \%$ of visible light pernanometer thickness [82]. Therefore, a layer of nanosheet $(\sim 1.2 \mathrm{~nm}$ in

thickness) leads to $\sim 3 \%$ loss in transmittance, which is quite comparable to graphene nanosheets $(\sim 2.3 \%$ transmittance loss per layer, $0.34 \mathrm{~nm})$. Importantly, the $\mathrm{Ti}_{3} \mathrm{C}_{2} \mathrm{~T}_{\mathrm{x}}$ nanosheets reassembled into an ordered, densely electrically interconnected geometry (Fig. 13b-d), which endows a bulk conductivity in the $\mathrm{Ti}_{3} \mathrm{C}_{2} \mathrm{~T}_{\mathrm{x}}$ TCEs [82]. Consequently, the best $\mathrm{Ti}_{3} \mathrm{C}_{2} \mathrm{~T}_{\mathrm{x}}$ TCEs showcased a FoM $\mathrm{e}_{\mathrm{e}}$ of $7.3\left(\mathrm{R}_{\mathrm{s}}=330 \Omega \mathrm{sq}^{-1}, \mathrm{~T}=86 \%\right)$ while the value obtained from the fitting of the bulk regime is $5 \pm 0.5$ (Fig. 13e) [82]. However, clear percolation regime is observed, as evidenced by the saturation in the $\mathrm{T}^{0.5}-1 \mathrm{vs}$ $\mathrm{R}_{\mathrm{s}}$ plot in Fig. 13e. As discussed in Section 2.3.2, such an issue is undesirable for the TCEs and should be avoided as much as possible.

Very recently, we achieved various $\mathrm{Ti}_{3} \mathrm{C}_{2} \mathrm{~T}_{\mathrm{x}}$ TCEs with good flake alignment [171]. By controlling the concentration and spinning velocity, a range of films with different transmittance were obtained (Fig. 14a-b). These films showcase an interconnected network without protruding corners of flakes. A combination of the interconnected network (Fig. 14c-d) and much decreased boundaries in the micrometer size flakes without water molecules trapped in between, result in very high DC conductivity up to $9880 \mathrm{~S} \mathrm{~cm}^{-1}(\mathrm{~T}=29 \%, \mathrm{t}=$ $88 \mathrm{~nm})$

[171].

Interestingly, the $\mathrm{R}_{\mathrm{s}}$ of the $\mathrm{Ti}_{3} \mathrm{C}_{2} \mathrm{~T}_{\mathrm{x}}$ TCEs scales almost inversely of $\mathrm{t}$, as shown in Fig. 14e. Such a behaviour is typical seen in the bulk-like materials. In other words, no apparent percolation problems are encountered in the $\mathrm{Ti}_{3} \mathrm{C}_{2} \mathrm{~T}_{\mathrm{x}}$ TCEs. This is further verified by the $\mathrm{T}$ vs $\mathrm{R}_{\mathrm{s}}$ plot in Fig. 14f, as the measured $\left(T, R_{s}\right)$ data are roughly on the curve without apparent deviation. In addition, the $\mathrm{FoM}_{\mathrm{e}}$ values are almost constant in a range of thickness (or T, Fig. $14 \mathrm{~g}$ ). The highest FoM $_{\mathrm{e}}$ achieved is 19 , similar to the one fitted in Fig. $14 \mathrm{f}$ $\left(\mathrm{FoM}_{\mathrm{e}}=16\right)$. 


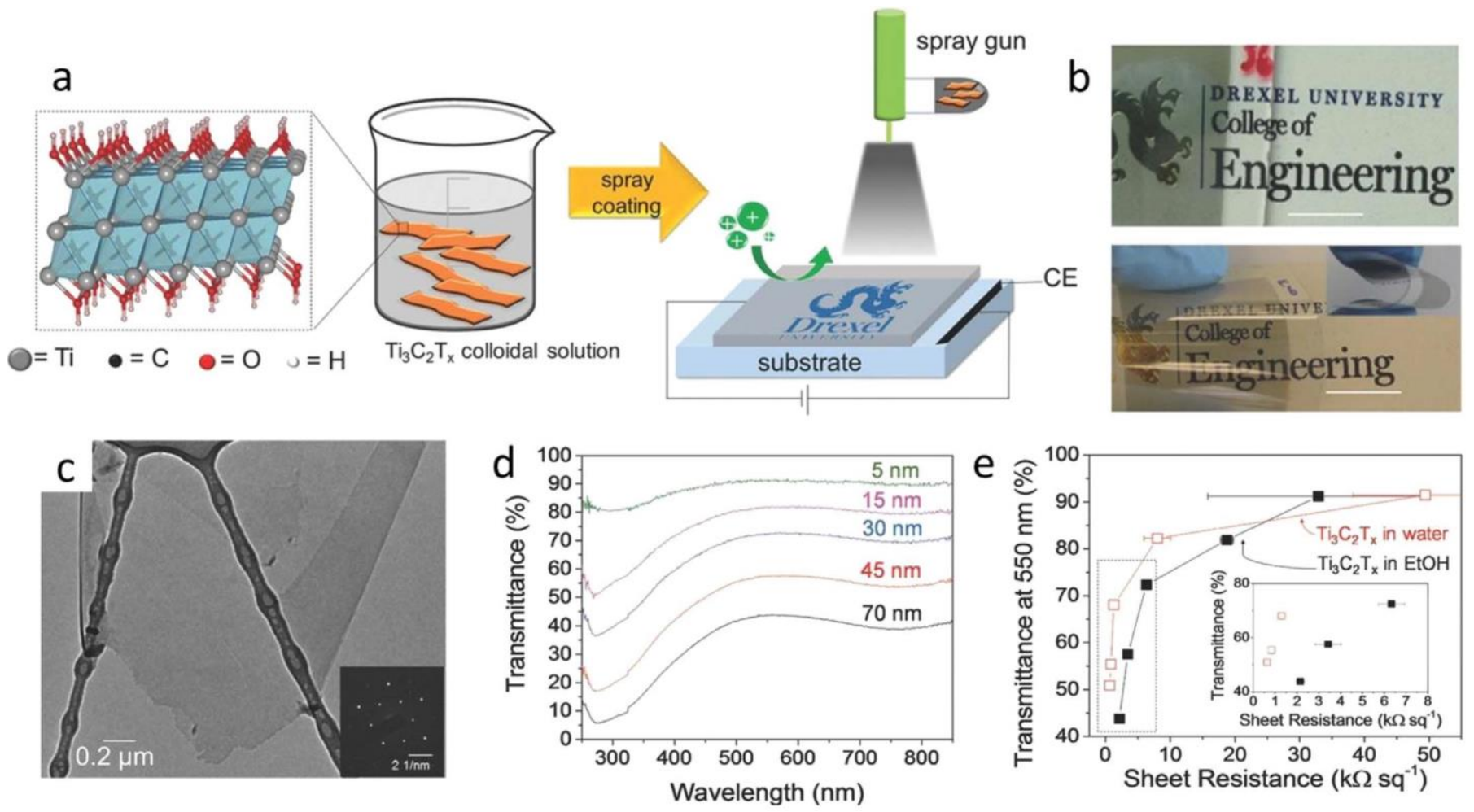

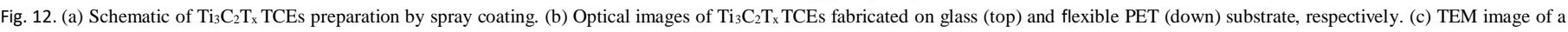

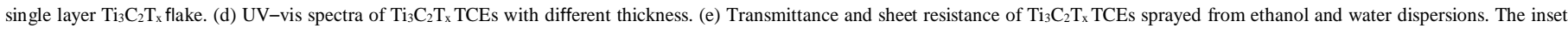
shows the low sheet-resistance region. Reprinted with permission from Ref. [184]. Copyright 2016 Wiley-VCH.
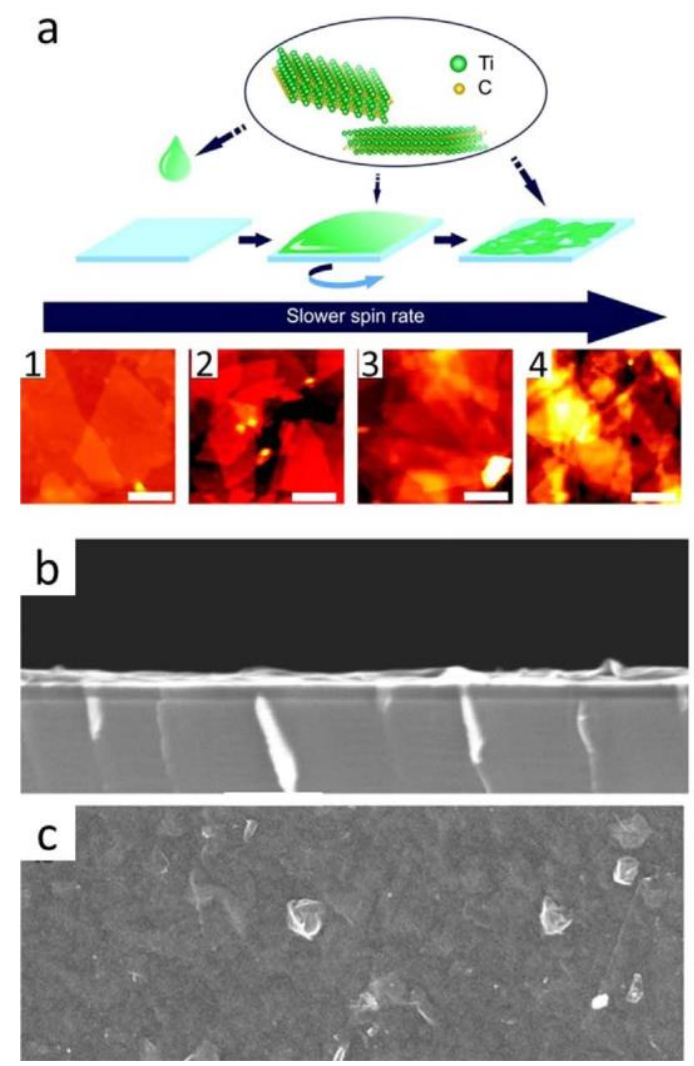

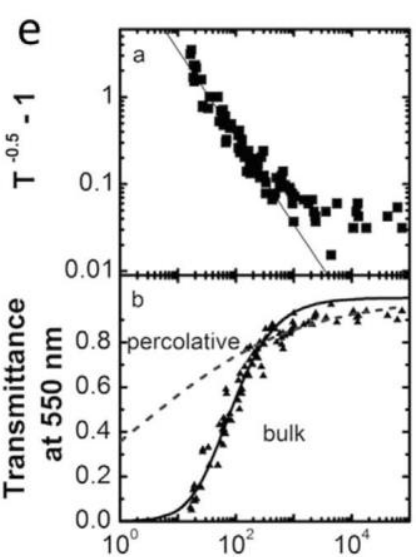

Sheet resistance $\left(\Omega \square^{-1}\right)$

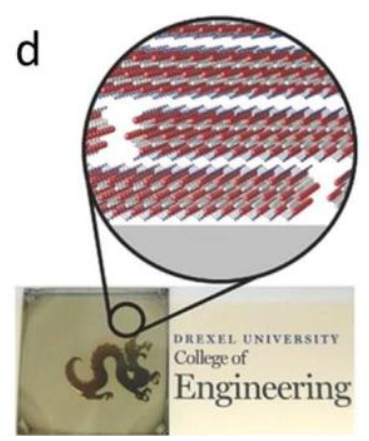

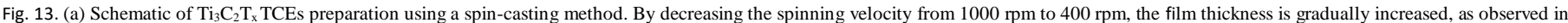

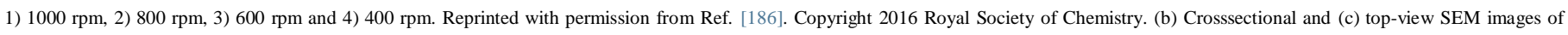

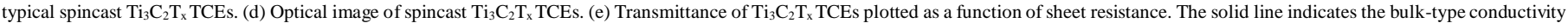
behaviour while the dashed line represents the percolative behaviour. Reprinted with permission from Ref. [82]. Copyright $2016 \mathrm{Wiley-VCH.}$ 

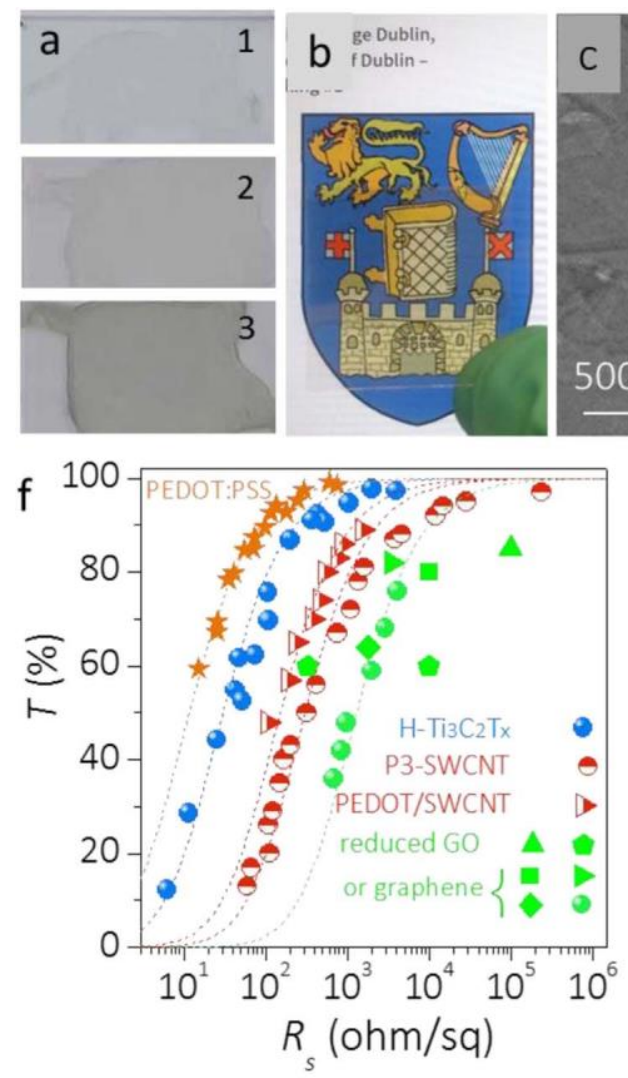
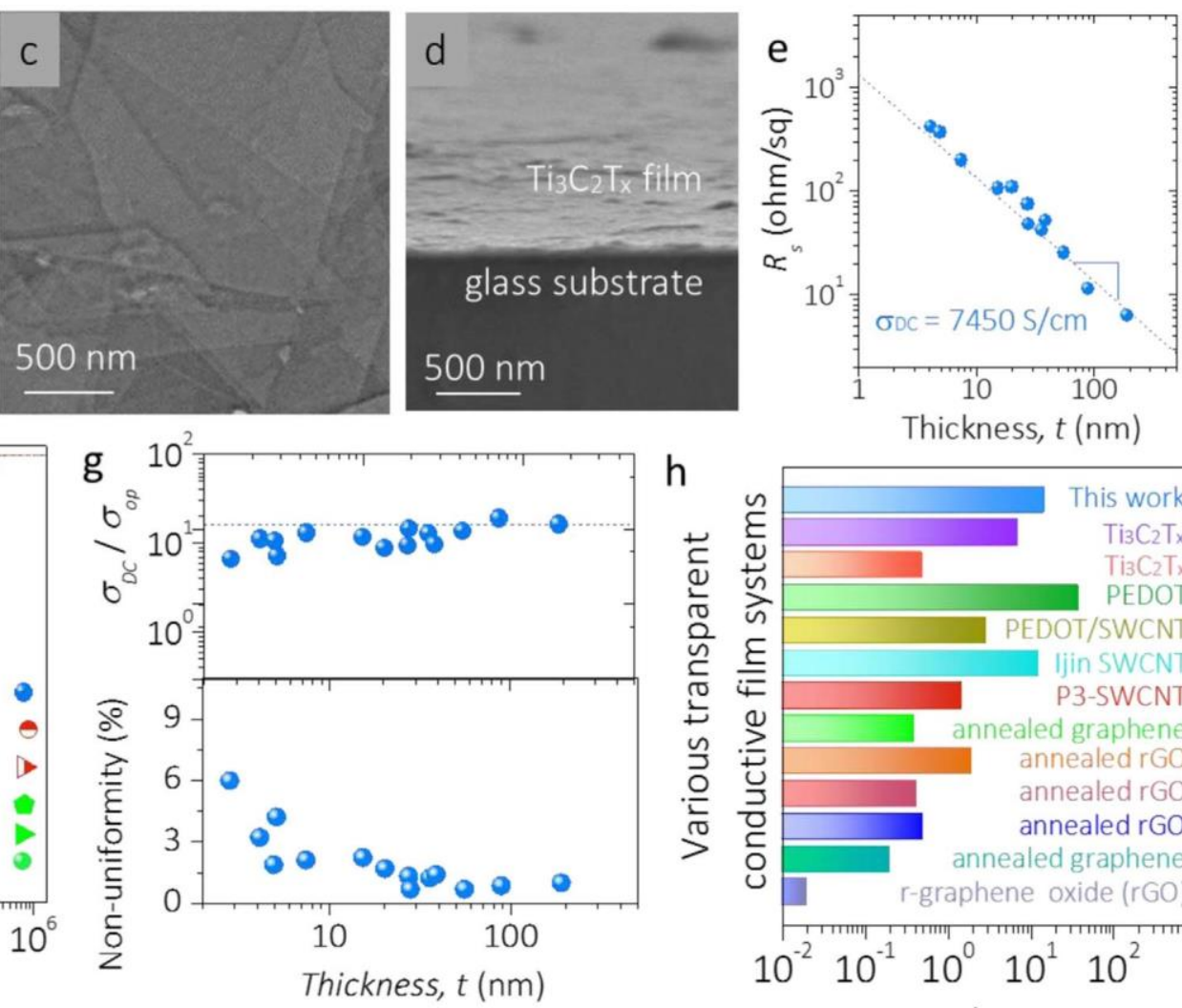

h
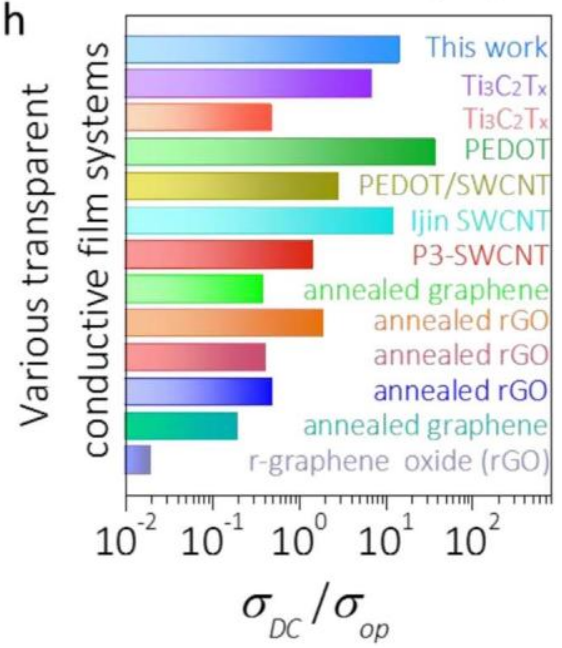

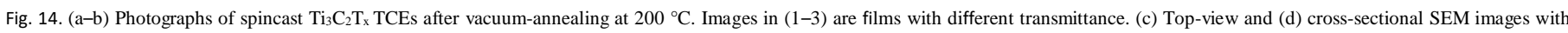

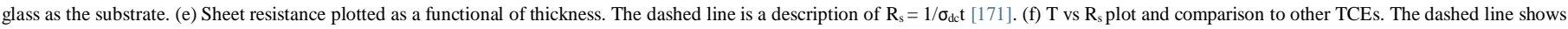
the bulk-like conductivity behaviour. (g) FoMe (up) and non-uniformity (down) plotted as a function of thickness. (h) Comparison of FoMe in this study to

other studies. Reprinted with permission from Ref. [171]. Copyright 2017 Wiley-VCH.

This value greatly exceeds that achieved in the solution-processed rGO films [116], and comparable to the best CNT-based TCEs (shown in Fig. 14h). We note this is quite significant, which allows the TCEs to be more transparent without compromising the conductivity. In other words, the technologically viable devices based on the $\mathrm{Ti}_{3} \mathrm{C}_{2} \mathrm{~T}_{\mathrm{x}}$ thin films would render the DC conductivity roughly independent of $\mathrm{T}[171]$. This unique property implies that for the highly transparent TCEs, the continuous $\mathrm{Ti}_{3} \mathrm{C}_{2} \mathrm{~T}_{\mathrm{x}}$ film could act as the efficient transparent current collector as well as the active material at the same time. Thus, transparent supercapacitor can be thus built based on the $\mathrm{Ti}_{3} \mathrm{C}_{2} \mathrm{~T}_{\mathrm{x}}$ TCEs without the need of extra metals as current collectors. In the following up Section 4, this point will be discussed in detail.

\subsection{Other MXene-based TCEs}

With over 20 MXene compositions that have been synthesized to date and most are predicted to be metallic, other MXenes could also be used as potential transparent conductive films. Vanadium carbide $\left(\mathrm{V}_{2} \mathrm{CT}_{\mathrm{x}}\right)$ films were shown to have a conductivity up to $1560 \mathrm{~S} \mathrm{~cm}^{-1}$ [187]. The challenging lies in the delamination of the $m-V_{2} C T_{x}$ into $\mathrm{dV}_{2} \mathrm{CT}_{\mathrm{x}}$. Ying et al. delaminated the $\mathrm{V}_{2} \mathrm{CT}_{\mathrm{x}}$ in the $10 \mathrm{wt} \%$ tetrabutylammonium hydroxide (TBAOH) solution [70]. The asobtained $\mathrm{V}_{2} \mathrm{CT}_{\mathrm{x}}$ TCEs displays a higher $\mathrm{FoM}_{\mathrm{e}}(6.5)$ than the $\mathrm{Ti}_{3} \mathrm{C}_{2} \mathrm{~T}_{\mathrm{x}}$ counterpart $[70,82]$. It's observed that annealing temperature plays an important role in achieving a high conductivity. For instance, the $\sigma_{\mathrm{dc}}$ in the asobtained films is 10 $\mathrm{S} \mathrm{cm}^{-1}$, which dramatically increases to $3300 \mathrm{~S} \mathrm{~cm}^{-1}$ after annealing, an indicative of 300-fold increase [70]. By further optimizing the synthesis recipe, such as employing less destructive etchant instead of HF, larger, cleaner sheets can be expected with less defects, thus higher DC conductivity. Consequently, the $\mathrm{FoM}_{\mathrm{e}}$ in the $\mathrm{V}_{2} \mathrm{CT}_{\mathrm{x}}$ TCEs can be pushed further.
Another example is $\mathrm{Ti}_{2} \mathrm{CT}_{\mathrm{x}}$ TCEs. Ying et al. prepared a concentrated $\mathrm{Ti}_{2} \mathrm{CT}_{\mathrm{x}}$ colloidal solution $\left(25 \mathrm{mg} \mathrm{mL}^{-1}\right)$ and thus a series of $\mathrm{Ti}_{2} \mathrm{CT}_{\mathrm{x}} \mathrm{TCEs}$. For the first time, a very high sheet conductivity has been achieved $\left(5250 \mathrm{~S} \mathrm{~cm}^{-1}\right)$ [79]. This is because the density of charge carriers is high $[82,188]$. Benefiting from this, a high $\mathrm{FoM}_{\mathrm{e}}$ of 5 is obtained. It is reasonable to assume that, the $\mathrm{Ti}_{2} \mathrm{CT}_{\mathrm{x}}$ TCEs have more advantages than the $\mathrm{Ti}_{3} \mathrm{C}_{2} \mathrm{~T}_{\mathrm{x}}$ counterpart, such as nontoxic, less expensive and even better optoelectronic properties [79]. However, the stability of $\mathrm{Ti}_{2} \mathrm{CT}_{\mathrm{x}}$ aqueous colloidal solution as well as the TCEs should be addressed before the scalable production.

\subsection{Limitations of MXene-TCEs}

Although the MXene-based TCEs have shown better optoelectronic properties than the rGO-based ones, there are some disadvantages in the former. First, the shelf life of MXene colloidal solution is much lower than that of GO counterpart [53]. While storing the MXene solution in the Ar-filled hermetical bottles can effectively extended the shelf life of $\mathrm{Ti}_{3} \mathrm{C}_{2} \mathrm{~T}_{\mathrm{x}}$, however, $\mathrm{Ti}_{2} \mathrm{CT}_{\mathrm{x}}$ solution still degrades quickly [53]. On the other hand, GO solution does not have this stability issue. Second, the production cost of MXene and MXene TCEs is much higher than that of GO. This is because that the chemical synthesis route to GO has been commercialized while MXene is still yet to come. Once the production cost is decreased, then MXene-based TCEs can be potentially scalable produced. Finally, by chemical doping of graphene-TCEs $[25,111]$, the optoelectronic properties can be substantially improved. However, up to date, there is no reports on the chemical doping of MXene TCEs. As indicated by Barsoum et al., the charge carrier mobility is quite low in the $\mathrm{Ti}_{3} \mathrm{C}_{2} \mathrm{~T}_{\mathrm{x}} \mathrm{MXenes}\left(0.9 \mathrm{~cm}^{2} \mathrm{~V}^{-1} \mathrm{~s}^{-1}\right)[82,188]$. If the charge carriers mobility of MXene can be dramatically improved, the $\mathrm{FoM}_{\mathrm{e}}$ can be enhanced to compete with ITO in the future. 


\section{Transparent supercapacitors}

\subsection{Introduction on the transparent supercapacitors}

As mentioned previously, one of the most important trends in the portable electronics is to develop flexible, touchable, and transparent products $[1,6]$. This require all the crucial components, including energy storage device, to be resilient and transparent as well $[15,23,171]$. Supercapacitors, also known as electrochemical capacitors, are devices that can be charged-discharged in seconds, and deliver a high power density with a long lifetime, in contrast to the undesirable charging-discharging rate and lifetime in Li-ion batteries $[23,54,71,141,164,167,169,171,173,174,181,189-209]$. However, the energy density for the supercapacitors (SC) is one order of magnitude lower than that of Li-ion batteries [54,141,169,193,201-204,208]. For the potential incorporation of SC into the transparent portable electronics, both the energy density and power density need to be improved considerably. For any SC, the performance metrics are the stored energy $(E)$ and power output $(P)$ :

$$
\begin{aligned}
& P=\frac{\frac{1}{2} C V \quad E=^{2}}{4 R_{E S R}}
\end{aligned}
$$

In the perspective of materials, the electrode capacitance (C) should be maximized while the equivalent series resistance $\left(R_{E S R}\right)$ be minimized. For the device, the operated voltage window (V) is limited by the aqueous electrolyte $(1.2 \mathrm{~V})$ and can be overcome by building the asymmetric configuration $[23,210]$. The key limitation lies in the development of high performance TCEs. Unlike the conventional TCEs which only conduct the electrons, TCEs for the transparent SCs need to possess a good charge-storage property. This is quite challenging, as approaching high $\mathrm{T}$, percolation problems are usually encountered in the TCEs, leading to quite high $\mathrm{R}_{\mathrm{ESR}}$, low $\mathrm{C}$ and thus undesirable $\mathrm{E}$ and P. Said otherwise, high-performance transparent SC requires the TCEs to possess two high figure of merits, electrical FoM $\mathrm{e}_{\mathrm{e}}$ and capacitive $\mathrm{FoM}_{\mathrm{c}}$, at the same time. While the former indicates the capability to conduct electrons at high transparency, as discussed previously [42,132], the latter (defined as the ratio of volumetric capacitance to optical conductivity, $\mathrm{C}_{\mathrm{v}} / \sigma_{\mathrm{op}}$ ) is an indicative of ability to store electrochemical energy in the transparent region [23,171]. Typically, a high $\mathrm{FoM}_{\mathrm{e}}$ implies good rate handling properties (thus power output, P) in the transparent SC, while a high $\mathrm{FoM}_{\mathrm{c}}$ suggests good energy storage properties $(\mathrm{E})$.

In this regard, the mainstream for developing transparent SC is focused on the quest of active materials. While metal grids (such as $\mathrm{Ag}, \mathrm{Cu}$, etc.) showcase very high FoM $_{\mathrm{e}}[16-18,128,160]$, they are not capacitive materials and thus cannot be used in transparent SC alone. On the other hand, CNTs, transition metal oxides and conductive polymers not only demonstrate a great potential for the TCEs with FoM $\mathrm{e}_{\mathrm{e}}$ as high as 39 in the case of PEDOT:PSS [15], but also find applications in the transparent SC [15,39,40,211-222]. For example, Higgins and Coleman spray-coated the PEDOT:PSS solution onto PET substrates, the as-obtained TCE was used as both the transparent current collector and active material for transparent SC, which demonstrated a high rate capability and a high areal capacitance (up to $1.9 \mathrm{mF} \mathrm{cm}-2$ for the $\mathrm{T}=70 \%$ film) without apparent percolation problems [15]. On the other hand, Wang et al. deposited PEDOT:PSS and $\mathrm{MnO}_{2}$ onto the Ni mesh TCEs via spin-casting strategy and electrodeposition methods, respectively [12,223]. By using the Ni mesh network as the transparent current collector, a high $\mathrm{FoM}_{\mathrm{e}}$ as high as $10^{4}$ is thus obtained. The PEDOT:PSS or $\mathrm{MnO}_{2}$ layer contribute to the capacitive charge storage. Consequently, the capacitive behaviour up to $100 \mathrm{~V} \mathrm{~s}^{-1}$ was achieved [12,223]. CNTs or carbon-based materials used as transparent, solidstate SC electrode were also reported [211,219,224,225]. For instances, Ajayan et al. reported nano-engineered carbon films from porous template and used as transparent SC electrode, demonstrating both long-term cycling and flexibility in the device [224]. By vacuum-filtration of SWCNT dispersion followed by a stamping method, Unalan et al. made SWCNT-based transparent SC which showcased good charge-storage properties [225]. It is important to emphasize that, unlike traditional SC electrodes, the gravimetric capacitance, $\mathrm{C}_{\mathrm{M}}$, is of little relevance when evaluating the chargestorage performance of transparent SCs. This is because the mass of the TCEs is insignificant compared with that of the substrates. Furthermore, to measure the mass of TCEs exactly is quite challenging [15]. As an alternative, all the evaluation metrics of transparent SC should be based on the geometrical area of the device. For example, areal capacitance $\left(\mathrm{C} / \mathrm{A}, \mathrm{mF} \mathrm{cm}^{-2}\right)$, energy density $\left(\mathrm{E} / \mathrm{A}, \mathrm{MW} \mathrm{h} \mathrm{cm}^{-2}\right.$ ) and power density (P/A, W $\left.\mathrm{cm}^{-2}\right)$, etc. are frequently used for the electrochemical characterizations of transparent SCs.

Unlike the 3D carbons which exhibit winded ion diffusion paths, 2D nanosheets can directly expose the active sites to the electrolyte. The shortened ion diffusion paths coupled with excellent electronic conductivity in the $2 \mathrm{D}$ nanosheets-based TCEs should render good chargestorage properties in the transparent SCs. In this regard, we focus on the 2D nanosheets, specifically, graphene and MXene TCEs, for transparent supercapacitors application, despite these TCEs also demonstrate a great potential in other applications, such as touch panel, displays, solar cell, to name just a few (Fig. 1) [1,2,6].

\subsection{Graphene-based transparent supercapacitors}

Lee et al. deposited graphene quantum dots (QDs) onto CVD-grown graphene interdigitated fingers using an electrophoretic method [49]. Using the underneath CVD-graphene TCE as the current collector and graphene QDs as the active materials, the device demonstrates excellent rate response (relaxation time of $8.5 \mathrm{~ms})$ and high transparency $(93 \%)$ as well as long-term cycling ( $100 \%$ after 10,000 cycles) [49]. By transferring the CVD-grown graphene films onto PDMS substrate using the methods that described in Section 2.2.1, transparent SC can be immediately built through sandwiching the graphene/ PDMS electrode with gel electrolyte (such as polyvinyl alcohol, PVA, and $\mathrm{H}_{3} \mathrm{PO}_{4}$ ) [46,47,226], the latter works as both the separator and solid-state electrolyte. This process is demonstrated in Fig. 15a. In a typical run, Dai et al. reported a graphene-based transparent $\mathrm{SC}$, which demonstrates a $\mathrm{T}$ of $86 \%$ with good rate response and capacitive behaviour (Fig. 15b-c) [226]. The C/A of the transparent SC reaches $4.2 \mu \mathrm{F} \mathrm{cm}^{-2}$ [226]. By introducing the wrinkles on the CVD-grown graphene TCEs, transparent, flexible and stretchable SCs can be fabricated as a result. For instances, Dai et al. produced the wrinkled CVDgrown graphene films using a wrinkled $\mathrm{Cu}$ foil (extruded by tweezers) [46]. Benefiting from the unique morphology (Fig. 15d), the resultant SC displays a good stretchability (up to $40 \%$ strain) in the course of hundreds of stretching cycles without obvious performance change. In addition, the C/A of the transparent SC reaches $5.8 \mu \mathrm{F} \mathrm{cm}^{-2}$ at a $\mathrm{T}$ of $57 \%$ and the capacitance keeps almost constant upon stretching, as shown in Fig. 15e [46]. On the other hand, by using a prestraining-then-buckling method, Chou et al. were able to fabricate stretchable transparent SC based on the few-layer CVD-grown graphene assisted by the PDMS lamination [227]. As indicated in Fig. 15f, due to the mismatch of the elastic modulus between graphene film and PDMS substrate, a buckled morphology of graphene films was obtained. Upon stretching, the electrochemical performance of the transparent SC is even larger than that of the planar state, i.e., $5.33 \mu \mathrm{F} \mathrm{cm}^{-2}$ in the $40 \%$ stretched device vs $4.27 \mu \mathrm{F} \mathrm{cm} \mathrm{cm}^{-2}$ in the planar device at the same T of $73 \%$ (Fig. 15g-h) [227]. 

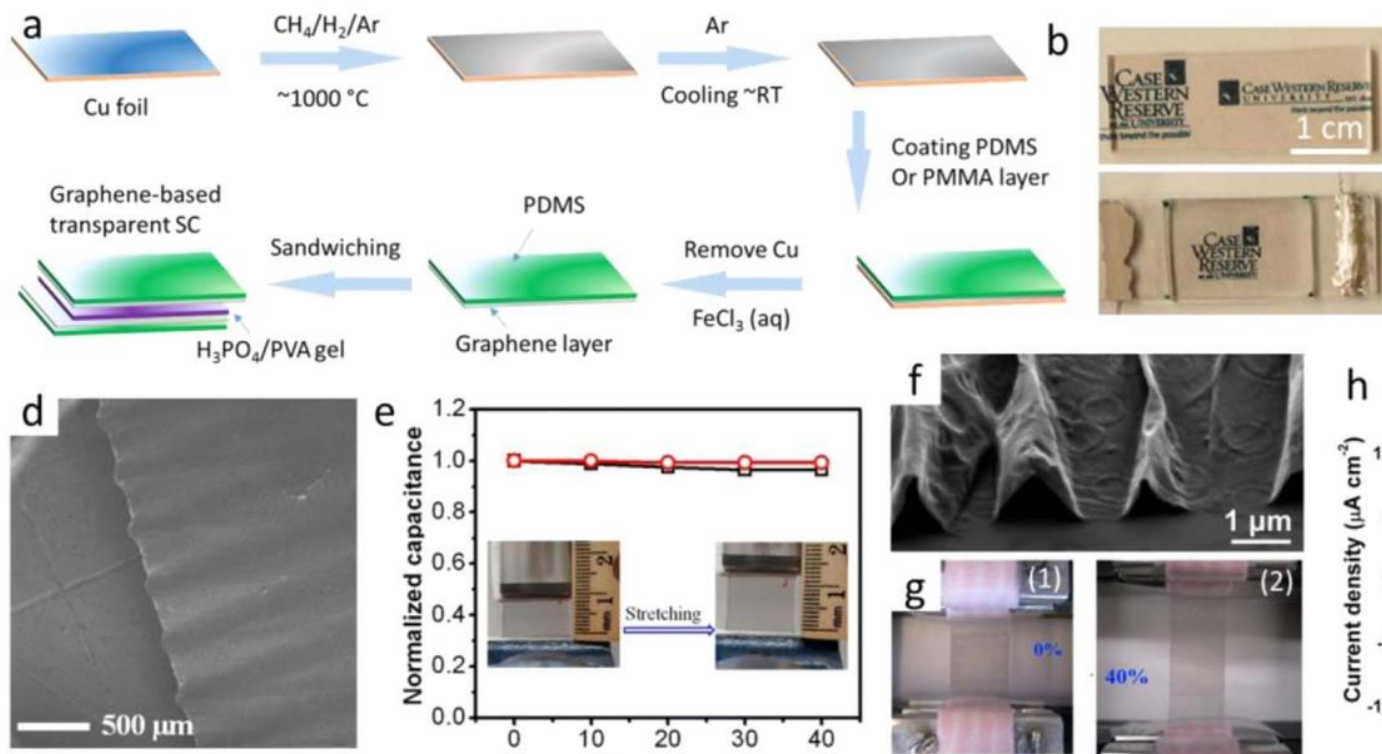

Or PMMA layer

PDMS
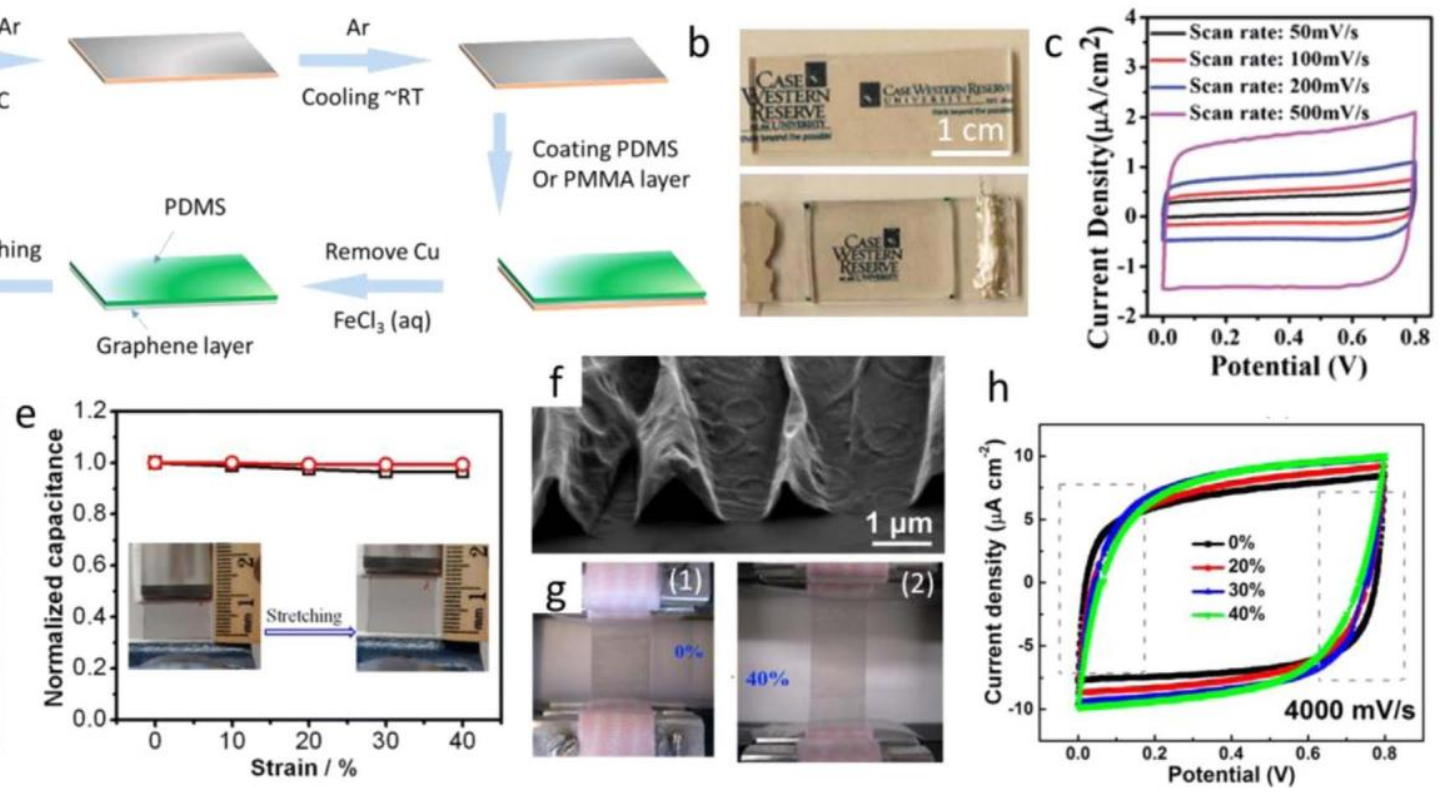

Fig. 15. (a) Scheme of transparent SC fabrication based on CVD-grown graphene. (b) Optical images and (c) CV curves of CVD-graphene based SC. Reprinted with permission from Ref. [226]. Copyright 2014 The Royal Society of Chemistry. (d) SEM image of wrinkled graphene sheets produced by CVD method with wrinkled Cu as the substrate. (e) Capacitance plotted as a function of strain. Insets are the images showing different extent of stretching. Reprinted with permission from Ref. [46]. Copyright 2014 American Chemical Society. (f) SEM image of the laminated few-layer

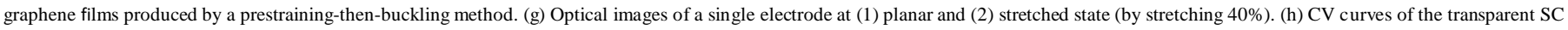
under different stretching states. The scan rate is $4000 \mathrm{mV} \mathrm{s}^{-1}$. Reprinted with permission from Ref. [227]. Copyright 2014 American Chemical Society.
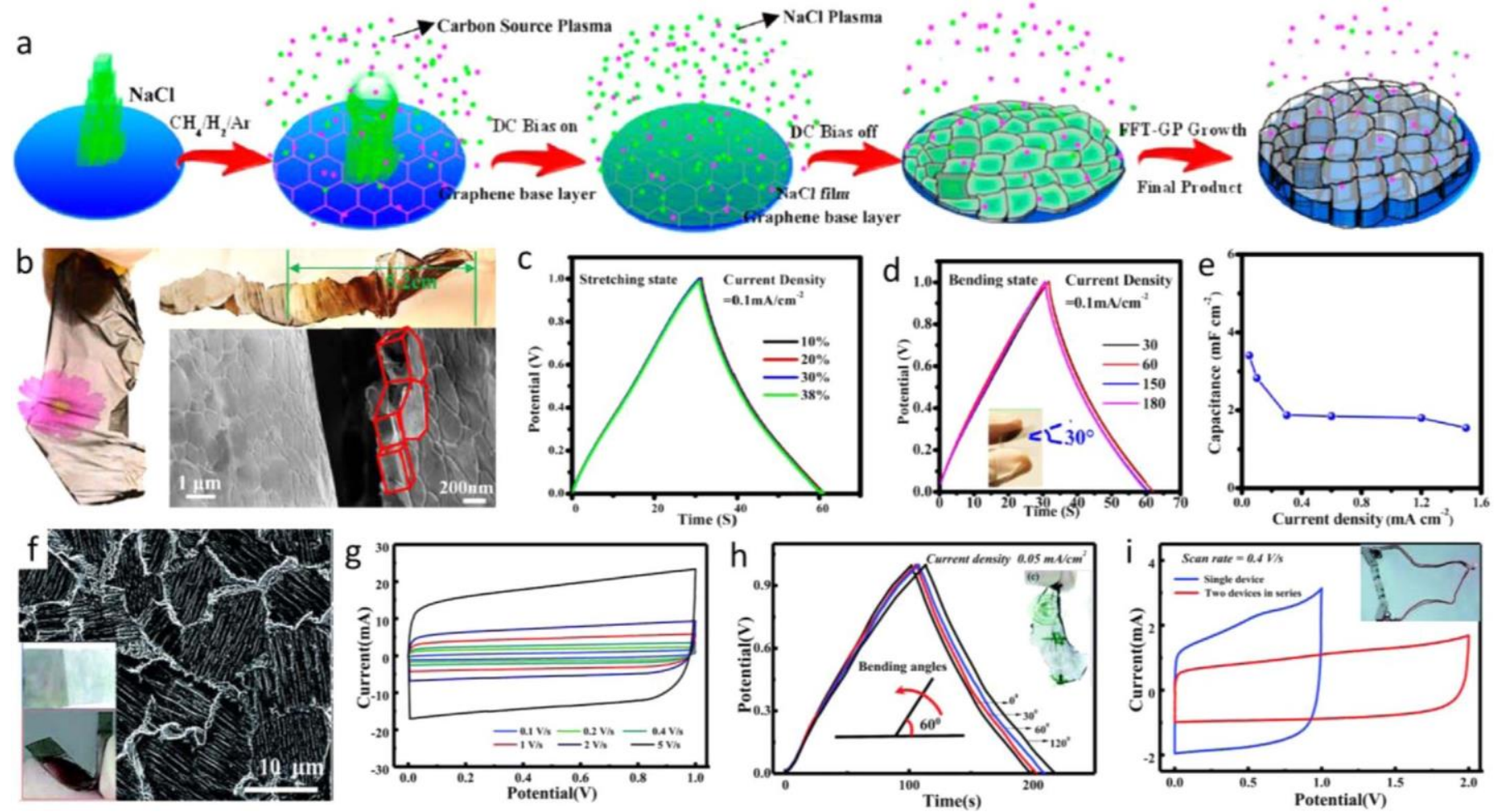

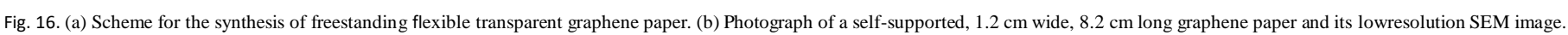

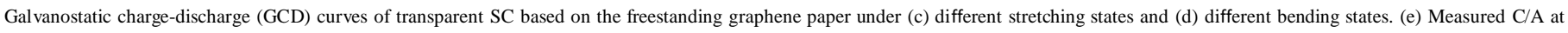

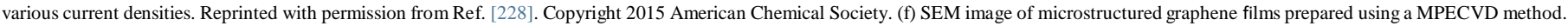

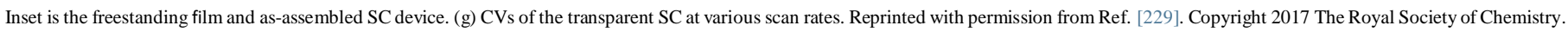

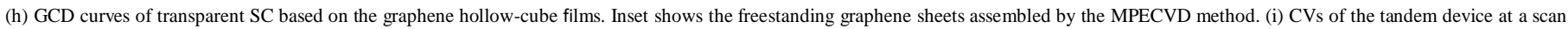
rate of $0.4 \mathrm{~V} \mathrm{~s}^{-1}$. Inset is the demonstration of powering a LED light by the tandem device. Reprinted with permission from Ref. [230]. Copyright 2017 Royal Society of Chemistry.

To further improve both the stretchability and capacitance of the flexible, transparent SCs, freestanding graphene paper was obtained through a microwave plasma-enhanced (MPE-) CVD method with sodium chloride $(\mathrm{NaCl})$ as the template [228]. Under the effect of plasma ball, the $\mathrm{NaCl}$ powder 
melts and forms a thin layer on top of the as-formed graphene base layer. The decomposed $\mathrm{C} / \mathrm{H}$ radicals further grow on the thin $\mathrm{NaCl}$ layer. When the bias was turned off, the $\mathrm{NaCl}$ recrystallizes from the layer, leading to the formation of graphene fragments, at the same time, the prismlike $\mathrm{NaCl}$ crystals can serve as template for further growth of prismlike graphene building blocks, as illustrated in Fig. 16a-b [228]. The freestanding graphene paper/ PDMS-based $\mathrm{SC}$ showcases a good electrochemical response, including a high C/A up to 3.1 $\mathrm{mF} \mathrm{cm} \mathrm{cm}^{-2}$ at $\mathrm{T}=68 \%$ (per electrode) with almost constant capacitance upon stretching or bending, as shown in Fig. 16ce [228]. The capacitance is two orders of magnitude higher than the CVD-grown graphene [46,226,227], demonstrating a great potential of the freestanding graphene paper for transparent SC application. Similarly, 3D self-supporting graphene ribbons were also prepared by taking advantage of the multistage-recrystallization of $\mathrm{NaCl}$ in a MPECVD system [229]. The key to the formation of freestanding graphene ribbons is to form polygonal $\mathrm{NaCl}$-grains and linear $\mathrm{NaCltwins}$ by turning off both the heater and DC bias. The assembled symmetric device, with a $\mathrm{T}$ of $50.6 \%$, demonstrated $4.88 \mathrm{mF} \mathrm{cm}^{-2}$ at $0.02 \mathrm{~mA} \mathrm{~cm}^{-2}$, in contrast to 4.95 $\mathrm{mF} \mathrm{cm}{ }^{-2}$ under the bending state of $60^{\circ}$ (Fig. 16f-g) [229]. After 20,000 cycles, the capacitance maintained $95.5 \%$ of the initial value, suggesting a long lifetime. In addition, the highest $\mathrm{E}$ was $605.2 \mu \mathrm{W} \mathrm{h} \mathrm{\textrm {cm } ^ { - 3 }}$ at a $\mathrm{P}$ of $8.93 \mathrm{~mW} \mathrm{~cm}^{-}$ ${ }^{3}$, while the maximum $\mathrm{P}$ was $817.3 \mathrm{~mW} \mathrm{~cm}^{-3}$ at the $\mathrm{E}$ of $295 \mu \mathrm{W} \mathrm{h} \mathrm{cm}{ }^{-3}$ [229]. Moreover, using a similar method, $\mathrm{Li}$ et al. prepared freestanding graphene hollow-cube films with improved C/A $\left(5.48 \mathrm{mF} \mathrm{cm}^{-2}\right)$, volumetric E $(657.2 \mu \mathrm{W}$ $\left.\mathrm{h} \mathrm{cm}^{-3}\right)$ and $\mathrm{P}\left(954.3 \mathrm{~mW} \mathrm{~cm}^{-3}\right)$ at the cost of transmittance $(\mathrm{T}=44 \%$ for the single electrode) (Fig. 16h) [230]. A single device possessed a good robust nature. By connecting two symmetric transparent SCs into a tandem device, the output voltage/ energy/power can be controlled to meet the requirement, as shown in Fig. 16i. Another similar work on transparent freestanding graphene films with quite comparable electrochemical performance is also reported, suggesting the synthesis approach of transparent graphene wrinkled paper is of general interest [231].

In spite of these progresses, the fabrication procedures of the aforementioned wrinkled graphene films/freestanding papers are rather complicated which either involve high temperature processing $\left(\sim 1000{ }^{\circ} \mathrm{C}\right.$ for CVD growth of graphene) or multiple steps to obtain high-quality graphene films $[46,47,227,228,230]$. For the potential application of graphene-based transparent SCs, sustainable, feasible and facile processes are of essential importance. In this regard, Hsu et al. obtained freestanding graphene fiber mesh from the parafilm waste via an environmentally friendly approach [232]. The hollow graphene fiber mesh, which was chemically-doped by $\mathrm{HNO}_{3}$, possesses a transmittance of $76 \%$ (which decreased to $69 \%$ for the transparent SC), a low sheet resistance $\left(\sim 32 \Omega \mathrm{sq}^{-1}\right)$ and a high flexibility, as shown in Fig. 17a-e. According to Eq. (1), the $\mathrm{FoM}_{\mathrm{e}}$ is calculated to be 40, suggesting the graphene fiber alone is a good transparent current collector. The highest $\mathrm{C} / \mathrm{A}$ in the freestanding graphene fiber mesh reaches $245 \mu \mathrm{F} \mathrm{cm}{ }^{-2}$ at $50 \mathrm{mV} \mathrm{s}^{-1}$, and demonstrate good flexibility and long-term cycling, as indicated in Fig. $17 \mathrm{f}-\mathrm{i}$. The $\mathrm{C} / \mathrm{A}$ is improved to $1.1 \mathrm{mF} \mathrm{cm}^{-2}$ in the hollow nanocarbon/graphene fiber mesh composite, the former provides larger surface area for ion adsorption/desorption [232]. Very recently, highly transparent microsupercapacitors were reported by a direct inkjet printing-hard masking strategy (Fig. 17j) [233]. The transmittance of the graphene/PET SC device can be easily tuned by simply changing the number of printed graphene layers (inset in Fig. $17 \mathrm{k}$ ). The resilient nature of the transparent SC coupled with the facile device fabrication compensated the low-capacitance disadvantage (Fig. 171) [233].

On the other hand, by using reduced graphene oxide as both the TCE and the active material, transparent SC can be fabricated straightforward. As indicated

by Chen et al., nearly ideal double-layer capacitance were observed in the rGO-based transparent device [48]. However, the rGO-based transparent SCs displayed unsatisfactory capacitance. Through compositing rGO and cellulose nanofiber $(\mathrm{CNF})$, a transparent $\mathrm{CNF}-(\mathrm{rGO})_{\mathrm{n}}$ hybrid paper was fabricated through a $\mathrm{LBL}$ technique with $\mathrm{Cu}$ ions acted as anchoring agent. Benefiting from the unique structure, with rGO layer compactly stacked onto the $\mathrm{CNF}$ pillars, the transparent paper-based device exhibits a C/A of $1.73 \mathrm{mF} \mathrm{cm}^{-2}$ and a $\mathrm{T}$ of $56 \%$ [234], the capacitance values are much higher than that of the transparent devices based on pure rGO [47,48]. Alternatively, through hybridizing graphene with other pseudocapacitive materials, such as metal oxides [220], sulfides [235], hydroxides [236,237], or redox-active interlayer [238], etc., the capacitance and thus energy/power density of the transparent SCs can be further enhanced. This is best evidenced by a 20 -fold enhancement of the $\mathrm{C} / \mathrm{A}$ (from $5.6 \mu \mathrm{F} \mathrm{cm}^{-2}$ to $101 \mu \mathrm{F} \mathrm{cm}^{-2}$ ) after stacking bilayer graphene with a redox active layer made of ultrathin $\mathrm{p}$ aminophenol (p-AP), the latter is prone to be adsorbed onto the CVD-grown graphene predominantly through $\pi-\pi$ interaction (as shown in Fig. 18a) [238]. Such a synergistic effect results in a boost of capacitance as well as excellent robustness (Fig. 18b) [238]. To further improve the capacitance, Liu and Guo et al. employed graphene/copper sulfide $(\mathrm{CuS})$ hybrid grids as the TCE through a combination of photolithography, CVD and a low temperature solvothermal reaction [235]. The excellent optoelectronic properties $\left(\mathrm{T}=85 \%, \mathrm{R}_{\mathrm{s}}=20 \Omega \mathrm{sq}^{-}\right.$ ${ }^{1}, \mathrm{FoM}_{\mathrm{e}}=111$ ) ensure a high-rate response in the transparent SC. Importantly, the areal capacitance reaches $17.3 \mathrm{mF} \mathrm{cm}^{-2}$ at $\mathrm{T}=40 \%$ (at $620 \mathrm{~nm}$ ) in the $\mathrm{PANi} /$ graphene/ CuS-based transparent SC [235]. Such a capacitance is quite similar as that of transparent $\mathrm{SC}$ devices based on $\mathrm{Ni}(\mathrm{OH})_{2}$ nanosheets@graphene and/or FeOOH nanowires@graphene [236,237], and is the champion in terms of transparent SCs' electrochemical performance.

\subsection{MXene for transparent energy storage}

As another emerging member in the 2D family, MXene has drawn tremendous research attention ranging from synthesis [168,239-244], properties [165,172,175,187,245-247], density functional theory studies [248255], characterizations [165,256,257], and applications [50,54,55,71,163,164,167,169,173,179-181,258-260], etc. Recently, some excellent reviews covering on MXenes, especially on the synthesis and energy storage applications, have been published

$[57,64,67,69,76,162,176,261]$. Here we will focus on the aspects of transparent supercapacitors based on MXene TCEs. In particular, we will introduce the electrochemical responses of both MXene TCEs and MXene-based transparent SCs, including symmetric and asymmetric configurations.

\subsubsection{Electrochemical responses of $\mathrm{Ti}_{3} \mathrm{C}_{2} \mathrm{~T}_{\mathrm{x}} \mathrm{TCEs}$}

As one of the most widely studied MXene, $\mathrm{Ti}_{3} \mathrm{C}_{2} \mathrm{~T}_{\mathrm{x}}$ nanosheets possess a metallic electronic conductivity up to $9880 \mathrm{~S} \mathrm{~cm}^{-1}$ [171], as well as excellent charge-storage capability [55]. This is significant, as TCEs can be thus fabricated at room-temperature on the PET substrate, unlike the conventional procedures which either encounter complex procedures $[39,40]$ or using rigid substrates (such as ITO [262] or FTO [40]). As such, robust $\mathrm{Ti}_{3} \mathrm{C}_{2} \mathrm{~T}_{\mathrm{x}}$ TCEs can be made in a scalable, cost-effective approach for capacitive (or pseudocapacitive) charge storage.

As described previously, for the transparent SC, both the $\mathrm{FoM}_{\mathrm{e}}$ and $\mathrm{FoM}_{\mathrm{c}}$ are critically important. While the former figure of merit (electrically) largely determines the electron conductive network, the latter figure of merit (capacitively) essentially controls the amount energy stored in the device $[15,23]$. Both FoMs should be maximized in order to achieve advanced transparent SCs. To obtain the FoM TCEs in a three-electrode setup, based on which the intrinsic areal capacitances of various TCEs (with a 

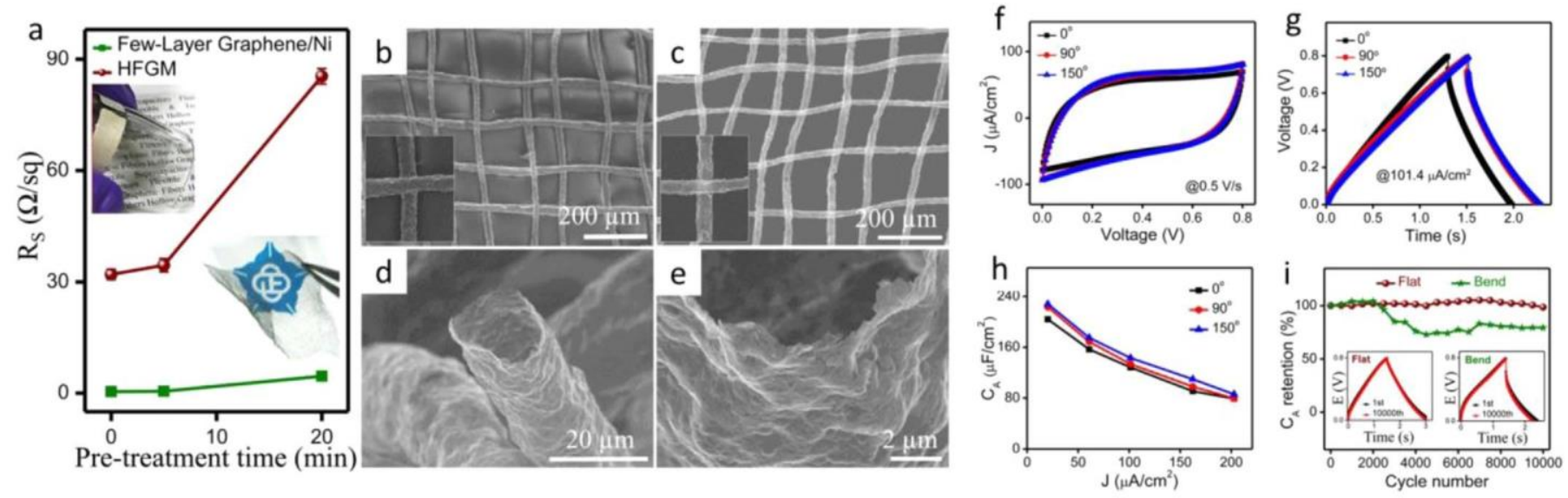

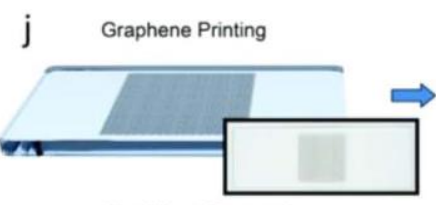

Hard Mask Removal

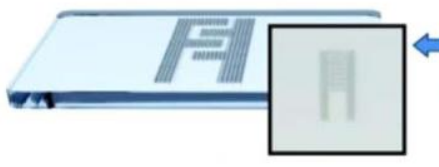

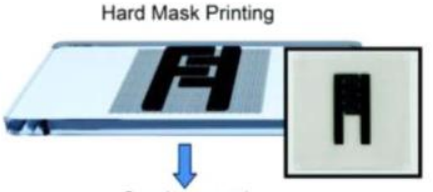

Graphene etch
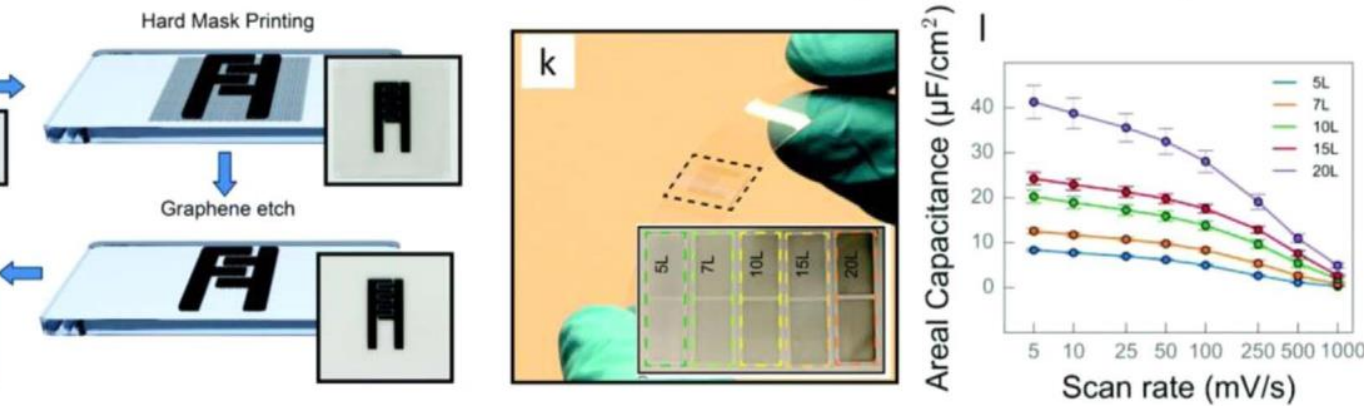

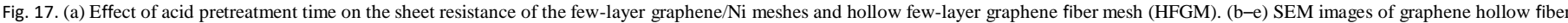

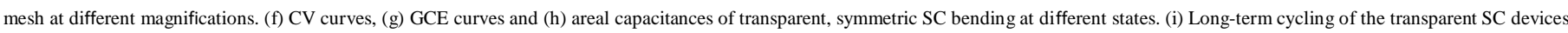

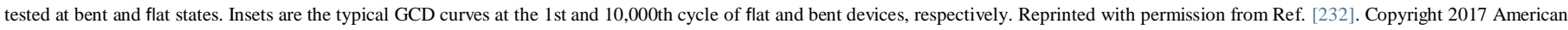

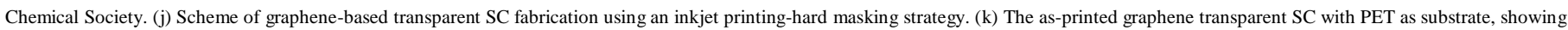

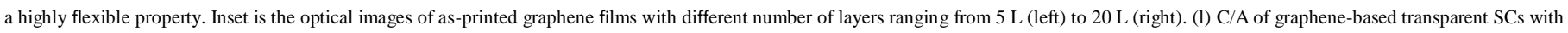
different number of printed layers. Reprinted with permission from Ref. [233]. Copyright 2017 Royal Society of Chemistry.
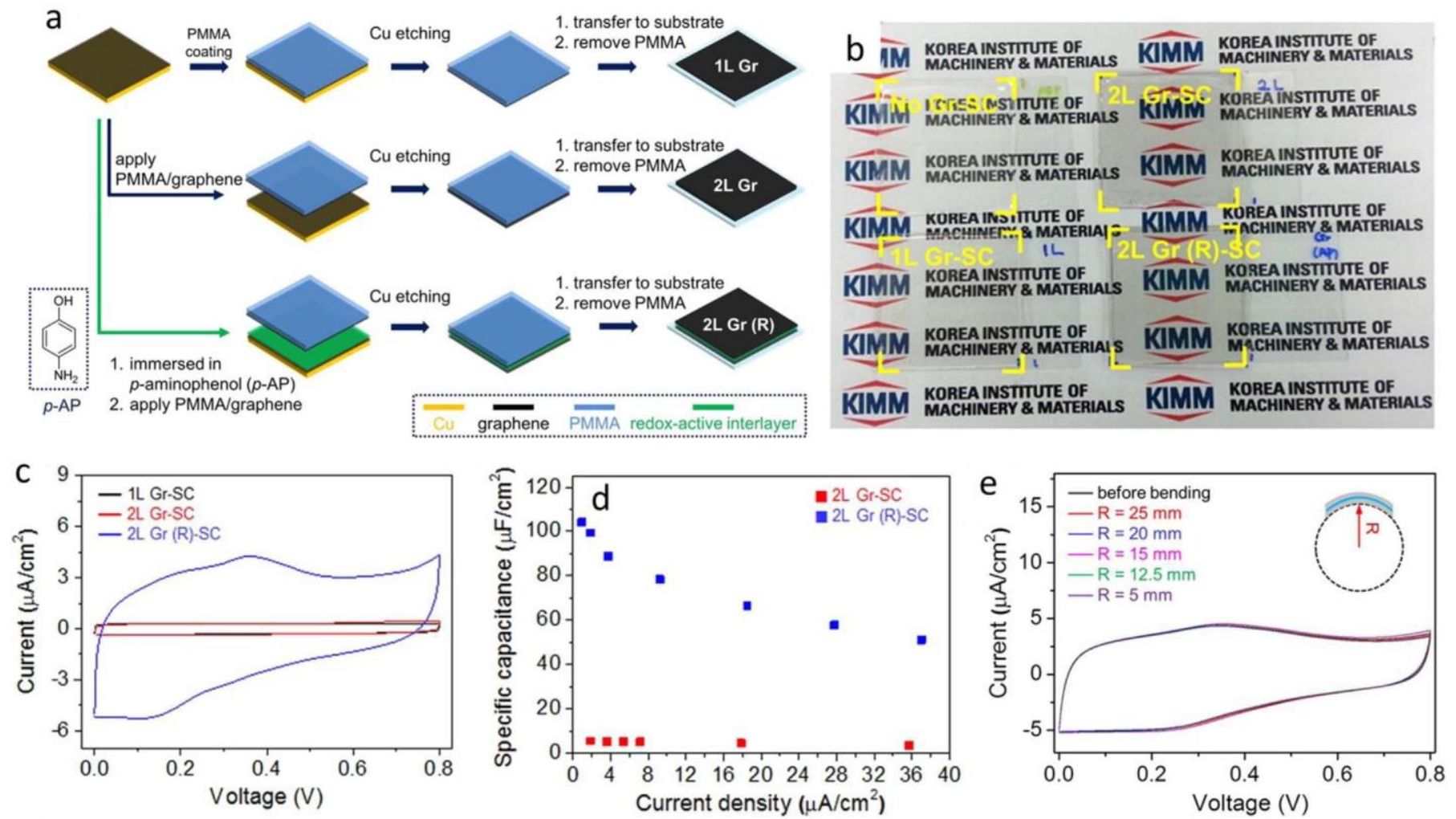


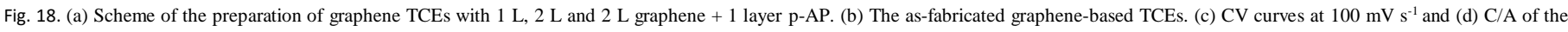
transparent SCs. (e) CV curves of the transparent SC under different bending states. Reprinted with permission from Ref. [238]. Copyright 2015 American Chemical Society.

range of $\mathrm{T}$ ) are achieved.

In practical, for a given TCE, the intrinsic areal capacitance $\left(\mathrm{C}_{\mathrm{A}}\right)$ and volumetric capacitance $\left(\mathrm{C}_{\mathrm{V}}\right)$ are two most relevant measures and are related via $\mathrm{C}_{\mathrm{A}}=\mathrm{C}_{\mathrm{V}} \mathrm{t}$. Both $\mathrm{C}_{\mathrm{A}}$ and $\mathrm{C}_{\mathrm{V}}$ are independent quantities and achieved in the absence of electron or ion transport limitations [15]. Although a TCE can be engineered with an ultrahigh $\mathrm{T}$ by making it sufficiently thin, the percolation problems become dominant, which results in a dramatically boosted $\mathrm{R}_{\mathrm{s}}$ and thus negatively affect power. On the other hand, high $\mathrm{T}$ leads to much compromised $\mathrm{C}_{\mathrm{A}}$ and hence energy [263]. To quantify these trade-offs, $\mathrm{C}_{\mathrm{A}}$ is correlated with $\mathrm{T}$ for a set of TCEs through the expression [263]:

$T=\left[1+\longleftarrow \sigma C_{o p} A\right] C_{V}$

By fitting $\mathrm{T}$ vs $\mathrm{C}_{\mathrm{A}}$ data, the $\mathrm{FoM}_{\mathrm{c}}=\mathrm{C}_{\mathrm{V}} / \sigma_{\mathrm{op}}\left(\mathrm{F} \mathrm{S}^{-1} \mathrm{~cm}^{-2}\right)$ can be obtained, then $\mathrm{C}_{V}$ of the TCEs can be thus calculated by $\mathrm{C}_{V}=\mathrm{FoM}_{c} \times \sigma_{\text {op }}$. The higher this value is, the better the charge storage properties in the TCEs. Although ultrahigh $\mathrm{FoM}_{\mathrm{e}}$ values are achieved in the silver nanowires-based TCE [16] and metallic mesh electrode [12], these metals showcase poor charge storage performance. Graphene and conducting polymers also demonstrate somewhat low volumetric capacitance for the transparent SCs $[15,263]$. On the other hand, $\mathrm{Ti}_{3} \mathrm{C}_{2} \mathrm{~T}_{\mathrm{x}}$ MXene was claimed to possess ultrahigh volumetric capacitance in the nontransparent $\mathrm{Ti}_{3} \mathrm{C}_{2} \mathrm{~T}_{\mathrm{x}}$ hydrogel or clay films [55,58]. Thus, it's reasonable to believe that $\mathrm{Ti}_{3} \mathrm{C}_{2} \mathrm{~T}_{\mathrm{x}}$ TCEs should show excellent volumetric capacitance when used as a transparent SC electrode.

To examine this, Zhang et al. fabricated $\mathrm{Ti}_{3} \mathrm{C}_{2} \mathrm{~T}_{\mathrm{x}}$ TCEs with a range of thickness and characterized the films in a three-electrode configuration [23,171]. While the $\mathrm{T}=98 \%$ sample severely deviates from the quasirectangular shape (Fig. 19a), increasing the film thickness (thus decreasing the $\mathrm{T})$ gradually increases the $\mathrm{C} / \mathrm{A}$ and better rate capability, as demonstrated in Fig. $19 \mathrm{~b}-\mathrm{d}$. The $\mathrm{T}=98 \%$ exhibits $0.13 \mathrm{mF} \mathrm{cm}^{-2}$ at $10 \mathrm{mV} \mathrm{s}^{-1}$, a value that is
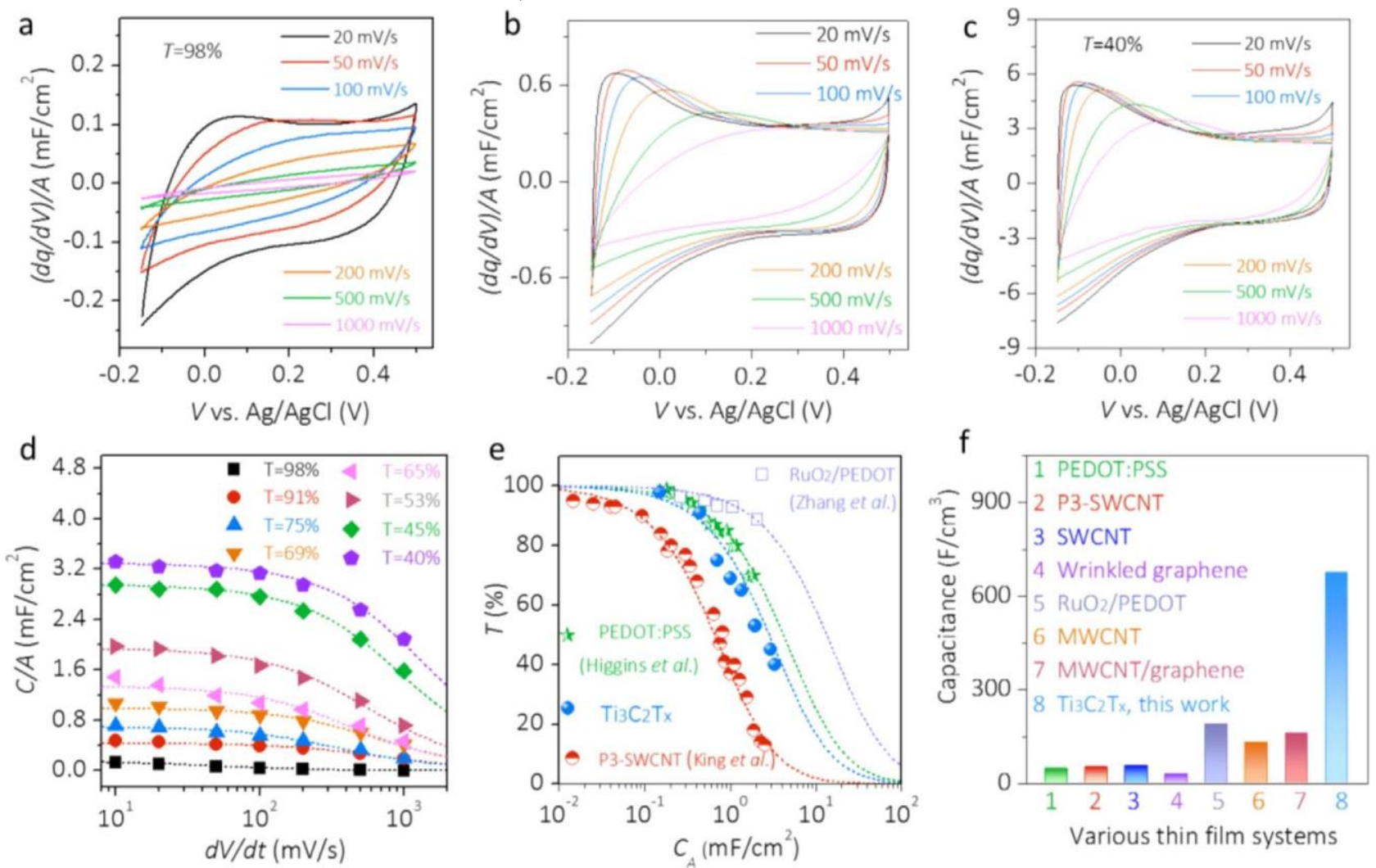

close to PEDOT:PSS film [15] but substantially higher than that of graphene quantum dot-based TCE [49]. In the T $=40 \%$ sample (film thickness $\sim 60 \mathrm{~nm}$ ), the $\mathrm{C} / \mathrm{A}$ is $3.4 \mathrm{mF} \mathrm{cm}^{-2}$ at $10 \mathrm{mV} \mathrm{s}^{-1}$ and maintains $3.0 \mathrm{mF} \mathrm{cm} \mathrm{cm}^{-2}$ at $200 \mathrm{mV} \mathrm{s}^{-1}$ (Fig. 19d) [171].

In order to obtain the $\mathrm{C}_{\mathrm{A}}$ in the $\mathrm{Ti}_{3} \mathrm{C}_{2} \mathrm{~T}_{\mathrm{x}}$ electrodes with a given thickness, the data in Fig. 19d (C/A vs v) is fitted using Eq. (8)

$C A /=C_{A}[1-\underline{\Delta v} \tau V(1-e-\underline{\Delta} v \underline{V})]$

where $\tau=R_{E S R} C$ is the time constant, $\Delta V$ is the voltage window, $v$ is the sweep rate. In general, $\mathrm{C}_{\mathrm{A}}$ is higher for the thicker TCE as expected. By correlating the $\mathrm{C}_{\mathrm{A}}$ with $\mathrm{T}$, and further fitting these two parameters using Eq. (7), the $\mathrm{FoM}_{\mathrm{c}}=$ $\mathrm{C}_{\mathrm{V}} / \sigma_{\mathrm{op}}$ of the $\mathrm{Ti}_{3} \mathrm{C}_{2} \mathrm{~T}_{\mathrm{x}} \mathrm{TCEs}$ as transparent supercapacitor is thus revealed. It was found that the $\mathrm{FoM}_{\mathrm{c}}$ in $\mathrm{Ti}_{3} \mathrm{C}_{2} \mathrm{~T}_{\mathrm{x}}$ is $1.3 \mathrm{~F} \mathrm{~S}^{-1} \mathrm{~cm}^{-2}$, although substantially higher than the P3-SWCNT $\left(0.3 \mathrm{~F} \mathrm{~S}^{-1} \mathrm{~cm}^{-2}\right)$ (Fig. 19e) [15,263], but still lower than that of PEDOT:PSS $\left(1.6 \mathrm{~F} \mathrm{~S} \mathrm{~S}^{-1} \mathrm{~cm}^{-2}\right)$. This can be ascribed to the much higher optical conductivity in the $\mathrm{Ti}_{3} \mathrm{C}_{2} \mathrm{~T}_{\mathrm{x}}\left(520 \mathrm{~S} \mathrm{~cm}^{-1}\right)$ in contrast to $24 \mathrm{~S} \mathrm{~cm}^{-1}$ and 31 $\mathrm{S} \mathrm{cm}^{-1}$ in the PEDOT:PSS and $\mathrm{RuO}_{2}$ /PEDOT:PSS, respectively $[15,23,171]$. Taking the optical conductivity $\left(\sigma_{o p}\right)$ into consideration, the $C_{V}$ of $T_{3} C_{2} T_{x}$ films as transparent SC electrode was calculated to be $676 \mathrm{~F} / \mathrm{cm}^{3}$, much higher than that achieved in the rest of all transparent SC electrodes, such as SWCNT [211,263], grapheme [32] or PEDOT:PSS [15], etc., as shown in Fig. 19f [171]. In this perspective, $\mathrm{Ti}_{3} \mathrm{C}_{2} \mathrm{~T}_{\mathrm{x}}$ TCEs hold great promise in the transparent $\mathrm{SC}$ in achieving high energy/power performance.

\subsection{2. $\mathrm{Ti}_{3} \mathrm{C}_{2} \mathrm{~T}_{\mathrm{x}}$ TCEs-based transparent supercapacitors}

To further explore the device performance, Zhang et al. fabricated the first all-MXene based transparent SC by sandwiching two robust $\mathrm{Ti}_{3} \mathrm{C}_{2} \mathrm{~T}_{\mathrm{x}}$ TCEs with gel electrolyte, as shown in Fig. 20a [23,171]. Using 


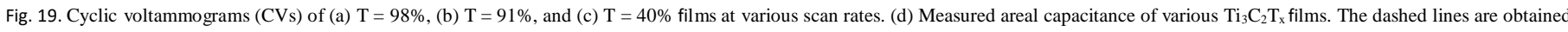

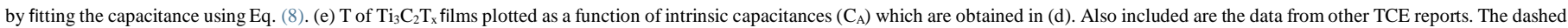

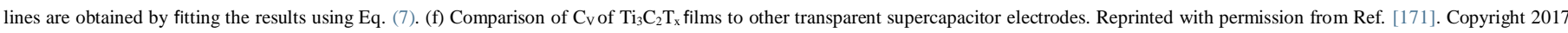
Wiley-VCH.

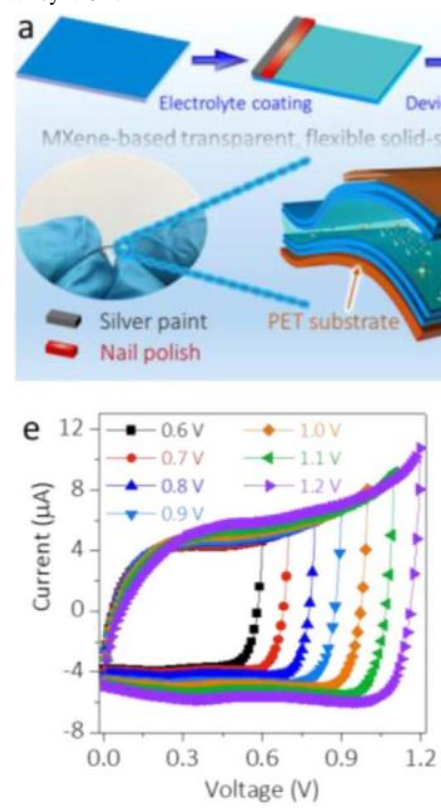

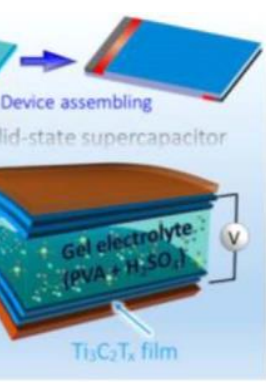

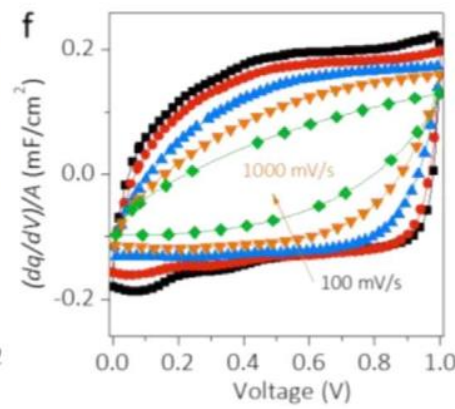

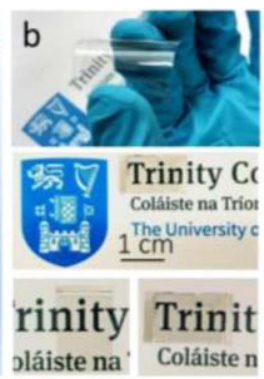
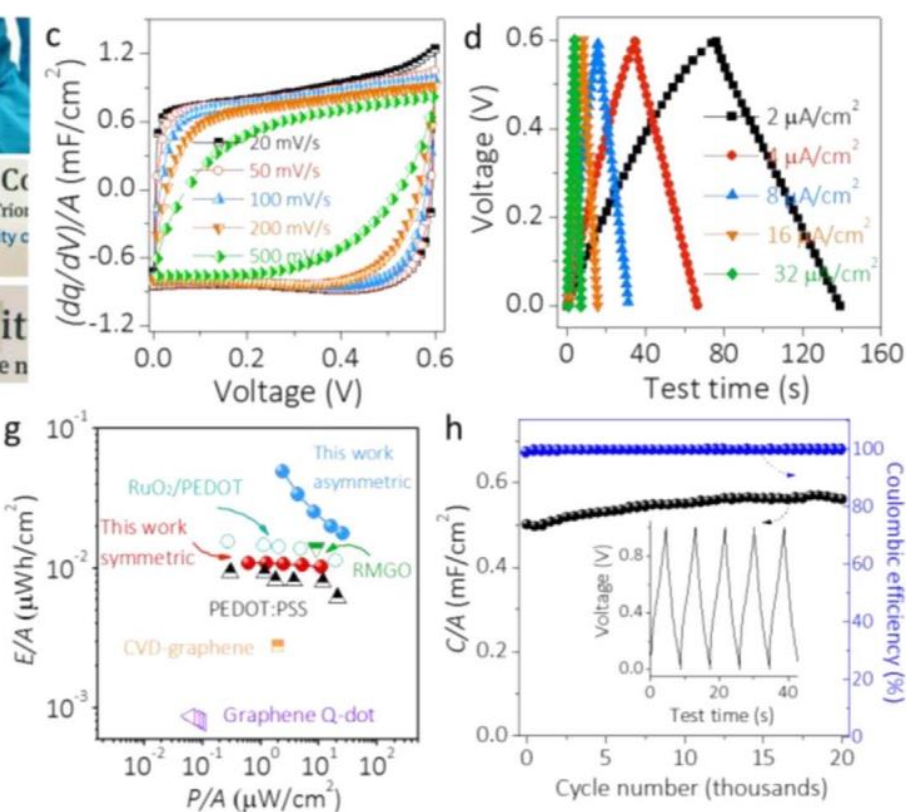

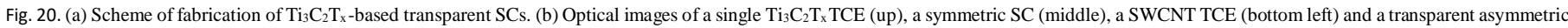

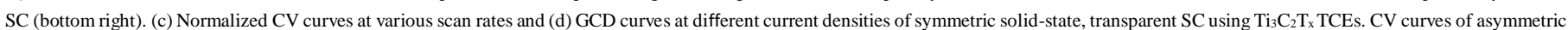

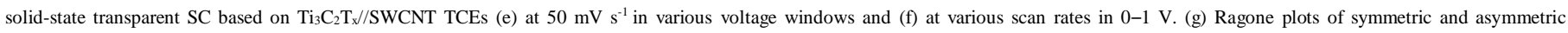

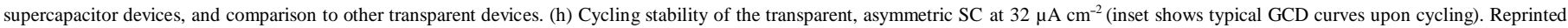
with permission from Ref. [171]. Copyright 2017 Wiley-VCH.

the $\mathrm{T}=91 \%$ as the electrode, the $\mathrm{Ti}_{3} \mathrm{C}_{2} \mathrm{~T}_{\mathrm{x}}$-based symmetric $\mathrm{SC}$ reaches a transmittance of $80 \%$ (Fig. 20b), much higher than that of graphenebased transparent SCs $[46,227-229,231]$. The as-fabricated device showcases a highly capacitive behaviour, including rectangular CV shape up to $200 \mathrm{mV} \mathrm{s}^{-1}$, rapid current response upon voltage reversal, and linear galvanostatic chargedischarge (GCD) curves (Fig. 20c-d). The C/A in the symmetric device is 0.86 $\mathrm{mF} \mathrm{cm}^{-2}$. The asymmetric SC (T of $72 \%$, Fig. 20b) was also fabricated by sandwiching SWCNT and $\mathrm{Ti}_{3} \mathrm{C}_{2} \mathrm{~T}_{\mathrm{x}}$ TCEs in sequence. Thanks to a wider voltage window, the asymmetric, transparent SC displays a much enhanced energy density without losing its capacitive charge storage behaviour and lifetime (Fig. 20e-h) [171]. This is best evidenced by the energy density of 0.05 $\mu \mathrm{W} \mathrm{h} / \mathrm{cm}^{2}$ at a power density of $2.4 \mu \mathrm{W} / \mathrm{cm}^{2}$, coupled with stable capacitance over 20,000 cycles. The high Coulombic efficiency (100\%) indicates the excellent performances are not due to other parasitic reactions [58]. It is reasonable to expect even improved electrochemical performance in the transparent $\mathrm{Ti}_{3} \mathrm{C}_{2} \mathrm{~T}_{\mathrm{x}}$-based SCs by further optimization, such as controlling the surface chemistry on the $\mathrm{Ti}_{3} \mathrm{C}_{2} \mathrm{~T}_{\mathrm{x}}$ nanosheets, introducing guest species to minimize the junction resistance occurred in the intraflakes, and/or pairing with other electrodes to extend the voltage window, etc.

\subsubsection{Challenges and opportunities of MXene-based transparent supercapacitors}

In spite of the excellent optoelectronic and charge storage properties in the MXene-base transparent SCs, the stability of both MXene dispersions and devices cannot be ignored. According to Zhang et al., the shelf-life of MXene dispersions can be extended by proper storage [53]. However, the thermodynamically unstable nature of MXene nanosheets drives the spontaneous oxidation on the flakes, resulting in a quick performance decay upon exposure in the ambient condition. Clearly, there are still many unclear issues, such as effect of surface functionalities, metal contaminations as well as defects on the MXene shelf life. Methods aiming to protect the device from degradation are also needed. By introducing guest species to protect the MXene surface, and/or sacrificing the top surface to protect the interior nanosheets, are all potential strategies in maintaining excellent performance of MXenebased TCEs and transparent SCs.

Moreover, the current synthesis route of MXene involves the usage of HFcontaining solution which raises the safety issues, costs and environmental concerns. Currently, the market price for $\mathrm{Ti}_{3} \mathrm{AlC}_{2} \mathrm{MAX}$ phase is high; $\sim \$ 550$ per $150 \mathrm{~g}$ power (Y-carbon Ltd., Ukraine). Processing the MAX into m-MXene and further d-MXene nanosheets dispersion, followed by a proper dispersion storage, add even higher costs to the total manufacturing price. This is the biggest challenging that MXene field faces today which hinders any real products from entering the market. Clearly, scalable production route from MAX phase to delaminated MXenes is highly needed; the synthesis route should be free from HF or other corrosive etchants, and should be costeffective. Once the scalable production of high-quality MXene flakes/dispersions is available, scale-up production of high performance MXene-based TCEs and transparent SCs are possible.

Beyond the stability and high-cost issues, MXene-based transparent SCs have other performance limitations. Compared to graphene/metal hydroxidebased transparent SC, which demonstrated a C/A up to $18 \mathrm{mF} \mathrm{cm}-2(\mathrm{~T}=40 \%)$ $[230,236]$, the $\mathrm{Ti}_{3} \mathrm{C}_{2} \mathrm{~T}_{\mathrm{x}}$ transparent $\mathrm{SC}$ showcases a higher $\mathrm{T}$ (73\%) but a much lower $\mathrm{C} / \mathrm{A}\left(1.2 \mathrm{mF} \mathrm{cm}^{-2}\right)$. Methods for further capacitance enhancement are needed. Through hybridizing other pseudocapacitive materials such as metal oxides and conducting polymers, etc., improved charge storage properties can be expected [54,264]. From the perspective of $\mathrm{FoM}_{e}$, chemically-doped CVDgrown graphene TCE has shown a superior high $\mathrm{FoM}_{\mathrm{e}}$ up to 195 [134] which approaches that of ITO. However, the highest $\mathrm{FoM}_{\mathrm{e}}$ that has been achieved in the MXenes is 16 in the case of $\mathrm{Ti}_{3} \mathrm{C}_{2} \mathrm{~T}_{\mathrm{x}}$ [171]. To compete with graphene and finally replace ITO, the $\mathrm{FoM}_{\mathrm{e}}$ of MXene-TCEs should be greatly improved. This can be possibly achieved either through chemical-doping of MXene nanosheets to dramatically increase the charge mobility, or via controlling the flakes alignment to decrease the junction resistance. Assuming the optoelectronic and electrochemical charge-storage properties are significantly improved, and the stability and high-cost issues are addressed, then a new era 
of MXenes is coming, which will open numerous opportunities in the cuttingedge applications.

5. Summary and outlook

Over the past several decades, the industry of portable electronics has been quickly expanded in our daily life. One of key technologies in these products is to develop high-performance transparent conductive electrodes (TCEs). Indium tin oxide (ITO) has dominated the market for a long time, despite its drawbacks such as brittleness, high-cost and complicated fabrication procedures. Questing materials to replace ITO for future flexible, wearable, interacted electronics is of highly urgent. Conductive polymers have been regarded as promising candidates, however, the poor environmental stability and noticeable colour limit their applications. One-dimensional carbon nanotube or silver nanowires have shown excellent optoelectronic properties, including high figure of merit $\left(\mathrm{FoM}_{\mathrm{e}}\right)$ which serves an important evaluation metrics in the field of TCEs. However, the surface roughness in these CNT or Ag nanowires-based TCEs are serious concerns, especially the haze effect in the latter.

Two-dimensional materials, with unique properties in many areas, have attracted intensive research attention in recent years. Due to the high charge carrier concentrations and mobility, graphene nanosheets have been regarded as the most promising candidate for replacing ITO. While reduced-graphene oxide and liquid-exfoliated graphene dispersions enable a quick fabrication of TCEs through the solution-processing techniques (including spin-, spray-, dip, LBL-coatings, inkjetprinting, hard-masking, etc.), the $\mathrm{FoM}_{\mathrm{e}}$ in these resultant TCEs is insignificant with maximum value $~ 1.6$ [41]. The chemical vapour deposition method can precisely control the graphene flake size and number of layers by choosing different catalytic substrates and changing the CVD parameters. To date, the CVD-grown graphene has demonstrated the most promising optoelectronic properties for TCEs, including the benchmark performance: $\mathrm{R}_{\mathrm{s}} \sim 30 \Omega \mathrm{sq}^{-1}$ at $\mathrm{T}=90 \%\left(\mathrm{FoM}_{\mathrm{e}}=116\right)$ in the 4-layer CVDgraphene TCE [25], which is quite comparable to the ITO. However, the strict TCE fabrication procedures coupled with issues such as incomplete etching of substrates and/or exist of polymer residues during thin film transferring, are the concerns that must be taken into consideration. Future work on the graphene TCEs should focus on developing high-quality graphene at lowtemperature and come up with methods without etching or transferring steps. By combining graphene freestanding paper with other pseudocapacitive materials and forming a hybrid, with graphene to transport electrons while redox active materials to store charge, the graphenebased transparent supercapacitor demonstrate quite promising electrochemical performance. Further studies should be concentrated on the facile production of such hybrids with improved transparency, as the current state-of-the-art transparent supercapacitor showcase a relative low transmittance $\sim 40 \%$ [46,227,230]. For potential incorporation of transparent supercapacitor into transparent electronics, the higher the critical parameters, including areal/volumetric capacitance, energy/power density, transmittance, and long-term cycling, etc., the better.

As a new class in the 2D family materials, MXenes possess abundant surface groups, high electronic conductivities and many other unique properties, rendering them quite attractive in various applications. $\mathrm{Ti}_{3} \mathrm{C}_{2} \mathrm{~T}_{\mathrm{x}}$ is the most widely studied MXene with an ultrahigh DC conductivity (up to 9880 $\mathrm{S} \mathrm{cm}^{-1}$ [171]) and excellent charge-storage properties [55,58]. Although the optoelectronic properties in the $\mathrm{Ti}_{3} \mathrm{C}_{2} \mathrm{~T}_{\mathrm{x}}$ has outperformed that of solutionprocessed graphene, however, there is still long distance to reach the ITO performance. To further push the $\mathrm{Ti}_{3} \mathrm{C}_{2} \mathrm{~T}_{\mathrm{x}}$ limit as efficient TCEs, several directions are proposed. Firstly, increasing the charge carrier mobility of MXene nanosheets can substantially improve the optoelectronic properties. This can be realized by chemical-doping the MXene nanosheets or hybridizing with guest species. Furthermore, understanding the movement of charge carriers along the tunnelling barriers is also crucial. In addition, optimization of the MXene synthesis/ composition and understanding the influence of surface functionalities on the MXene electronic properties should be effective. Finally, building the MXene nanosheet mesh on the flexible PET can substantially improves the transmittance of $\mathrm{Ti}_{3} \mathrm{C}_{2} \mathrm{~T}_{\mathrm{x}} \mathrm{TCEs}$. This requires a delicate design of thin film fabrication.

MXene TCEs can be used for high-performance transparent supercapacitor, with excellent volumetric capacitance, high energy density/ power handing and long lifetime. While these progresses are exciting, several issues should be paid with much attention. Stability of the MXene dispersions and devices, largescale, environmentally green production of MXenes as well as relatively low areal capacitance in the prototype cells, are all challenges for MXene-based transparent supercapacitors. Despite these many challenges, the future of MXene TCEs is very bright, due to not only the unique properties that MXene have demonstrated, but also the quite encouraging research results based on the continuous efforts in this emerging field.

\section{Acknowledgements}

The paper was written solely by C.F.Z. This work is supported by European Research Council (ERC 3D2Dprint).

\section{References}

[1] D.S. Hecht, L. Hu, G. Irvin, Adv. Mater. 23 (2011) 1482-1513.

[2] Y. Xu, J. Liu, Small 12 (2016) 1400-1419.

[3] G. Eda, Y.-Y. Lin, S. Miller, C.-W. Chen, W.-F. Su, M. Chhowalla, Appl. Phys. Lett. 92 (2008) 233305

[4] Y. Yang, S. Jeong, L. Hu, H. Wu, S.W. Lee, Y. Cui, Proc. Natl. Acad. Sci. USA 108 (2011) 13013-13018

[5] D.S. Chang, S. Te Lai, Int. J. Adv. Manuf. Technol. 78 (2015) 753-763.

[6] L. Yu, C. Shearer, J. Shapter, Chem. Rev. 116 (2016) 13413-13453.

[7] J. Song, S.A. Kulinich, J. Li, Y. Liu, H. Zeng, Angew. Chem. Int. Ed. 127 (2015) 472 476.

[8] C.-Y. Chen, W.-K. Lee, Y.-J. Chen, C.-Y. Lu, H.Y. Lin, C.-C. Wu, Adv. Mater. 27 (2015) 4883-4888

[9] M.H. Ahn, E.S. Cho, S.J. Kwon, Vacuum 101 (2014) 221-227.

[10] Y. Galagan, A. Mescheloff, S.C. Veenstra, R. Andriessen, E.A. Katz, Phys. Chem. Chem. Phys. 17 (2015) 3891-3897.

[11] C.-C. Kim, H.-H. Lee, K.H. Oh, J.-Y. Sun, Science 353 (2016) 682-687.

[12] Y.-H. Liu, J.-L. Xu, S. Shen, X.-L. Cai, L.-S. Chen, S.-D. Wang, J. Mater. Chem. A 5 (2017) 9032-9041.

[13] Xuan Wang, A. Linjie Zhi, K. Müllen, Nano Lett. 8 (2008) 323-327.

[14] Y. Xia, K. Sun, J. Ouyang, Adv. Mater. 24 (2012) 2436-2440.

[15] T.M. Higgins, J.N. Coleman, ACS Appl. Mater. Interfaces 7 (2015) 16495-16506.

[16] S. De, T.M. Higgins, P.E. Lyons, E.M. Doherty, P.N. Nirmalraj, W.J. Blau, J.J. Boland, J.N. Coleman, ACS Nano 3 (2009) 1767-1774.

[17] H. Lu, D. Zhang, X. Ren, J. Liu, W.C.H. Choy, ACS Nano 8 (2014) 19080-19087. [18] B.Y. Ahn, D.J. Lorang, J.A. Lewis, Nanoscale 3 (2011) 2700-2702.

[19] M. Yu, Z. Wang, C. Hou, Z. Wang, C. Liang, C. Zhao, Y. Tong, X. Lu, S. Yang, Adv Mater. 29 (2017) 1602868.

[20] Y. Zeng, Y. Meng, Z. Lai, X. Zhang, M. Yu, P. Fang, M. Wu, Y. Tong, X. Lu, Adv Mater. 29 (2017) 1702698.

[21] M. Yu, D. Lin, H. Feng, Y. Zeng, Y. Tong, X. Lu, Angew. Chem. Int. Ed. 56 (2017) $5454-5459$.

[22] Y. Huang, Y. Zeng, M. Yu, P. Liu, Y. Tong, F. Cheng, X. Lu, Small Methods 2 (2018) 1700230.

[23] C. Zhang, T.M. Higgins, S.-H. Park, S.E. O, D. Long, J.N. Coleman, V. Nicolosi, Nano Energy 28 (2016) 495-505.

[24] Y.H. Kim, S.J. Kim, Y.-J. Kim, Y.-S. Shim, S.Y. Kim, B.H. Hong, H.W. Jang, ACS Nano 9 (2015) 10453-10460.

[25] S. Bae, H. Kim, Y. Lee, X. Xu, J.-S. Park, Y. Zheng, J. Balakrishnan, T. Lei, H. Ri Kim, Y. Il Song, Y.-J. Kim, K.S. Kim, B. Özyilmaz, J.-H. Ahn, B.H. Hong, S. Iijima, Nat. Nanotechnol. 5 (2010) 574-578.

[26] X. Duan, S. Indrawirawan, H. Sun, S. Wang, Catal. Today 249 (2015) 184-191.

[27] H. Ji, L. Zhang, M.T. Pettes, H. Li, S. Chen, L. Shi, R. Piner, R.S. Ruoff, Nano Lett. 12 (2012) 2446-2451.

[28] B. Mendoza-Sánchez, B. Rasche, V. Nicolosi, P.S. Grant, Carbon 52 (2013) 337-346.

[29] L.T. Le, M.H. Ervin, H. Qiu, B.E. Fuchs, W.Y. Lee, Electrochem. Commun. 13 (2011) 355-358.

[30] Y. Wang, Z. Shi, Y. Huang, Y. Ma, C. Wang, M. Chen, Y. Chen, J. Phys. Chem. C 113 (2009) 13103-13107.

[31] M. Stoller, S. Park, Y. Zhu, J. An, R. Ruoff, Nano Lett. 8 (2008) 3498-3502. [32] J. Yan, J. Liu, Z. Fan, T. Wei, L. Zhang, Carbon 50 (2012) 2179-2188.

[33] C.. Rao, K. Gopalakrishnan, U. Maitra, ACS Appl. Mater. Interfaces 7 (2015) 78097832.

[34] Q. Liu, J. Chen, Y. Li, G. Shi, ACS Nano 10 (2016) 7901-7906.

[35] S. De, J.N. Coleman, MRS Bull. 36 (2011) 774-781. 
[36] B. Ruzicka, L. Degiorgi, R. Gaal, L. Thien-Nga, R. Bacsa, J.-P. Salvetat, L. Forró, Phys. Rev. B 61 (2000) R2468-R2471.

[37] S. De, P.E. Lyons, S. Sorel, E.M. Doherty, P.J. King, W.J. Blau, P.N. Nirmalraj, J.J. Boland, V. Scardaci, J. Joimel, J.N. Coleman, ACS Nano 3 (2009) 714-720. [38] V. Scardaci, R. Coull, J.N. Coleman, Appl. Phys. Lett. 97 (2010) 23114.

[39] H. Lin, L. Li, J. Ren, Z. Cai, L. Qiu, Z. Yang, H. Peng, Sci. Rep. 3 (2013) 1353.

[40] J. Ge, G. Cheng, L. Chen, Nanoscale 3 (2011) 3084-3088.

[41] S. De, J.N. Coleman, ACS Nano 4 (2010) 2713-2720.

[42] S. De, P.J. King, M. Lotya, A. O’Neill, E.M. Doherty, Y. Hernandez, G.S. Duesberg, J.N Coleman, Small 6 (2010) 458-464.

[43] K.S. Kim, Y. Zhao, H. Jang, S.Y. Lee, J.M. Kim, K.S. Kim, J.-H. Ahn, P. Kim, J.Y. Choi, B.H. Hong, Nature 457 (2009) 706-710.

[44] X. Yang, C. Cheng, Y. Wang, L. Qiu, D. Li, Science 341 (2013) 534-537.

[45] Z.-S. Wu, K. Parvez, S. Li, S. Yang, Z. Liu, S. Liu, X. Feng, K. Müllen, Adv. Mater. 27 (2015) 4054-4061.

[46] T. Chen, Y. Xue, A.K. Roy, L. Dai, ACS Nano 8 (2014) 1039-1046.

[47] Y. Gao, Y.S. Zhou, W. Xiong, L.J. Jiang, M. Mahjouri-samani, P. Thirugnanam, X. Huang, M.M. Wang, L. Jiang, Y.F. Lu, APL Mater. 1 (2013) 12101.

[48] A. Yu, I. Roes, A. Davies, Z. Chen, Appl. Phys. Lett. 96 (2010) 253105.

[49] K. Lee, H. Lee, Y. Shin, Y. Yoon, D. Kim, H. Lee, Nano Energy 26 (2016) 746-754.

[50] M.R. Lukatskaya, O. Mashtalir, C.E. Ren, Y. Dall'Agnese, P. Rozier, P.L. Taberna, M. Naguib, P. Simon, M.W. Barsoum, Y. Gogotsi, Science 341 (2013) 1502-1505.

[51] M. Naguib, O. Mashtalir, J. Carle, V. Presser, J. Lu, L. Hultman, Y. Gogotsi, M. Barsoum, ACS Nano 6 (2012) 1322-1331.

[52] M. Naguib, M. Kurtoglu, V. Presser, J. Lu, J. Niu, M. Heon, L. Hultman, Y. Gogotsi, M. Barsoum, Adv. Mater. 23 (2011) 4248-4253.

[53] C. Zhang, S. Pinilla, N. McEvoy, C.P. Cullen, B. Anasori, E. Long, S.-H. Park, A. Seral-Ascaso, A. Shmeliov, D. Krishnan, C. Morant, X. Liu, G.S. Duesberg, Y. Gogotsi, V. Nicolosi, Chem. Mater. 29 (2017) 4848-4856.

[54] C. Zhang, M. Beidaghi, M. Naguib, M.R. Lukatskaya, M.-Q. Zhao, B. Dyatkin, K.M. Cook, S.J. Kim, B. Eng. X. Xiao, D. Long, W. Qiao, B. Dunn, Y. Gogotsi, Chem. Mater 28 (2016) 3937-3943.

[55] M. Ghidiu, M.R. Lukatskaya, M.-Q. Zhao, Y. Gogotsi, M.W. Barsoum, Nature 516 (2014) 78-81.

[56] M. Naguib, J. Come, B. Dyatkin, V. Presser, P.-L. Taberna, P. Simon, M. Barsoum, Y. Gogotsi, Electrochem. Commun. 16 (2012) 61-64.

[57] B. Anasori, M.R. Lukatskaya, Y. Gogotsi, Nat. Rev. Mater. 2 (2017) 16098.

[58] M.R. Lukatskaya, S. Kota, Z. Lin, M.-Q. Zhao, N. Shpigel, M.D. Levi, J. Halim, P.L. Taberna, M.W. Barsoum, P. Simon, Y. Gogotsi, Nat. Energy 2 (2017) 17105.

[59] H. Li, Y. Hou, F. Wang, M.R. Lohe, X. Zhuang, L. Niu, X. Feng, Adv. Energy Mater. 7 (2017) 1601847.

[60] J. Yan, C.E. Ren, K. Maleski, C.B. Hatter, B. Anasori, P. Urbankowski, A. Sarycheva, Y. Gogotsi, Adv. Funct. Mater. 27 (2017) 1701264.

[61] Y. Yue, N. Liu, Y. Ma, S. Wang, W. Liu, C. Luo, H. Zhang, F. Cheng, J. Rao, X. Hu, J. Su, Y. Gao, ACS Nano (2018).

[62] Z. Wang, H. Kim, H.N. Alshareef, Adv. Mater. 30 (2018) 1706656.

[63] J. Zhang, S. Seyedin, Z. Gu, W. Yang, X. Wang, J.M. Razal, Nanoscale 9 (2017) $18604-$ 18608.

[64] X. Zhang, Z. Zhang, Z. Zhou, J. Energy Chem. 27 (2018) 73-85.

[65] Y. Zhong, X. Xia, F. Shi, J. Zhan, J. Tu, H.J. Fan, Adv. Sci. 3 (2016) 1500286.

[66] D. Xiong, X. Li, Z. Bai, S. Lu, Small (2018) 1703419.

[67] H. Wang, Y. Wu, X. Yuan, G. Zeng, J. Zhou, X. Wang, J.W. Chew, Adv. Mater. 30 (2018) 1704561.

[68] K. Xu, Z. Lin, C. Merlet, P.-L. Taberna, L. Miao, J. Jiang, P. Simon, ChemSusChem (2018).

[69] S. Sun, C. Liao, A.M. Hafez, H. Zhu, S. Wu, Chem. Eng. J. 338 (2018) 27-45.

[70] G. Ying, S. Kota, A.D. Dillon, A.T. Fafarman, M. Barsoum, FlatChem 8 (2018) 25-30.

[71] F. Du, H. Tang, L. Pan, T. Zhang, H. Lu, J. Xiong, J. Yang, C. Zhang, Electrochim. Acta 235 (2017) 690-699.

[72] M. Alhabeb, K. Maleski, B. Anasori, P. Lelyukh, L. Clark, S. Sin, Y. Gogotsi, Chem. Mater. 29 (2017) 7633-7644.

[73] Z. Gholamvand, D. Mcateer, A. Harvey, C. Backes, J.N. Coleman, Chem. Mater. 28 (2016) 2641-2651.

[74] Y. Dong, S.S.K. Mallineni, K. Maleski, H. Behlow, V.N. Mochalin, A.M. Rao, Y. Gogotsi, R. Podila, Nano Energy 44 (2017) 103-110.

[75] F. Liu, J. Zhou, S. Wang, B. Wang, C. Shen, L. Wang, Q. Hu, Q. Huang, A. Zhou, J. Electrochem. Soc. 164 (2017) A709-A713.

[76] V.M. Hong, Ng, H. Huang, K. Zhou, P.S. Lee, W. Que, J.Z. Xu, L.B. Kong, J. Mater. Chem. A 5 (2017) 3039-3068.

[77] V. Chabot, D. Higgins, A. Yu, X. Xiao, Z. Chen, J. Zhang, Energy Environ. Sci. 7 (2014) 1564

[78] X. Cao, Z. Yin, H. Zhang, Energy Environ. Sci. 7 (2014) 1850-1865.

[79] G. Ying, A.D. Dillon, A.T. Fafarman, M. Barsoum, Mater. Res. Lett. 5 (2017) 391-398.

[80] J. Halim, M.R. Lukatskaya, K.M. Cook, J. Lu, C.R. Smith, L. Näslund, S.J. May, L. Hultman, Y. Gogotsi, P. Eklund, M. Barsoum, Chem. Mater. 26 (2014) 2374-2381.

[81] M. Mariano, O. Mashtalir, F.Q. Antonio, W.-H. Ryu, B. Deng, F. Xia, Y. Gogotsi, A.D. Taylor, Nanoscale 8 (2016) 16371-16378.

[82] A.D. Dillon, M.J. Ghidiu, A.L. Krick, J. Griggs, S.J. May, Y. Gogotsi, M.W. Barsoum, A.T. Fafarman, Adv. Funct. Mater. 26 (2016) 4162-4168.
[83] K.S. Novoselov, A.K. Geim, S.V. Morozov, D. Jiang, Y. Zhang, S.V. Dubonos, I.V Grigorieva, A.A. Firsov, Science 306 (2004) 666-669. [84] A.C. Ferrari, et al., Nanoscale 7 (2015) 4598-4810.

[85] A.S. Mayorov, R.V. Gorbachev, S.V. Morozov, L. Britnell, R. Jalil, L.A. Ponomarenko, P. Blake, K.S. Novoselov, K. Watanabe, T. Taniguchi, A.K. Geim, Nano Lett. 11 (2011) 2396-2399.

[86] A.A. Balandin, Nat. Mater. 10 (2011) 569-581.

[87] C. Lee, X. Wei, J.W. Kysar, J. Hone, Science 321 (2008) 385-388.

[88] C. Hwang, D.A. Siegel, S.-K. Mo, W. Regan, A. Ismach, Y. Zhang, A. Zettl, A Lanzara, Sci. Rep. 2 (2012) 590.

[89] K.S. Novoselov, V.I. Fal9ko, L. Colombo, P.R. Gellert, M.G. Schwab, K. Kim, Nature 490 (2012) 192-200.

[90] R.R. Nair, P. Blake, A.N. Grigorenko, K.S. Novoselov, T.J. Booth, T. Stauber, N.M.R. Peres, A.K. Geim, Science 320 (2008) 1308.

[91] A. Bianco, H.-M. Cheng, T. Enoki, Y. Gogotsi, R.H. Hurt, N. Koratkar, T. Kyotani, M Monthioux, C.R. Park, J.M.D. Tascon, J. Zhang, Carbon 65 (2013) 1-6.

[92] Y. Hernandez, V. Nicolosi, M. Lotya, F.M. Blighe, Z. Sun, S. De, I.T. McGovern, B. Holland, M. Byrne, Y.K. Gun'Ko, J.J. Boland, P. Niraj, G. Duesberg, S. Krishnamurthy, R. Goodhue, J. Hutchison, V. Scardaci, A.C. Ferrari, J.N. Coleman, Nat. Nanotechnol. 3 (2008) 563-568.

[93] K.R. Paton, E. Varrla, C. Backes, R.J. Smith, U. Khan, A. O’Neill, C. Boland, M. Lotya, O.M. Istrate, P. King, T. Higgins, S. Barwich, P. May, P. Puczkarski, I. Ahmed, M. Moebius, H. Pettersson, E. Long, J. Coelho, S.E. O'Brien, E.K. McGuire, B.M. Sanchez, G.S. Duesberg, N. McEvoy, T.J. Pennycook, C. Downing, A. Crossley, V. Nicolosi, J.N. Coleman, Nat. Mater. 13 (2014) 624630.

[94] C. Xiang, M. Li, M. Zhi, A. Manivannan, N. Wu, J. Mater. Chem. 22 (2012) 1916119167.

[95] X. Li, W. Cai, L. Colombo, R.S. Ruoff, Nano Lett. 9 (2009) 4268-4272.

[96] X. Li, W. Cai, J. An, S. Kim, J. Nah, D. Yang, R. Piner, A. Velamakanni, I. Jung, E. Tutuc, S.K. Banerjee, L. Colombo, R.S. Ruoff, Science 324 (2009) 1312-1314.

[97] M. Losurdo, M.M. Giangregorio, P. Capezzuto, G. Bruno, Phys. Chem. Chem. Phys. 13 (2011) 20836-20843.

[98] X. Zhang, L. Wang, J.H. Xin, B.I. Yakobson, F. Ding, J. Am. Chem. Soc. 136 (2014) 3040-3047.

[99] D.A. Dikin, S. Stankovich, E.J. Zimney, R.D. Piner, G.H.B. Dommett, G. Evmenenko, S.T. Nguyen, R.S. Ruoff, Nature 448 (2007) 457-460.

[100] S. Murali, N. Quarles, L.L. Zhang, J.R. Potts, Z. Tan, Y. Lu, Y. Zhu, R.S. Ruoff, Nano Energy 2 (2013) 764-768.

[101] R. Raccichini, A. Varzi, S. Passerini, B. Scrosati, Nat. Mater. 14 (2015) 271-279.

[102] A.K. Geim, K.S. Novoselov, Nat. Mater. 6 (2007) 183-191.

[103] M. Lotya, Y. Hernandez, P.J. King, R.J. Smith, V. Nicolosi, L.S. Karlsson, F.M. Blighe, S. De, Z. Wang, I.T. McGovern, G.S. Duesberg, J.N. Coleman, J. Am. Chem. Soc. 131 (2009) 3611-3620

[104] J.N. Coleman, Acc. Chem. Res. 46 (2013) 14-22.

[105] V. Nicolosi, M. Chhowalla, M.G. Kanatzidis, M.S. Strano, J.N. Coleman, Science 340 (2013) 1226419-1226419.

[106] W. Fang, A.L. Hsu, Y. Song, J. Kong, Nanoscale 7 (2015) 20335-20351.

[107] J. Zhang, P. Hu, X. Wang, Z. Wang, D. Liu, B. Yang, W. Cao, J. Mater. Chem. 22 (2012) 18283.

[108] W. Song, C. Jeon, S. Youn Kim, Y. Kim, S. Hwan Kim, S.-I. Lee, D.S. Jung, M.W. Jung, K.-S. An, C.-Y. Park, Carbon 68 (2014) 87-94.

[109] M. Losurdo, M.M. Giangregorio, P. Capezzuto, G. Bruno, Phys. Chem. Chem. Phys. 13 (2011) 20836.

[110] T. Kobayashi, M. Bando, N. Kimura, K. Shimizu, K. Kadono, N. Umezu, K. Miyahara, S. Hayazaki, S. Nagai, Y. Mizuguchi, Y. Murakami, D. Hobara, Appl. Phys. Lett. 102 (2013) 23112.

[111] Y. Zhang, L. Zhang, C. Zhou, Acc. Chem. Res. 46 (2013) 2329-2339.

[112] A. Ambrosi, M. Pumera, Nanoscale 6 (2014) 472-476.

[113] B.H. Lee, J.-H. Lee, Y.H. Kahng, N. Kim, Y.J. Kim, J. Lee, T. Lee, K. Lee, Adv. Funct. Mater. 24 (2014) 1847-1856.

[114] Q.-Q. Zhuo, Q. Wang, Y.-P. Zhang, D. Zhang, Q.-L. Li, C.-H. Gao, Y.-Q. Sun, L. Ding, Q.-J. Sun, S.-D. Wang, J. Zhong, X.-H. Sun, S.-T. Lee, ACS Nano 9 (2015) 594-601.

[115] J. Zhao, S. Pei, W. Ren, L. Gao, H.-M. Cheng, ACS Nano 4 (2010) 5245-5252.

[116] H.A. Becerril, J. Mao, Z. Liu, R.M. Stoltenberg, Z. Bao, Y. Chen, ACS Nano 2 (2008) 463-470.

[117] Q. Liu, M. Zhang, L. Huang, Y. Li, J. Chen, C. Li, G. Shi, ACS Nano 9 (2015) 1232012326.

[118] Z.-S. Wu, K. Parvez, X. Feng, K. Müllen, Nat. Commun. 4 (2013) 2487.

[119] Z. Liu, S.P. Lau, F. Yan, Chem. Soc. Rev. 44 (2015) 5638-5679.

[120] Q. Zheng, Z. Li, J. Yang, J.-K. Kim, Prog. Mater. Sci. 64 (2014) 200-247.

[121] M.F. El-Kady, R.B. Kaner, Nat. Commun. 4 (2013) 1475.

[122] D. Lin, Y. Liu, Z. Liang, H.-W. Lee, J. Sun, H. Wang, K. Yan, J. Xie, Y. Cui, Nat. Nanotechnol. 11 (2016) 626-632.

[123] D.-Y. Kim, S. Sinha-Ray, J.-J. Park, J.-G. Lee, Y.-H. Cha, S.-H. Bae, J.-H. Ahn, Y.C. Jung, S.M. Kim, A.L. Yarin, S.S. Yoon, Adv. Funct. Mater. 24 (2014) 4986-4995

[124] S.J. An, Y. Zhu, S.H. Lee, M.D. Stoller, T. Emilsson, S. Park, A. Velamakanni, J. An, R.S. Ruoff, J. Phys. Chem. Lett. 1 (2010) 1259-1263.

[125] X. Li, G. Zhang, X. Bai, X. Sun, X. Wang, E. Wang, H. Dai, Nat. Nanotechnol. 3 (2008) $538-542$. 
[126] G. Eda, G. Fanchini, M. Chhowalla, Nat. Nanotechnol. 3 (2008) 270-274.

[127] S.H. Domingues, I.N. Kholmanov, T. Kim, J. Kim, C. Tan, H. Chou, Z.A. Alieva, R. Piner, A.J.G. Zarbin, R.S. Ruoff, Carbon 63 (2013) 454-459.

[128] I.N. Kholmanov, S.H. Domingues, H. Chou, X. Wang, C. Tan, J.-Y. Kim, H. Li, R. Piner, A.J.G. Zarbin, R.S. Ruoff, ACS Nano 7 (2013) 1811-1816.

[129] Y. Chen, X. Yang, M. Kitta, Q. Xu, Nano Res. 10 (2017) 3811-3816.

[130] G. Ma, K. Li, Y. Li, B. Gao, T. Ding, Q. Zhong, J. Su, L. Gong, J. Chen, L. Yuan, B. Hu, J. Zhou, K. Huo, ChemElectroChem 3 (2016) 1360-1368.

[131] J. Wu, H.A. Becerril, Z. Bao, Z. Liu, Y. Chen, P. Peumans, Appl. Phys. Lett. 92 (2008) 263302.

[132] P.J. King, U. Khan, M. Lotya, S. De, J.N. Coleman, ACS Nano 4 (2010) 4238-4246.

[133] L. Peng, Y. Feng, P. Lv, D. Lei, Y. Shen, Y. Li, W. Feng, J. Phys. Chem. C 116 (2012) 4970-4978.

[134] Y. Zhu, Z. Sun, Z. Yan, Z. Jin, J.M. Tour, ACS Nano 5 (2011) 6472-6479.

[135] H. Dong, Z. Wu, Y. Jiang, W. Liu, X. Li, B. Jiao, W. Abbas, X. Hou, ACS Appl Mater. Interfaces 8 (2016) 31212-31221.

[136] D. Konios, C. Petridis, G. Kakavelakis, M. Sygletou, K. Savva, E. Stratakis, E. Kymakis, Adv. Funct. Mater. 25 (2015) 2213-2221.

[137] X. Lin, J. Jia, N. Yousefi, X. Shen, J.-K. Kim, J. Mater. Chem. C 1 (2013) 6869.

[138] H. He, X. Li, J. Wang, T. Qiu, Y. Fang, Q. Song, B. Luo, X. Zhang, L. Zhi, Small 9 (2013) 820-824.

[139] X. Wu, S. Li, Y. Zhao, Y. Tang, J. Liu, X. Guo, D. Wu, G. He, ACS Appl. Mater. Interfaces 6 (2014) 15753-15759.

[140] J. Ning, J. Wang, X. Li, T. Qiu, B. Luo, L. Hao, M. Liang, B. Wang, L. Zhi, J. Mater. Chem. A 2 (2014) 10969-10973.

[141] C.J. Zhang, S.-H. Park, O. Ronan, A. Harvey, A. Seral-Ascaso, Z. Lin, N. McEvoy, C.S Boland, N.C. Berner, G.S. Duesberg, P. Rozier, J.N. Coleman, V. Nicolosi, Small 13 (2017) 1701677

[142] J.N. Coleman, M. Lotya, A. O’Neill, S.D. Bergin, P.J. King, et al., Science 331 (2011) $568-571$.

[143] G. Cunningham, M. Lotya, C.S. Cucinotta, S. Sanvito, S.D. Bergin, R. Menzel, M.S.P. Shaffer, J.N. Coleman, ACS Nano 6 (2012) 3468-3480.

[144] M. Lotya, P.J. King, U. Khan, S. De, J.N. Coleman, ACS Nano 4 (2010) 3155-3162.

[145] E. Varrla, K.R. Paton, C. Backes, A. Harvey, R.J. Smith, J. McCauley, J.N. Coleman, Nanoscale 6 (2014) 11810-11819.

[146] M.S. Kang, K.T. Kim, J.U. Lee, W.H. Jo, J. Mater. Chem. C 1 (2013) 1870.

[147] S. Park, R.S. Ruoff, Nat. Nanotechnol. 4 (2009) 217-224.

[148] X. Tong, C. Xie, L. Si, J. Che, Y. Xiao, Mater. Chem. Phys. 143 (2013) 85-92.

[149] S. De, C.S. Boland, P.J. King, S. Sorel, M. Lotya, U. Patel, Z.L. Xiao, J.N. Coleman, Nanotechnology 22 (2011) 285202.

[150] S. Sorel, U. Khan, J.N. Coleman, Appl. Phys. Lett. 101 (2012) 103106.

[151] T. Fang, A. Konar, H. Xing, D. Jena, Appl. Phys. Lett. 91 (2007) 92109.

[152] D. Simien, J.A. Fagan, W. Luo, J.F. Douglas, K. Migler, J. Obrzut, ACS Nano 2 (2008) 1879-1884.

[153] W. Cai, Y. Zhu, X. Li, R.D. Piner, R.S. Ruoff, Appl. Phys. Lett. 95 (2009) 123115. [154] X. Li, Y. Zhu, W. Cai, M. Borysiak, B. Han, D. Chen, R.D. Piner, L. Colombo, R.S. Ruoff, Nano Lett. 9 (2009) 4359-4363.

[155] P. Blake, P.D. Brimicombe, R.R. Nair, T.J. Booth, D. Jiang, F. Schedin, L.A. Ponomarenko, S.V. Morozov, H.F. Gleeson, E.W. Hill, A.K. Geim, K.S. Novoselov, Nano Lett. 8 (2008) 1704-1708.

[156] J.H. Heo, D.H. Shin, S. Kim, M.H. Jang, M.H. Lee, S.W. Seo, S.-H. Choi, S.H. Im, Chem. Eng. J. 323 (2017) 153-159.

[157] L. La Notte, E. Villari, A.L. Palma, A. Sacchetti, M. Michela Giangregorio, G. Bruno, A. Di Carlo, G.V. Bianco, A. Reale, Nanoscale 9 (2017) 62-69.

[158] U. Dettlaff-Weglikowska, V. Skákalová, R. Graupner, S. Jhang, B. Kim, H. Lee, L. Ley, Y. Park, S. Berber, D. Tománek, S. Roth, J. Am. Chem. Soc. 127 (2005) 5125-5131.

[159] J.K. Wassei, K.C. Cha, V.C. Tung, Y. Yang, R.B. Kaner, J. Mater. Chem. 21 (2011) 3391.

[160] A.G. Ricciardulli, S. Yang, G.-J.A.H. Wetzelaer, X. Feng, P.W.M. Blom, Adv Funct. Mater. (2018) 1706010

[161] M. Barsoum, Prog. Solid State Chem. 28 (2000) 201-281.

[162] M. Naguib, V.N. Mochalin, M.W. Barsoum, Y. Gogotsi, Adv. Mater. 26 (2014) 992 1005 .

[163] M. Naguib, J. Halim, J. Lu, K.M. Cook, L. Hultman, Y. Gogotsi, M.W. Barsoum, J. Am. Chem. Soc. 135 (2013) 15966-15969.

[164] M. Naguib, O. Mashtalir, M.R. Lukatskaya, B. Dyatkin, C. Zhang, V. Presser, Y Gogotsi, M. Barsoum, Chem. Commun. 50 (2014) 7420-7423.

[165] O. Mashtalir, M. Naguib, V.N. Mochalin, Y. Dall'Agnese, M. Heon, M. Barsoum, Y. Gogotsi, Nat. Commun. 4 (2013) 1716

[166] Z. Ling, C.E. Ren, M.-Q. Zhao, J. Yang, J.M. Giammarco, J. Qiu, M. Barsoum, Y. Gogotsi, Proc. Natl. Acad. Sci. USA 111 (2014) 16676-16681.

[167] M.-Q. Zhao, C.E. Ren, Z. Ling, M.R. Lukatskaya, C. Zhang, K.L. Van Aken, M.W Barsoum, Y. Gogotsi, Adv. Mater. 27 (2015) 339-345.

[168] B. Anasori, Y. Xie, M. Beidaghi, J. Lu, B.C. Hosler, L. Hultman, P.R.C. Kent, Y. Gogotsi, M. Barsoum, ACS Nano 9 (2015) 9507-9516.

[169] J. Xiong, L. Pan, H. Wang, F. Du, Y. Chen, J. Yang, C. Zhang, Electrochim. Acta 268 (2018) 503-511.

[170] L. Wang, H. Zhang, B. Wang, C. Shen, C. Zhang, Q. Hu, A. Zhou, B. Liu, Electron. Mater. Lett. 12 (2016) 702-710.
[171] C. Zhang, B. Anasori, A. Seral-Ascaso, S.-H. Park, N. McEvoy, A. Shmeliov, G.S Duesberg, J.N. Coleman, Y. Gogotsi, V. Nicolosi, Adv. Mater. 29 (2017) 1702678.

[172] J. Come, Y. Xie, M. Naguib, S. Jesse, S.V. Kalinin, Y. Gogotsi, P.R.C. Kent, N. Balke, Adv. Energy Mater. 6 (2016) 1502290.

[173] C. Zhang, M.P. Kremer, A. Seral-Ascaso, S. Park, N. McEvoy, B. Anasori, Y. Gogotsi, V. Nicolosi, Adv. Funct. Mater. 28 (2018) 1705566.

[174] C. Zhang, S.J. Kim, M. Ghidiu, M.-Q. Zhao, M.W. Barsoum, V. Nicolosi, Y. Gogotsi, Adv. Funct. Mater. 26 (2016) 4143-4151.

[175] M. Hu, Z. Li, T. Hu, S. Zhu, C. Zhang, X. Wang, ACS Nano 10 (2016) 11344-11350.

[176] D. Zhang, S. Wang, Y. Ma, S. Yang, J. Energy Chem. 27 (2018) 128-145.

[177] M. Naguib, J. Halim, J. Lu, K.M. Cook, L. Hultman, Y. Gogotsi, M. Barsoum, J. Am. Chem. Soc. 135 (2013) 15966-15969.

[178] D. Sun, M. Wang, Z. Li, G. Fan, L.-Z. Fan, A. Zhou, Electrochem. Commun. 47 (2014) 80-83.

[179] D. Er, J. Li, M. Naguib, Y. Gogotsi, V.B. Shenoy, ACS Appl. Mater. Interfaces 6 (2014) 11173-11179.

[180] O. Mashtalir, M.R. Lukatskaya, M.-Q. Zhao, M. Barsoum, Y. Gogotsi, Adv. Mater. 27 (2015) 3501-3506.

[181] S.J. Kim, M. Naguib, M. Zhao, C. Zhang, H.-T. Jung, M. Barsoum, Y. Gogotsi, Electrochim. Acta 163 (2015) 246-251.

[182] B. Ahmed, D.H. Anjum, M.N. Hedhili, Y. Gogotsi, H.N. Alshareef, Nanoscale 8 (2016) $7580-7587$.

[183] A. Lipatov, M. Alhabeb, M.R. Lukatskaya, A. Boson, Y. Gogotsi, A. Sinitskii, Adv. Electron. Mater. 2 (2016) 1600255.

[184] K. Hantanasirisakul, M.-Q. Zhao, P. Urbankowski, J. Halim, B. Anasori, S. Kota, C.E. Ren, M. Barsoum, Y. Gogotsi, Adv. Electron. Mater. 2 (2016) 1600050.

[185] A. Ali, A. Belaidi, S. Ali, M.I. Helal, K.A. Mahmoud, J. Mater. Sci. Mater. Electron. 27 (2016) 5440-5445.

[186] M. Mariano, O. Mashtalir, F.Q. Antonio, W.-H. Ryu, B. Deng, F. Xia, Y. Gogotsi, A.D. Taylor, Nanoscale 8 (2016) 16371-16378.

[187] A. Champagne, L. Shi, T. Ouisse, B. Hackens, J.-C. Charlier, Phys. Rev. B 97 (2018) 115439.

[188] A. Miranda, J. Halim, M. Barsoum, A. Lorke, Appl. Phys. Lett. 108 (2016) 33102.

[189] M. Tian, Y. Sun, C. Zhang, J. Wang, W. Qiao, L. Ling, D. Long, J. Power Sources 364 (2017) 182-190.

[190] C. Zhang, K.B. Hatzell, M. Boota, B. Dyatkin, M. Beidaghi, D. Long, W. Qiao, E.C Kumbur, Y. Gogotsi, Carbon 77 (2014) 155-164.

[191] C. Zhang, Y. Xie, J. Wang, A. Pentecost, D. Long, L. Ling, W. Qiao, J. Solid State Electrochem. 18 (2014) 2673-2682.

[192] C. Zhang, R. Maloney, M.R. Lukatskaya, M. Beidaghi, B. Dyatkin, E. Perre, D. Long, W. Qiao, B. Dunn, Y. Gogotsi, J. Power Sources 274 (2015) 121-129.

[193] L. Kong, C. Zhang, S. Zhang, J. Wang, R. Cai, C. Lv, W. Qiao, L. Ling, D. Long, J. Mater. Chem. A 2 (2014) 17962-17970.

[194] X. Xiao, C. Zhang, S. Lin, L. Huang, Z. Hu, Y. Cheng, T. Li, W. Qiao, D. Long, Y. Huang, L. Mai, Y. Gogotsi, J. Zhou, Energy Storage Mater. 1 (2015) 1-8.

[195] L. Fan, L. Yang, X. Ni, J. Han, R. Guo, C. Zhang, Carbon 107 (2016) 629-637.

[196] C. Zhang, Y. Xie, M. Zhao, A.E. Pentecost, Z. Ling, J. Wang, D. Long, L. Ling, W. Qiao, ACS Appl. Mater. Interfaces 6 (2014) 9751-9759.

[197] C. Zhang, Y. Xie, G. Sun, A. Pentecost, J. Wang, W. Qiao, L. Ling, D. Long, Y Gogotsi, J. Electrochem. Soc. 161 (2014) 1486-1494.

[198] L. Kong, C. Zhang, J. Wang, W. Qiao, L. Ling, D. Long, Sci. Rep. 6 (2016) 21177.

[199] X. Zhang, J. Zhou, W. Dou, J. Wang, X. Mu, Y. Zhang, A. Abas, Q. Su, W. Lan, E. Xie, C. Zhang, J. Power Sources 383 (2018) 124-132.

[200] X. Xiao, T. Li, Z. Peng, H. Jin, Q. Zhong, Q. Hu, B. Yao, Q. Luo, C. Zhang, L. Gong, J. Chen, Y. Gogotsi, J. Zhou, Nano Energy 6 (2014) 1-9.

[201] Y. Wei, Y. Tao, C. Zhang, J. Wang, W. Qiao, L. Ling, D. Long, Electrochim. Acta 188 (2016) 385-392.

[202] L. Kong, C. Zhang, J. Wang, D. Long, W. Qiao, L. Ling, Mater. Chem. Phys. 149-150 (2015) 495-504.

[203] T.M. Higgins, S.-H. Park, P.J. King, C. Zhang, N. McEvoy, N.C. Berner, D. Daly, A Shmeliov, U. Khan, G. Duesberg, V. Nicolosi, J.N. Coleman, ACS Nano 10 (2016) 3702-3713.

[204] L. Liu, Y. Wei, C. Zhang, C. Zhang, X. Li, J. Wang, L. Ling, W. Qiao, D. Long, Electrochim. Acta 153 (2015) 140-148.

[205] Z. Hu, X. Xiao, C. Chen, T. Li, L. Huang, C. Zhang, J. Su, L. Miao, J. Jiang, Y. Zhang, J. Zhou, Nano Energy 11 (2015) 226-234.

[206] D. Ge, L. Yang, L. Fan, C. Zhang, X. Xiao, Y. Gogotsi, S. Yang, Nano Energy 11 (2015) 568-578.

[207] X. Xiao, Z. Peng, C. Chen, C. Zhang, M. Beidaghi, Z. Yang, N. Wu, Y. Huang, L. Miao, Y. Gogotsi, J. Zhou, Nano Energy 9 (2014) 355-363.

[208] L. Kong, C. Zhang, J. Wang, W. Qiao, L. Ling, D. Long, ACS Nano 9 (2015) 1120011208.

[209] C. Zhang, S.-H. Park, S.E. O’Brien, A. Seral-Ascaso, M. Liang, D. Hanlon, D. Krishnan, A. Crossley, N. McEvoy, J.N. Coleman, V. Nicolosi, Nano Energy 39 (2017) $151-161$.

[210] M. Yu, Y. Lu, H. Zheng, X. Lu, Chem. -Eur. J. 24 (2018) 3639-3649.

[211] T. Chen, H. Peng, M. Durstock, L. Dai, Sci. Rep. 4 (2014) 3612.

[212] E.P. Gilshteyn, T. Kallio, P. Kanninen, E.O. Fedorovskaya, A.S. Anisimov, A.G. Nasibulin, RSC Adv. 6 (2016) 93915.

[213] P. Chen, G. Shen, Appl. Phys. Lett. 94 (043113) (2009) 1-3. 
[214] T. Cheng, Y.-Z. Zhang, J.-P. Yi, L. Yang, J.-D. Zhang, W.-Y. Lai, W. Huang, J. Mater. Chem. A 4 (2016) 13754-13763.

[215] J. Rodríguez-Moreno, E. Navarrete-Astorga, E.A. Dalchiele, R. Schrebler, J.R. RamosBarrado, F. Martín, Chem. Commun. 50 (2014) 5652.

[216] H. Moon, H. Lee, J. Kwon, Y.D. Suh, D.K. Kim, I. Ha, J. Yeo, S. Hong, S.H. Ko, Sci. Rep. 7 (2017) 41981.

[217] T. Cheng, Y.-Z. Zhang, J.-D. Zhang, W.-Y. Lai, W. Huang, J. Mater. Chem. A 4 (2016 10493-10499.

[218] G. Cai, P. Darmawan, M. Cui, J. Wang, J. Chen, S. Magdassi, P.S. Lee, Adv. Energy Mater. 6 (2016) 1501882.

[219] Z. Niu, W. Zhou, J. Chen, G. Feng, H. Li, Y. Hu, W. Ma, H. Dong, J. Li, S. Xie, Small 9 (2013) 518-524.

[220] X. Huang, H. Zhang, N. Li, Nanotechnology 28 (2017) 75402.

[221] B. Yao, L. Huang, J. Zhang, X. Gao, J. Wu, Y. Cheng, X. Xiao, B. Wang, Y. Li, J. Zhou, Adv. Mater. 28 (2016) 6353-6358.

[222] T. Qiu, B. Luo, M. Giersig, E.M. Akinoglu, L. Hao, X. Wang, L. Shi, M. Jin, L. Zhi, Small 10 (2014) 4136-4141.

[223] Y.-H. Liu, J.-L. Xu, X. Gao, Y.-L. Sun, J.-J. Lv, S. Shen, L.-S. Chen, S.-D. Wang, Energy Environ. Sci. 10 (2017) 2534-2543.

[224] H.Y. Jung, M.B. Karimi, M.G. Hahm, P.M. Ajayan, Y.J. Jung, Sci. Rep. 2 (2012) 773.

[225] R. Yuksel, Z. Sarioba, A. Cirpan, P. Hiralal, H.E. Unalan, ACS Appl. Mater. Interfaces 6 (2014) 15434-15439.

[226] X. Fan, T. Chen, L. Dai, RSC Adv. 4 (2014) 36996.

[227] P. Xu, J. Kang, J.-B. Choi, J. Suhr, J. Yu, F. Li, J.-H. Byun, B.-S. Kim, T.-W. Chou, ACS Nano 8 (2014) 9437-9445.

[228] N. Li, G. Yang, Y. Sun, H. Song, H. Cui, G. Yang, C. Wang, Nano Lett. 15 (2015) 3195-3203.

[229] N. Li, X. Huang, H. Zhang, Z. Shi, Y. Li, C. Wang, J. Mater. Chem. A 5 (2017) $14595-$ 14603.

[230] N. Li, X. Huang, H. Zhang, Z. Shi, C. Wang, J. Mater. Chem. A 5 (2017) 16803-16811.

[231] N. Li, X. Huang, H. Zhang, Y. Li, C. Wang, ACS Appl. Mater. Interfaces 9 (2017) 9763-9771.

[232] D.D. Nguyen, P.-Y. Hsieh, M.-T. Tsai, C.-Y. Lee, N.-H. Tai, B.D. To, D.T. Vu, C.C. Hsu, ACS Appl. Mater. Interfaces 9 (2017) 40645-40654.

[233] S. Sollami Delekta, A.D. Smith, J. Li, M. Östling, Nanoscale 9 (2017) 6998-7005. [234] K. Gao, Z. Shao, X. Wu, X. Wang, Y. Zhang, Nanoscale 5 (2013) 5307-5311.

[235] P. Yao, S. Xie, M. Ye, R. Yu, Q. Liu, D. Yan, W. Cai, W. Guo, X.Y. Liu, RSC Adv. 7 (2017) 29088.

[236] N. Li, X. Huang, R. Li, Y. Chen, Y. Li, Z. Shi, H. Zhang, Electrochim. Acta 219 (2016) 61-69.

[237] N. Li, X. Huang, H. Zhang, J. Alloy. Compd. 712 (2017) 194-203.

[238] K. Jo, S. Lee, S.-M. Kim, J. Bin In, S.-M. Lee, J.-H. Kim, H.-J. Lee, K.-S. Kim, Chem. Mater. 27 (2015) 3621-3627.

[239] F. Liu, J. Zhou, S. Wang, B. Wang, C. Shen, L. Wang, Q. Hu, Q. Huang, A. Zhou, J, Electrochem. Soc. 164 (2017) A709-A713.

[240] M. Alhabeb, K. Maleski, T.S. Mathis, A. Sarycheva, C.B. Hatter, S. Uzun, A. Levitt, Y. Gogotsi, Angew. Chem. Int. Ed. 57 (2018) 5444-5448.

[241] P. Urbankowski, B. Anasori, K. Hantanasirisakul, L. Yang, L. Zhang, B. Haines, S.J. May, S.J.L. Billinge, Y. Gogotsi, Nanoscale 9 (2017) 17722-17730.

[242] J. Halim, S. Kota, M.R. Lukatskaya, M. Naguib, M.Q. Zhao, E.J. Moon, J. Pitock, J. Nanda, S.J. May, Y. Gogotsi, M. Barsoum, Adv. Funct. Mater. 26 (2016) 3118-3127.

[243] P. Urbankowski, B. Anasori, T. Makaryan, D. Er, S. Kota, P.L. Walsh, M. Zhao, V.B Shenoy, M.W. Barsoum, Y. Gogotsi, Nanoscale 8 (2016) 11385-11391.

[244] M. Ghidiu, M. Naguib, C. Shi, O. Mashtalir, L.M. Pan, B. Zhang, J. Yang, Y. Gogotsi, S.J.L. Billinge, M.W. Barsoum, Chem. Commun. 50 (2014) 9517-9520.

[245] M.R. Lukatskaya, S.-M. Bak, X. Yu, X.-Q. Yang, M. Barsoum, Y. Gogotsi, Adv. Energy Mater. 5 (2015) 1500589.

[246] M. Ghidiu, J. Halim, S. Kota, D. Bish, Y. Gogotsi, M. Barsoum, Chem. Mater. 28 (2016) 3507-3514.

[247] M. Ghidiu, S. Kota, J. Halim, A.W. Sherwood, N. Nedfors, J. Rosen, V.N. Mochalin, M. Barsoum, Chem. Mater. 29 (2017) 1099-1106.

[248] V. Mauchamp, M. Bugnet, E.P. Bellido, G.A. Botton, P. Moreau, D. Magne, M. Naguib, T. Cabioc'h, M. Barsoum, Phys. Rev. B 89 (2014) 235428. [249] Y. Xie, P.R.C. Kent, Phys. Rev. B 87 (2013) 235441.

[250] Q. Tang, Z. Zhou, P. Shen, J. Am. Chem. Soc. 134 (2012) 16909-16916.

[251] J. Song, D. Su, X. Xie, X. Guo, W. Bao, G. Shao, G. Wang, ACS Appl. Mater. Interfaces 8 (2016) 29427-29433.

[252] W. Bao, X. Ie, J. Xu, X. Guo, J. Ong, D. Su, A. Wang, Chem. A Eur. J. 23 (2017) 12613-12619.

[253] W. Bao, L. Liu, C. Wang, S. Choi, D. Wang, G. Wang, Adv. Energy Mater. (2018) 1702485 .

[254] C. Lin, W. Zhang, L. Wang, Z. Wang, W. Zhao, W. Duan, Z. Zhao, B. Liu, J. Jin, J. Mater. Chem. A 4 (2016) 5993-5998.

[255] E.S. Sim, G.S. Yi, M. Je, Y. Lee, Y.-C. Chung, J. Power Sources 342 (2017) 64-69.

[256] L.H. Karlsson, J. Birch, J. Halim, M. Barsoum, P. Persson, Nano Lett. 15 (2015) $4955-$ 4960.

[257] K.D. Fredrickson, B. Anasori, Z.W. Seh, Y. Gogotsi, A. Vojvodic, J. Phys. Chem. C 120 (2016) 28432-28440.

[258] K. Rasool, M. Helal, A. Ali, C.E. Ren, Y. Gogotsi, K.A. Mahmoud, ACS Nano 10 (2016) 3674-3684.
[259] H. Lin, X. Wang, L. Yu, Y. Chen, J. Shi, Nano Lett. 17 (2017) 384-391.

[260] L. Qin, Q. Tao, A. El Ghazaly, J. Fernandez-Rodriguez, P.O.Å. Persson, J. Rosen, F. Zhang, Adv. Funct. Mater. (2017) 1703808.

[261] M. Naguib, Y. Gogotsi, Acc. Chem. Res. 48 (2015) 128-135.

[262] I. Ryu, M. Yang, H. Kwon, H.K. Park, Y.R. Do, S.B. Lee, S. Yim, Langmuir 30 (2014) 1704-1709.

[263] P.J. King, T.M. Higgins, S. De, N. Nicoloso, J.N. Coleman, ACS Nano 6 (2012) 17321741.

[264] M. Boota, C. Chen, M. Bécuwe, L. Miao, Y. Gogotsi, Energy Environ. Sci. 9 (2016) 2586-2594. 